Resumen por el autor, E. C. MacDowell, Station for Experimental Evolution, Cold Spring Harbor.

El alcoholismo y el comportamiento de las ratas blancas. I. La influencia de los abuelos alcohólicos sobre el comportamiento de los individuos en un laberinto.

El presente trabajo trata del comportamiento de los individuos de la segunda generación no alcohólica (procedentes de una generación a la cual fué susministrado alcohol por el método de la inhalación), cuando se les coloca en un laberinto para que busquen la salida. Los individuos escojidos como tipo de comparación fueron los nietos de los hermanos y hermanas normales de los animales tratados por el alcohol. En el curso de todos los experimentos se cruzaron hermanos con hermanas.

El tratamiento mediante el alcohol no produjo anormalidades estructurales marcadas en la generación de los nietos; pero pareció modificar el comportamiento. En esta generación el autor enseñó a 31 ratas, procedentes de los individuos alcohólicos, y 29 ratas normales a buscar la salida en un laberinto circular de Watson, mediante tres pruebas diarias durante un periodo de doce dias. Cuando se comparan los individuos de ambas clases, tomando como criterio el tiempo empleado, la distancia recorrida, los errores hechos, el número de pruebas perfectas, la ocurrencia de las primeras pruebas perfectas y el tiempo empleado en ellas, puede comprobarse que los nietos de los alcohólicos, tomados en conjunto, son mas torpes que los normales en aprender la salida al centro del laberinto.

Translation by Jose F. Nonidez

Cornell Medical College, New York 


\title{
ALCOHOLISM AND THE BEHAVIOR OF WHITE RATS
}

\section{THE INFLUENCE OF ALCOHOLIC GRANDPARENTS UPON MAZE-BEHAVIOR}

\author{
E. C. MACDOWELL AND E. M. VICARI
}

Station for Experimental Evolution, Cold Spring Harbor, Long Island, New York

\author{
SEVHNTEEN FIGURES
}

\section{CONTENTS}

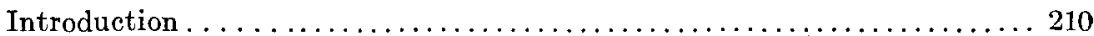

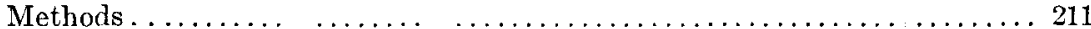

a. Source of material $\ldots \ldots \ldots \ldots \ldots \ldots \ldots \ldots \ldots \ldots \ldots \ldots \ldots \ldots \ldots \ldots \ldots$

b. Alcoholization of the grandparents . . . . . . . . . . . . . 213

c. The alcohol tanks . . . . . . . . . . . . . . . . . . . . . . . . 214

d. Training; apparatus and methods . . . . . . . . . . . . . . 214

e. 'Failures,' 'completes' and 'incompletes' . . . . . . . . . . . . 215

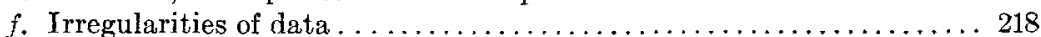

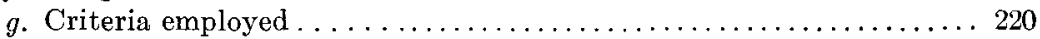

Results . . . . . . . . . . . . . . . . . . . . . . . . . . . 220

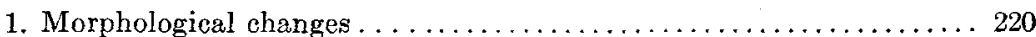

2. Comparison of the test and control rats on the basis of time . . . 221

a. Time: averages for different groups of trials . . . . . . . . . 221

b. Time: averages for each day ...................... 229

c. Variability of the tests vs. controls judged by time . . . . . . 240

$d$. What is the probability that the test data and the control data for time are not random samples from the same population? 243

$e$. Conclusions based on the time data . . . . . . . . . . . . . 244

3. Comparison of the test and control rats on the basis of the distance covered in running each trial . . . . . . . . . . . . . . . 246

a. Distance: averages for different groups of trials . . . . . . . 246

b. Distance: averages for each day .... . . . . . . . . . . . 250

c. Variability of the tests vs. controls judged by distance. . . . . 258

$d$. What is the probability that the test data and the control data for distance are not random samples from the same population? 260

$e$. Summary of results from the distance data . . . . . . . . . . 262

$f$. Correlation between time and distance data ............ 262

1 This is one of a series of papers on the general subject. Following studies will cover the results of training these same rats upon a multiple-choice apparatus, and of training the parental and grandparental generations. 
4. Comparison of the test and control rats on the basis of the rate of

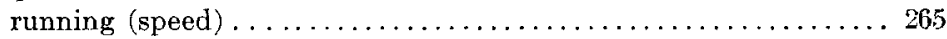

5. Comparison of the test and control rats on the basis of the numbers

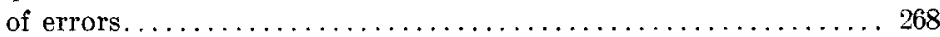

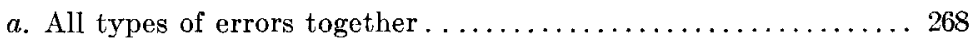

b. Each type of error separately . . . . . . . . . . . . . 270

c. The number of trials before each type of error was eliminated. . 272

6. Comparison of the test and control rats on the basis of perfect trials. 275

a. Number of perfect trials . . . . . . . . . . . . . . . . 275

b. Number of trials beforo the first perfect trial . . . . . . . . 277

c. Time spent in running perfect trials . . . . . . . . . . . 277

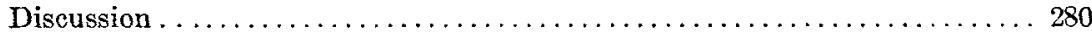

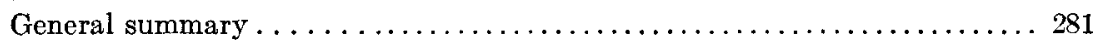

Appendix . . . . . . . . . . . . . . . . . . . . . . . . . . . . . . 285

\section{INTRODUCTION}

The following experiments have been carried on primarily to try to control or modify inheritance. It must be made clear in the beginning that whatever human relation they have is incidental. The human interest is more especially aroused by the chemical used than by any parallelism of the kinesthetic behavior of rats in a maze and the moral behavior of man. On the other hand, if it can be proved that alcohol does occasion changes in the normal inheritance of rats, as shown even by such an elementary type of behavior as learning a maze, a great field of possibilities is at once opened up; other modifications of inheritance, by means of the same or other chemicals, may be brought about in other animals, including man.

The general plan of the work undertaken has been to study the habit-forming abilities of rats in successive inbred generations following one generation treated with alcohol. For a standard or control the inbred descendants of the normal brothers and sisters of the alcoholized rats have been used. Preliminary studies indicated that strong doses would be required if any influence upon the germ-plasm is to be expected. For this reason the maximum exposure to alcohol fumes has been employed in the treatment of the grandparents of the rats whose training is the subject of the present paper. The results appear to indicate that inheritance can be modified to a certain degree by alcohol. 


\section{METHODS}

\section{a. Source of material}

The rats used in this paper were raised from a series of three brother-by-sister matings; two of these matings were made from two litters of rats from The Wistar Institute Standard Stock. The third line resulted from the combination of four lines from independent sources, including The Wistar Institute and Johns Hopkins University; these were brought together in a series of experiments on the same subject in which all the matings were made between unrelated individuals, instead of between brothers and sisters, as in the present series. The pedigrees of the rats are given in figure 1 ; those given alcohol were marked 'A.' In each strain one pair was given the alcohol treatment and one pair, litter mates of the alcoholized rats, was raised as normal controls. When the alcohol treatment was started, the plans involved a very much larger number of rats than appears in the results. The present report is based on the alcoholization of six rats, although 112 rats were given the alcohol treatment. The great reduction in the size of the experiment was due to circumstances resulting from the war. In the third strain there appears a second pair of rats (101/125) marked 'A.' These were concerned in the first series of experiments and were given a light dosage, increasing from thirty minutes a day at thirty days up to ninety minutes a day at fifty days. Since these rats are the common ancestors of both the test and the control animals in this strain, it is clear that the control rats in this strain are not strictly comparable with those in other strains; but within this strain the controls are strictly comparable with the alcoholized rats. Moreover, the three strains may still be put together, because: 1) the results (unpublished) of training the offspring of the lightly alcoholized ancestors, that is, the generation to which the pair $295 / 286$ belongs, appear to indicate that the treatment of the parents did not modify the behavior of the offspring; 2) even if there should remain some effect of the first alcoholization, this would work in the direction of reducing the difference that has been found between the tests and controls; 


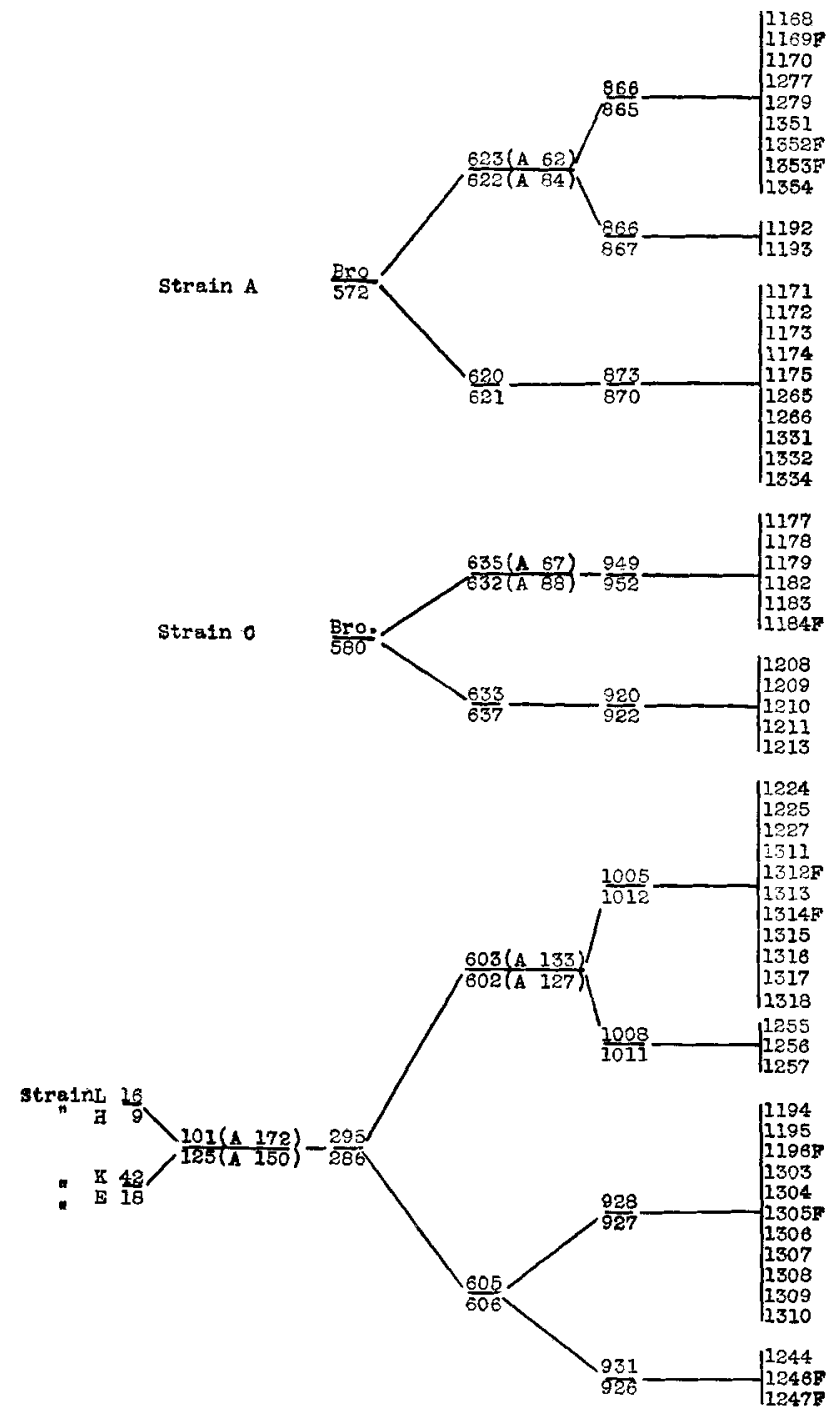

Fig. 1 Pedigrees of the rats used. Parents shown in the form of fractions; males above the line, females, below. 'Bro.' indicates that the father was a brother of the mother. Within each strain all the rats in the column at the right (those discussed herein) came from a single pair of great-grandparents, which were themselves brother and sister. Rats marked (F) are called 'failures,' meaning that they had one or more incomplete trials; those marked ' $A$ ' were treated with alcohol; the numbers in parentheses tell how many days of the rats' treatment could have influenced the offspring. One pair of rats in each strain were given alcohol till they were dead drunk once a day; pair 101/125 in strain $\mathrm{L}$ was given a light dose, measured by the time of exposure (ninety minutes) which appeared to cause no intoxication. 
3) since there are approximately equal numbers of tests and controls in this strain the comparative result is left unchanged. The term 'test' is used for a rat receiving alcohol and for its descendants. In the present paper it will refer to the grandchildren of alcoholized rats.

\section{b. Alcoholization of the grandparents}

When the rats to be alcoholized were four weeks old they were weaned; half the litter was saved as control and the other half started with the alcohol treatment. This division of the litter was made purely at random, obviously with no knowledge of the animals' behavior tendencies. Differences in weight at this age are very small and do not bear a very high correlation with adult size. Only litters with at least an even number of males and females could be used; odd individuals were held as stock.

The treatment was started by placing the rats in tanks of alcohol vapor for thirty minutes a day. After a week of this, the rats were left in the tanks until they were obviously influenced by the alcohol; that is, until they showed some lack of control of motion. This would require from one to two hours. This treatment was given for a week. Then they were left in the tanks until they were dead drunk and lay limp; this took from two to three hours for the young rats and from three to four hours for the old ones. The females received this treatment each day, even through the period of gestation up to a day or two before the birth of the litter, and it was resumed after the young were weaned at twenty-eight days; for the males the treatment was given every day. In this way the effective dosage of the two parents was different and it increased for successive litters. The dosage affecting each of the test rats is indicated in the pedigree chart. The numbers in parenthesis after each grandparent represent their respective doses, that of the male, the number of days before conception, and of the female, the number of days up to the day of the birth of the litter.

As far as possible, the treatment of the rats in the first generation was uniform, with the exception of the alcoholization. The 
normal rats in a litter were raised in cages directly above the cages of their respective brothers and sisters that were being alcoholized, in order to equalize the possible influence of the immediate surroundings. Before maturity the rats were separated into pairs; from each litter an equal number of alcoholic and normal pairs were mated. No alcohol was given to the rats in the subsequent generations. The largest rats among the offspring were chosen as parents of the next generation, with no knowledge of their training records. As many rats as possible from these matings of the progeny of alcoholized rats were to have been raised, but here again the experiment was unavoidably much reduced.

\section{c. The alcohol tanks}

Tanks of galvanized iron, 30 by 16 by 12 inches, with tightfitting covers, held the alcohol fumes and the rats during treatment. Inside were false bottoms of wire netting which held the rats above the alcohol filling the bottoms of the tanks. The covers were made with glass windows so the condition of the animals could be observed. A small hole in each end, at the level of the wire bottom, was made, on the supposition that the carbon dioxide might thereby tend to escape. In an earlier series of experiments the controls were daily placed in tanks of the same description without alcohol, as long as the test rats were in their tanks. Merely the confinement in the limited air space caused none of the symptoms observed in the rats from the alcohol tanks. The alcoholized rats would frequently remain unconscious for hours after they were returned to their cages; the controls upon leaving the control tanks would show no modification of their normal behavior. It can safely be concluded that the apparent intoxication was due to the alcohol fumes, and not to the confinement in tightly closed tanks.

\section{d. Training; apparatus and methods}

The apparatus used in training these rats was constructed after the plan of Watson ('14), namely, a circular maze con- 
sisting of five concentric alleys with doorways and blind alleys so arranged that the correct path from the outside to the center required a rat to turn alternately to the right and then to the left at the successive doorways. Two large mirrors were suspended from the ceiling above the maze in such a way as to direct the image of the maze into a set of lenses that focused it, greatly reduced, upon a sheet of paper. With the maze brilliantly illuminated and the light eut off from the paper by a dark box, the observer could plainly see on the paper the image of the rat as it went through the maze and could make a permanent record of the rat's course by following it with a pencil. A diagram of the maze as it appeared reflected on the paper was printed upon the sheets used to record the course of every trial of each rat (fig. 7). Frequently it was necessary to use several sheets to record a very long trial, in order to make it possible afterward to understand the course taken by the rat. The time required for each trial was recorded on these sheets.

When the rats were forty-nine days old their training was started. They were given seven days of preliminary training, which consisted of feeding them in the inner circle of the maze shut off from the alley. This was followed by the training proper (subsequently to be called 'training'), consisting of three successive trials a day for eight days. The rat was allowed to taste the food between trials, but was removed from the center as soon as it had taken a bite; after the third trial the rat was allowed to eat for five minutes. The food consisted of white bread and milk. At the end of the eight days of training, the rat was started upon the preliminary training on a multiple-choice apparatus. Thirty-one days were spent on the multiple-choice apparatus. At the end of this time the rat was returned to the maze to test its retention of the maze habit. The retention trials were continued, three a day, for four days. The results of the training on the multiple-choice apparatus will appear in a later paper. 


\section{e. 'Failures,' 'incompletes' and 'sompletes'}

If the rat did not happen to reach the center in a reasonable time on the very first trial, it was removed, fed in the center, and tried again the next day. In such cases all the time spent on different days in reaching the center for the first time was counted as the first trial. In certain cases (those rats marked ' $\mathrm{F}$ ' in the pedigree chart) after a rat had made one or more successful trials and then failed to reach the center after from ten to twenty minutes, the rat was called a 'failure' rat, or just a 'failure.' The time given before such trials were called off was not always the same, for in some trials the rat would continue to be active and keep investigating the alleys, in other cases the rat would give up the problem and lie still. When the rat did this, it was found useless to wait longer, while it seemed wiser to let a rat continue its searching if it was active, and especially if it was in an inner alley. During the experiment the difficulty of handling the data of rats with such failure records was not fully realized, or else a different plan would have been followed. As it was, the rats with these failures were continued throughout the training (in most cases the rat succeeded on the day following a failure); at the end of their training they gave about as good records as the rats in the same group that did not have failures. However, the influence of such failures on the following days remained a serious question. The trials immediately following are slower than the average of the other rats in the same group; even though this difference seems to disappear in later trials, the effect may none the less be operating. This makes the treatment of the data from such rats a matter of difficulty. The time spent on an unsuccessful trial could be added to the following successful trial as was the practice when a rat did not succeed on the first trial. But failing after the center has once been reached is an entirely different matter from not reaching the center for the first time. These failures are not of frequent occurrence; they never occur after the third day, and most of them occur on the first day; only ten rats out of sixty had a 'failure' and only one rat failed a second time after another successful trial. It seems as though some unusual 
temporary circumstances have occasioned this unusual behavior. That just these rats and not others responded in this manner may have been due to some particular sensitiveness, but the alcohol treatment of the grandparents does not seem responsible for any such hypothetical difference, since control rats as well as tests have 'failures'; the numbers are four controls and six tests, which, in such small numbers, is a very close approximation to equality. A second method of handling the data of the rats that had 'failures' would be to omit the time spent on 'failure' trials, assuming that the 'failure' was due to circumstances quite apart from the nature of the rat. But, as stated, this does not eliminate the effect of the 'failure' upon the immediately following trials.

Perhaps the best way to include the 'failure' rats is to put down a uniform time (ten minutes) for each 'failure' and treat that as a successful trial; then, in averaging, count the number of trials actually attempted. When a 'failure' occurred on the first or second trials, there were no more trials attempted that day. This method has been used for including the 'failure' rats in the two main series of summaries of the time data, although it is obviously not free from very real objection. In applying this to the summaries based on the individual days, a further adjustment was needed. Since the sum of the three trials for each rat was used instead of the average per trial, it was necessary to compensate in some way for the missing third trial when a 'failure' occurred on the second trial. This was done by increasing the sum of the first trial and the 'failure' (ten minutes) by one half of this sum. The two rats that lost a whole day through failures on the first trials have not been used in these averages.

Since no satisfactory method of including the data from these 'failure' rats has been discovered, the best method of meeting the situation seems to be to omit these data. Accordingly, for most of the criteria only the averages excluding these data are given. But, in order to show that the results are not dependent upon their exclusion, the averages for time, which may be considered the most important single criterion, are given both including and excluding these 'failure' rats. Theoretically, both sets 
of averages might be demanded throughout, but the doubling of every table would result in unjustifiable bulk, especially in the light of the clearness of the results as they stand.

When it became necessary to make drastic reductions in the size of the experiment, eleven rats in this generation, six tests and five controls, were taken out of the training after they had been given the eight days of training. They lack the training in the multiple-choice apparatus as well as retention on the maze. In order to have the same group of rats summarized for the maze and the multiple-choice apparatus, these eleven rats were not included in the major part of the calculating that has been done with the maze data. However, from the standpoint of this paper, these rats, as far as they went, are as good as others; accordingly, they have been included in the most important summaries. The time data are summarized, including, as well as excluding, these rats which we call 'incompletes,' since their training was not completed. There are then three sets of rats to be designated 'completes,' 'incompletes,' and 'failures.'

\section{f. Irregularities of data}

The number of rats included in the various averages is indicated in the tables; these numbers vary for different averages even within one group of rats. The details explaining each of these irregularities are given in the following paragraphs. Although we feel fully justified in making the minor exclusions and inclusions besides the main ones treated above, we wish to remove all suspicion of our having tried to influence the result one way or the other in so doing. These explanations are made here all together to avoid many scattered foot-notes.

Rat 1279: Record sheets for the first day lost; this rat is not included in the averages for the first day or for first half of training, all training, training and retention.

Rat 1311: Rècord sheets for third day lost; this rat is not included in averages for the third day, first half of training, all training, training and retention. 
Rat 1265: Time record. for twenty-first trial lost; averages for second half of training, all training, training and retention exclude this trial. In obtaining total time for the seventh day of training, there was substituted for the twenty-first trial a time based on its distance record.

Rat 1211: Showed very unusual behavior on the second day of retention, taking five minutes when it might have been expected to take five seconds. The rat was obviously sick, so its records have been omitted from the average for retention. For training and retention its exclusion makes such a slight difference that only the averages including it have been given.

Rat 1312: Failed to reach the center on the first trial on the second day and did not succeed until the first trial on the fourth day.

Rat 1169: Failed on the first trial on the second day and succeeded on the first trial on the third day. These last two rats are the only cases where a whole day was lost through failure; to give the arbitrary maximum in these cases seemed to make the result depend too heavily upon the arbitrary figures. In one case only half of the average would be based on actual records and in the other, three-quarters would be based on actual records. These two rats are so outstandingly different from the other 'failure' rats that it has seemed more fair to omit them from the averages including the first three days. They are included in the averages for the second half of training and for retention when the other 'failure' rats are included.

Rats 1193, 1168, and 1173 had no perfect trials in all of the thirty-six trials of training and retention. In the summaries on the number of trials before the first perfect trial, these rats have been given a score of 36 , as though they had had a perfect trial on the thirty-seventh trial (which was not given). To give averages free from this difficulty, these three rats are omitted from the alternative averages. 


\section{g. Criteria employed}

The evidence about to be presented is derived from three sources: the time for each trial, the distance covered on each crial, the number of departures from the true path, or errors. The time and distance data make it possible to calculate the speed or the distance covered per second; from the error data the occurrence of perfect or errorless trials is obtained. The number of perfect trials and the number of days before the first perfect trial can be used as criteria, since all the rats received the same number of trials. Under these main headings the test and control rats have been compared in various groupings of the strains and sexes, for various periods of the training.

The question of the differences between the behavior of the males and females presents a difficulty. Although we have made extended studies of this question on the animals so far summarized, we offer no conclusion. Since we have a much larger mass of data still awaiting analysis, namely, the records of the rats that were actually treated with alcohol and their immediate offspring, we withhold judgment for the present and give summaries with the males and females separately and together.

\section{RESULTS}

\section{Morphological characters}

Although this paper is on behavior, it may be of interest to note here that we have found, as the result of alcoholizing the rats, no signs of such morphological abnormalities as Stockard and Papanicolaou ('16 and '18) found in the descendants of alcoholized guinea-pigs. The few abnormalities that have appeared have been limited to one strain; they have appeared both in control and test rats. Very obviously, these abnormalities were carried in the strain and were not induced by alcohol. The immediate effect of the alcohol upon the treated animals was to render the hair exceptionally fine and attractive by keeping off all skin parasites. 
2. Comparison of the test and control rats on the basis of time

a. Time: averages per different groups of trials. The time data give the number of seconds taken in passing from the entrance of the maze to the doorway of the central food compartment. The observer sat with eyes on the record sheet within the dark box and the left hand on the stop-watch, which was fixed in position on the table by its holder; when the rat was observed to enter the maze the watch was started and it was stopped when the rat entered the final door. Of the various criteria, time is probably most free from errors in observation; the beginning and end of a trial were clearly marked events that could be measured accurately within the limits of the time of the observer's response to a sensory image.

The first table is based on the average time per trial of each rat for the following groups of trials: first half of training (12 trials), second half of training (12 trials), omitting the first day (21 trials), all training (24 trials), retention (12 trials), and training and retention (36 trials). The first division of the table gives the averages for the group of rats that were given full training, 'completes'; in the second division the averages include the rats that were not given full training, 'incompletes' as well as the 'completes'; the third division of the table includes the 'failures,' the 'completes' and the 'incompletes.' Each number in the body of the table is an average per trial in seconds of the averages for each rat; the number of rats involved in each average is given. Since there is a great difference in the time taken in different parts of the training, the tests and controls are compared by means of ratios instead of by differences. In every case the larger of the pair of averages has been divided by the smaller number, thus always giving ratios above 1.000. When the test average is larger, that is, the tests taking more time, the ratio is called 'plus'; and when the control average is larger, that is, the controls taking more time than the tests, the ratio is called 'minus.' Accordingly, a ratio of (+)1.500 indicates that the test average is one and a half times as large as the comparable control average; the tests took half as long again 


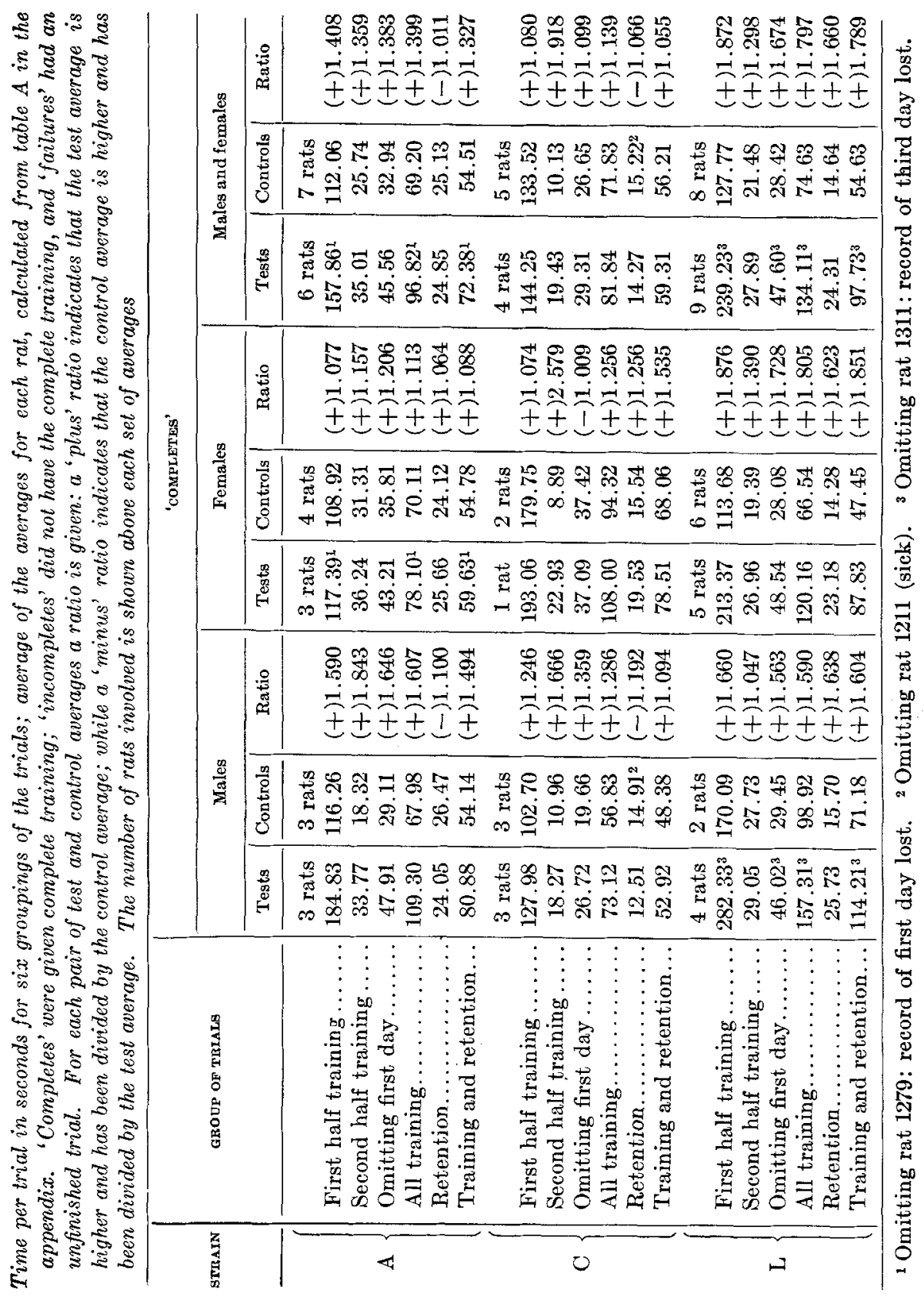


ALCOHOLISM AND BEHAVIOR OF WHITE RATS

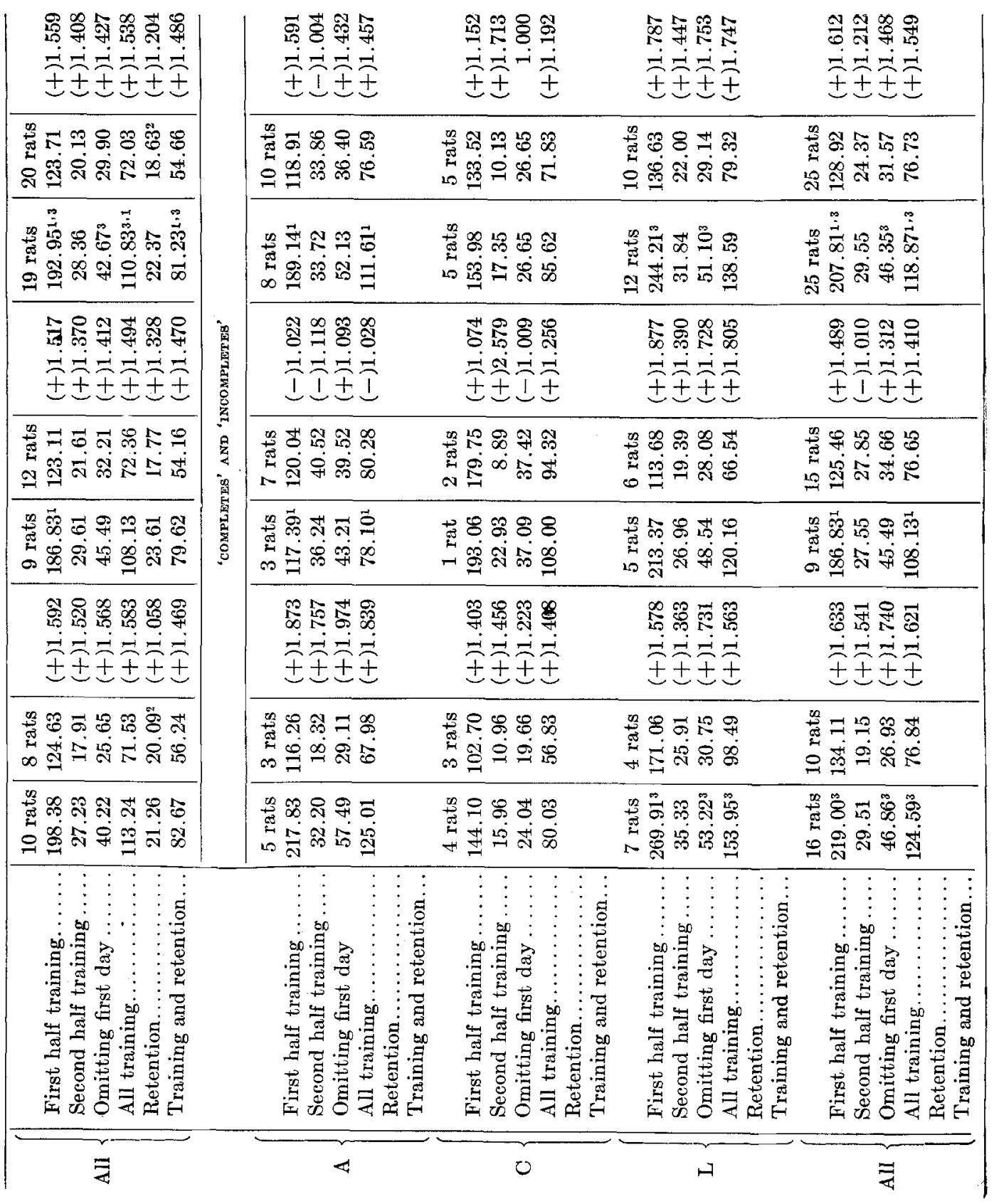




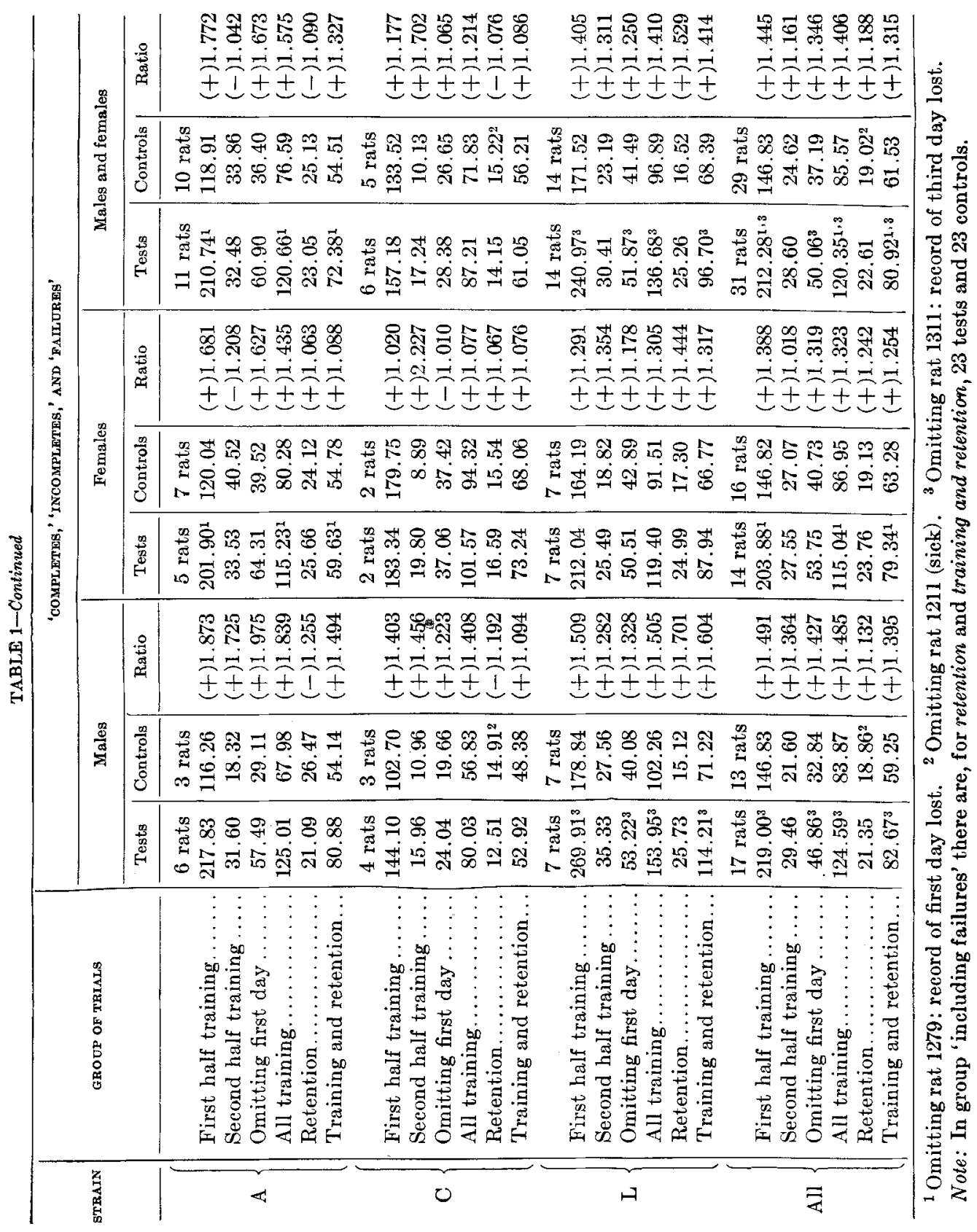


as the controls. A ratio of $(-) 1.500$ indicates that the controls took half as long again as the tests.

The males give 'plus' ratios for each group of the trials in training, whether the strains are given separately or together. In retention one strain gives 'plus' ratios and two strains give 'minus' ratios, but when all strains are averaged together and rat 1211 omitted (page 219), the ratio becomes 'plus' $((+) 1.058$ for 'completes' and $(+) 1.132$ when the 'failures' are added).

The females give fifty-six 'plus' ratios out of sixty-four when all the different combinations of the data are counted. In the group of 'completes,' strain C gives a ratio very slightly 'minus' ((-)1.009) for omitting the first day, but it will be noted that there is only one test rat and two controls involved in this ratio. When all the strains are combined, this period (omitting the first $d a y)$ gives 'plus' ratios of $(+) 1.412,(+) 1.312$, and $(+) 1.319$ for each of the three sets of rats, respectively. In strain A the 'completes' and 'incompletes' give slightly 'minus' ratios for the first and second halves of training, and so for all training as well. When the 'failure' rats are also included, the 'minus' ratio in strain A for the second half of training remains, but the ratios for the first half of training and for all training become 'plus.' All strains averaged together give 'plus' ratios for each group of trials and each set of rats, excepting the second half of training for the 'completes' and 'incompletes.' When the 'failure' rats are also added, the ratio for the second half of training becomes 'plus' $((+) 1.018)$; all the other ratios are over $(+) 1.200$. Combining all the data for the females by averaging the averages of each rat's thirty-six trials in training and retention, all strains together, the group of 'completes' gives a ratio of $(+) 1.470$; 'completes' and 'failures' give $(+) 1.254$.

The test males took more time than the controls in every case in training, but in retention the control males in two strains took more time than the tests; the females, on the other hand, show the tests taking more time in every case in retention, while in training they show a few cases where the controls took slightly more time. When the strains are averaged together, all the groups of trials show the test averages clearly greater than the 
control averages, excepting retention for the males, and the second half of training for the females; these two pairs of averages give ratios very close to 1.000 .

Combining the sexes (primary averaging, disregarding sex) and taking each strain separately, all the ratios are 'plus' excepting retention for strains $\mathrm{A}$ and $\mathrm{C}$, and the second half of training for strain A when the 'incompletes' are included with and without the 'failures.' The highest of these 'minus' ratios is (-)1.090.

When the strains as well as the sexes are averaged together, 'plus' ratios are given in every case. The differences and the probable errors of the differences between the averages are given in table 2. (The probable error of the difference is the square root of the sum of the squares of the probable errors of the two averages compared.) In a separate column are given the quotients of the differences divided by their probable errors. A quotient of three or more is usually regarded by statisticians as certainly indicating a significant difference. In the first half of training, omitting the first day, all training, and training and retention the differences are more than three times their probable errors and may be considered to be real or significant differences. In the second half of training the 'completes' alone give a significant difference, when the 'incompletes' and when the 'failures' are included, the differences are 1.99 and 1.74 times their probable errors; in retention the differences are 2.06 and 2.24 times their probable errors. So besides finding many more 'plus' than 'minus' ratios, the differenees are shown to be statistically significant when grouped to obtain large enough numbers to calculate probable errors.

The frequency distribution of the averages for each rat, including 'failures,' from which the averages in the preceding tables were obtained, are shown graphically in figure 2. For each group of trials there is a pair of overlapping curves; the solid line represents the controls, the broken line the tests. The number of rats in the test and control groups is so nearly equal that a reduction to a percentage basis is not necessary. The graphs show a clear tendency for the distribution of the tests to lie further up the scale than the distributions of the controls; at 


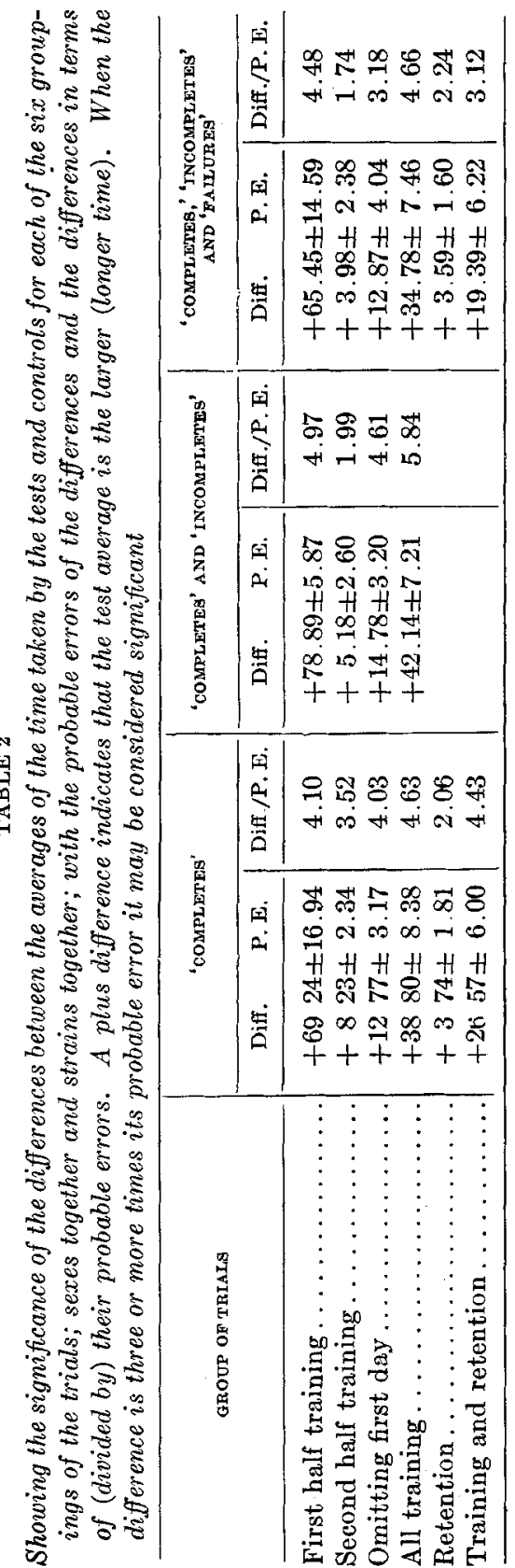


TIME PER TRIAL

FREQUENCY DISTRIEUTIONS OF AVERAGES FOREACH RAT
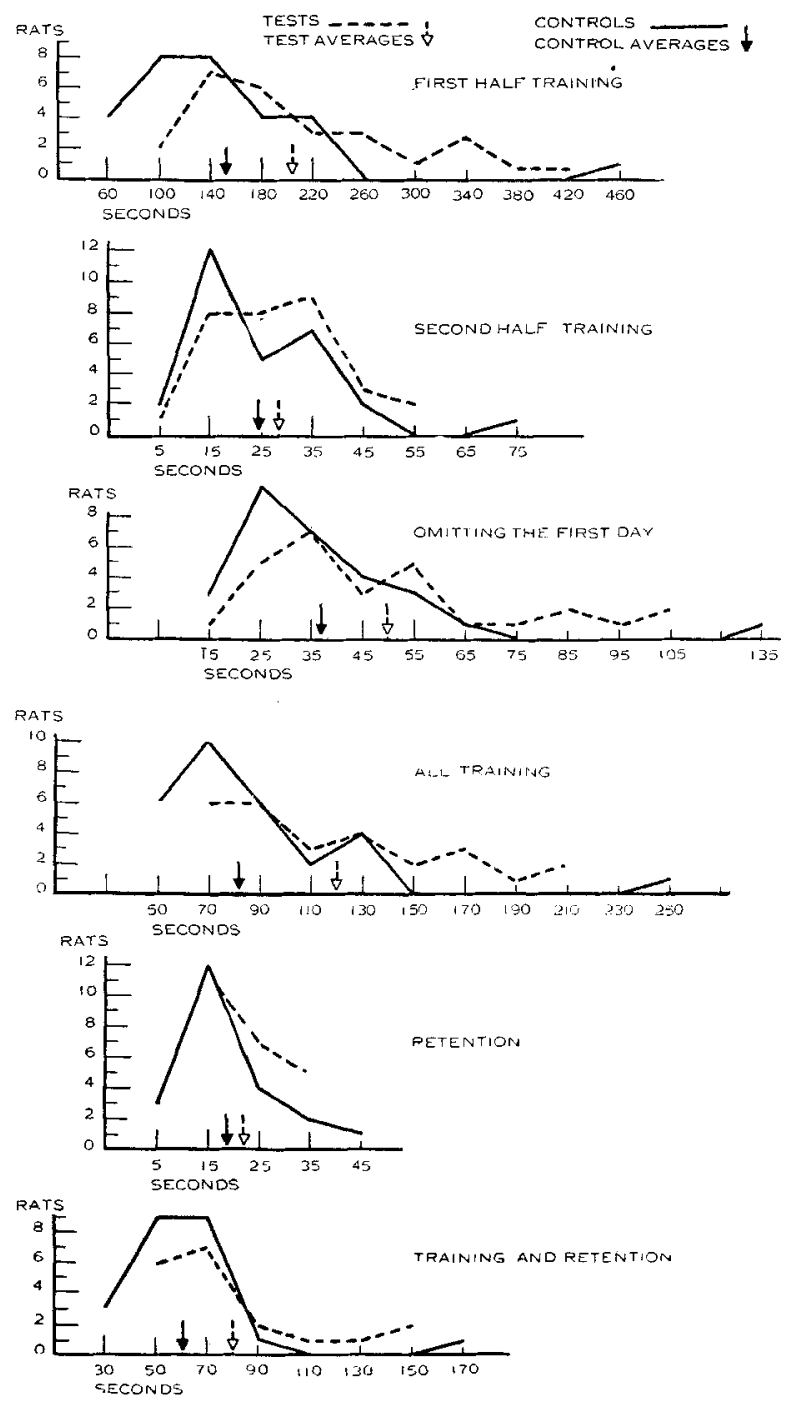

Fig. 2 Frequency distributions of the averages for each rat for time per trial, based on six different groupings of the trials. The broken lines are the tests; the solid lines, the controls. Units on the base line are seconds, units on the vertical scale are numbers of rats. 'Completes,' 'incompletes,' and 'failures' are used with the males and females in all strains. 
the lower end the controls are more numerous, at the upper end, the tests. This is evidence that the means are good indices of these two distributions; that the differences between the two groups of rats, tests and controls, as given by their averages, are real and not due to some peculiarity of the frequency distributions.

There can be no question but that there was a tendency for the test rats to spend more time in learning the maze than did the controls. That the differences in their averages is not significant in retention and in the second half of training when the 'incompletes' and 'failures' are included, in no way weakens this conclusion. The maze was simple enough to be learned by all rats, and the number of trials given was great enough to include overtraining for many of the rats; that is, many rats were continued after they had stopped improving their average time. Longer training would probably have removed the difference between the averages of the tests and controls. In the number of trials given, the differences between the averages was enough reduced in the last part of the period of training to fall within the range of chance variation. The averages for each rat from which the preceding summaries have been made are given in table $\mathrm{A}$ in the appendix.

b. Time: averages for each day. The next step in the analysis of the time data is the comparison of the averages of the tests and controls on each of the eight days of training and the four days of retention. This series of calculations is based on the total time spent each day by each rat in running its three trials. Instead of using averages based on groups of 12, 24, or 36 trials, the sums of the three trials on each day are now used. The succession of the averages of these sums gives a curve (learning curve) that shows the daily reduction in the time required to make three successive trips through the maze. Such a curve for all the strains and both sexes together is given in figure 3 . This curve shows that the tests (broken line) are above the controls (solid line), that is, took more time on each day of training and on all but the first day in retention. The light lines show the tests and controls when the 'failure' rats are included. The 


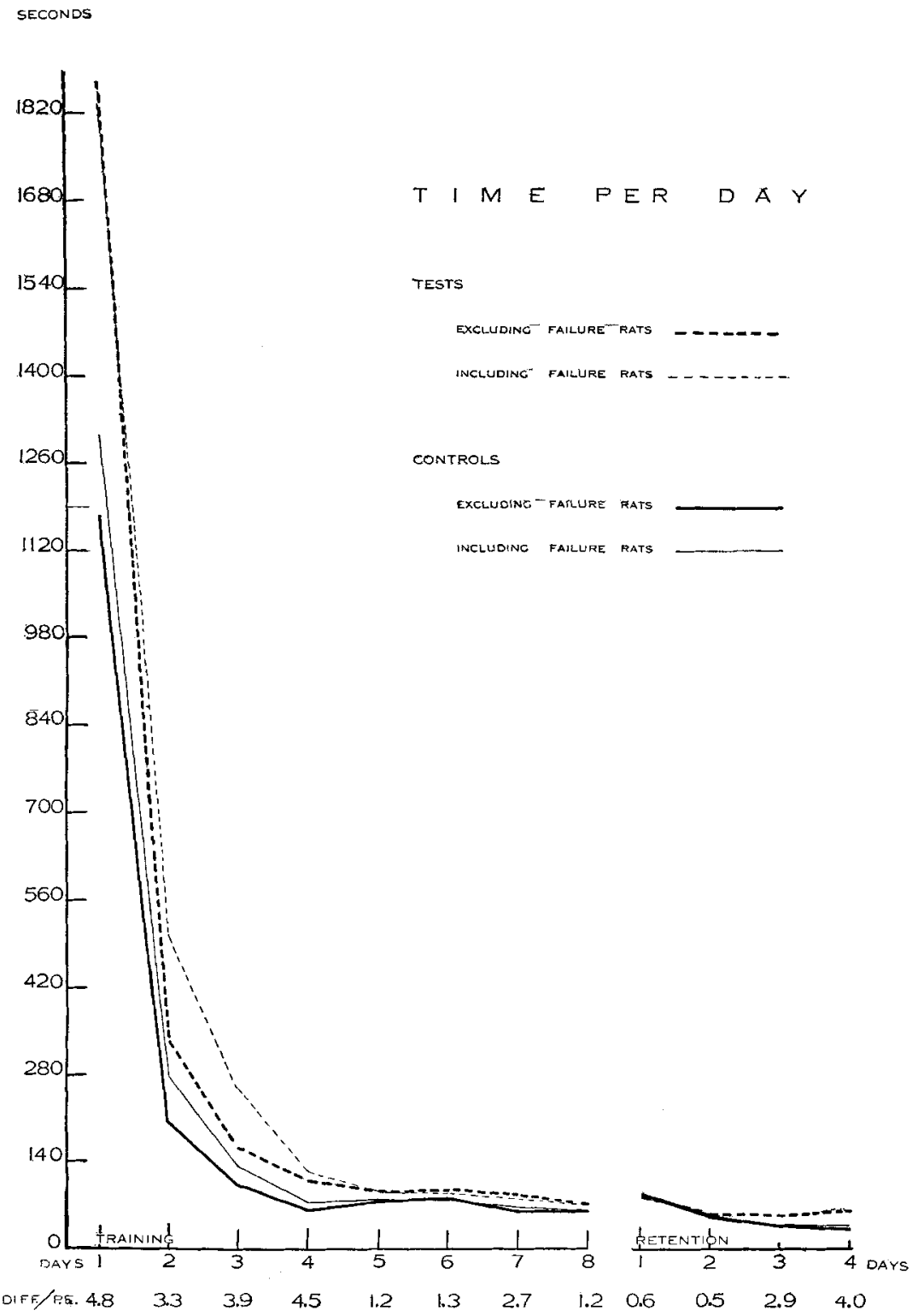

Fig. 3 Learning curve based on time; averages per trial on each day of training and retention. The broken lines are tests; the solid lines, controls; the heavy lines based on 'completes' and 'incompletes;' the light lines include 'failures' as well. Males and females in all strains are put together in all cases. The un its on the base lines are days: the first series of days are training; the second series, retention; units on the vertical seale are seconds. 
number below each day is the number of times the difference between the test and control averages is greater than its probable error, considering just the 'completes' and 'incompletes.' The data for this figure are given in table 3 .

The first half of table 3 is based on the 'completes' and 'incompletes,' the second half, at the right, includes the 'failures' as well. 'Completes' averaged alone are not given; they show substantially the same results as when averaged with 'incompletes.' In each half of the table there are three main sections: 1, males; 2, females; 3 , males and females (i.e., primary data put together regardless of sex, not averages of the averages of each sex). Under each of these headings the time per rat for the tests and controls is given for each day (eight days of training and then four days of retention). The three strains are considered separately, then all strains together. The number of rats in each series of averages is shown at the top of the series. As before, the averages are compared by ratios; plus ratios indicate that the tests took longer time than the controls; minus ratios indicate that the controls took longer time than the tests.

If just the signs of the ratios are studied, it is obvious that there is a great preponderance of 'plus' signs. When the 'completes' and 'incompletes' are considered, the males give 44 'plus' ratios out of 48 ; the females, 38 'plus' ratios out of 48 ; and the males and females together, 40 'plus' ratios out of 48 . When the 'failures' are included, out of 48 cases the males give 42 'plus' ratios, the females 37 'plus' ratios, and the males and females together 40 'plus' ratios. In the whole table there are 241 'plus' ratios out of a possible 288. This is, of course, only a general comparison, since in many of these averages the same data are repeated, but it indicates that combining the data in different ways gives the same result. In other words, the greater time taken by the tests is a real difference and not due to the special method of treating the data. Some of the ratios of tests vs. controls given in table 3 are shown graphically in figure 4; the sexes together, each strain separately, and all strains together. The straight horizontal line represents equality between the test and control average, or the ratio of 1.000 . 


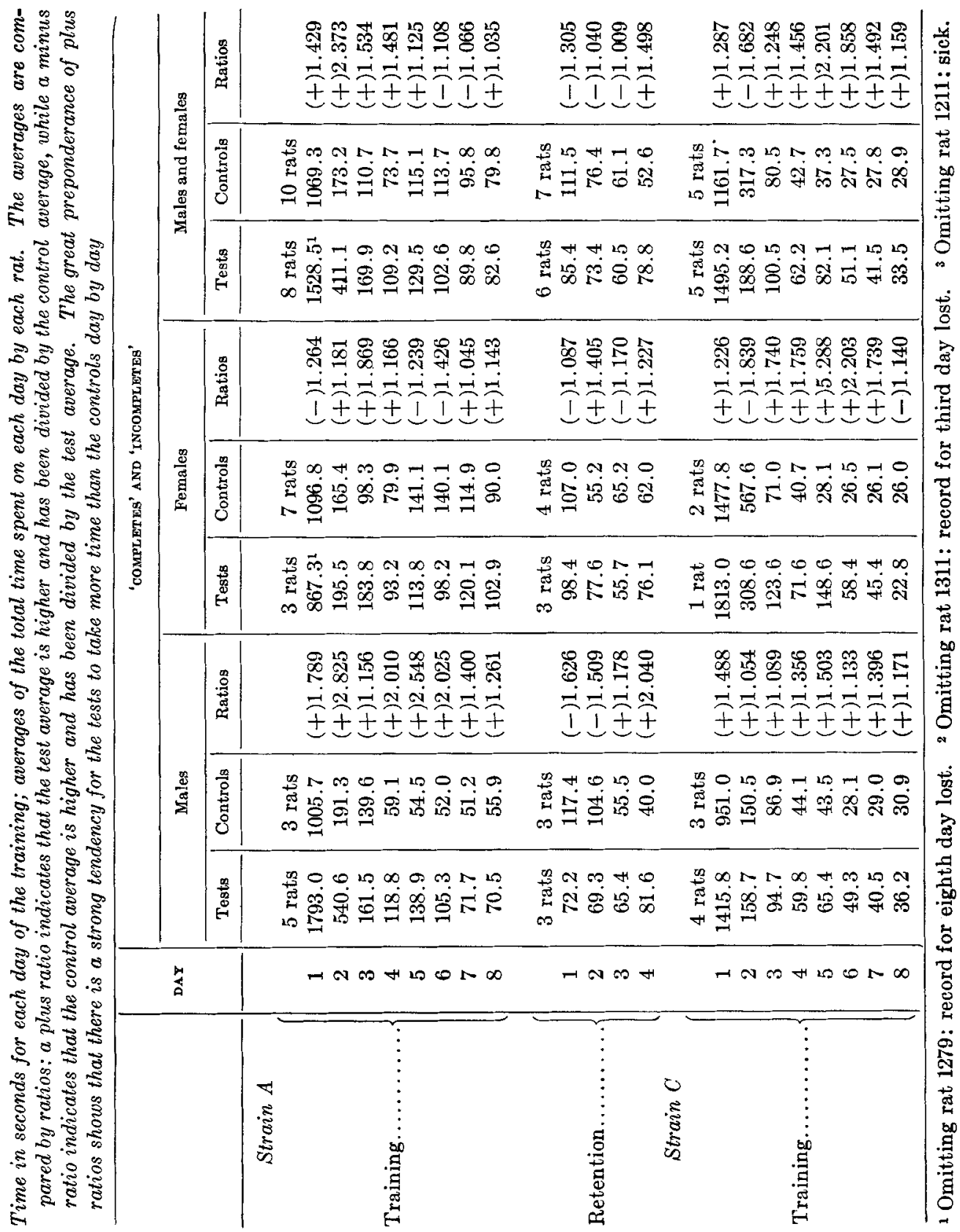




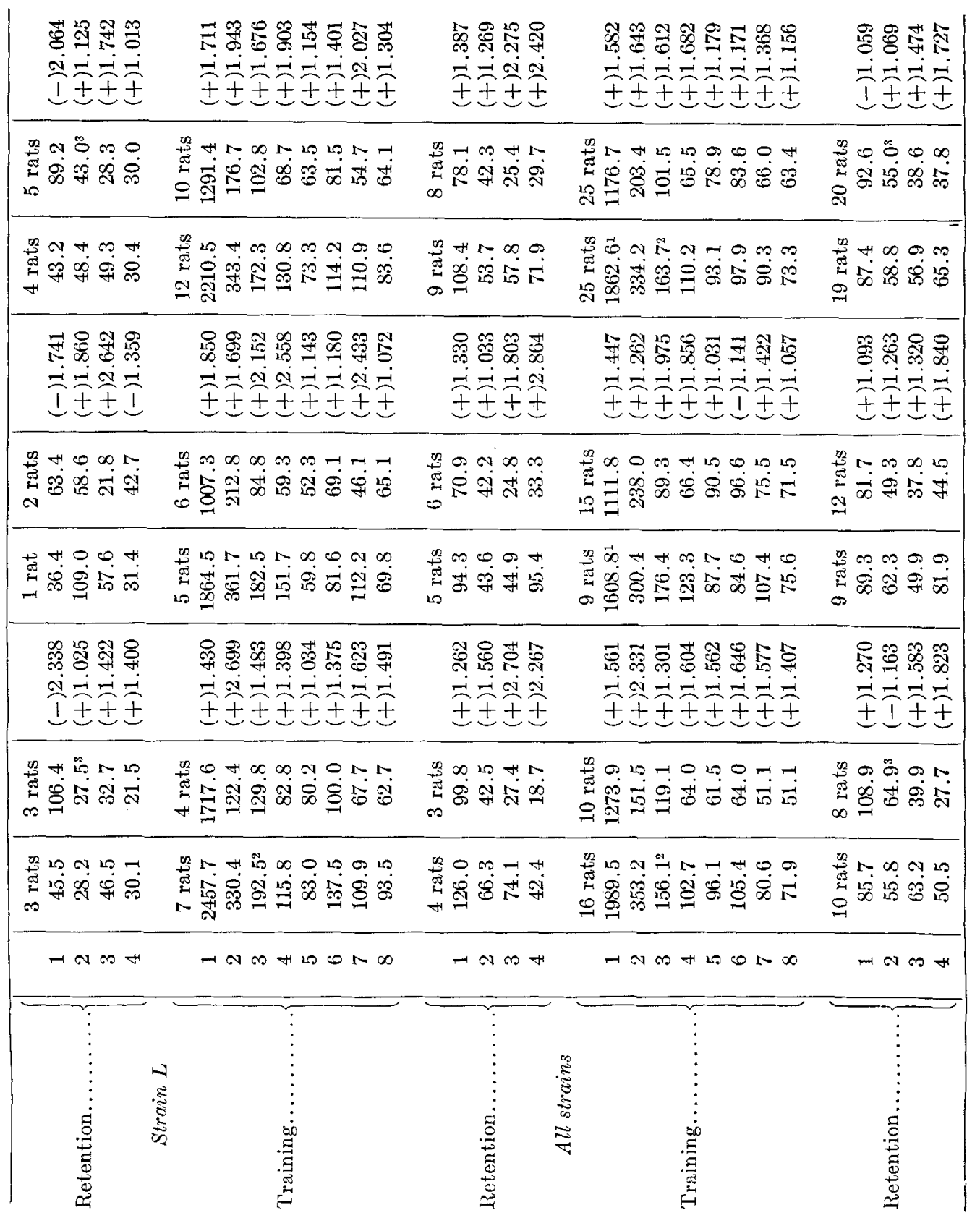




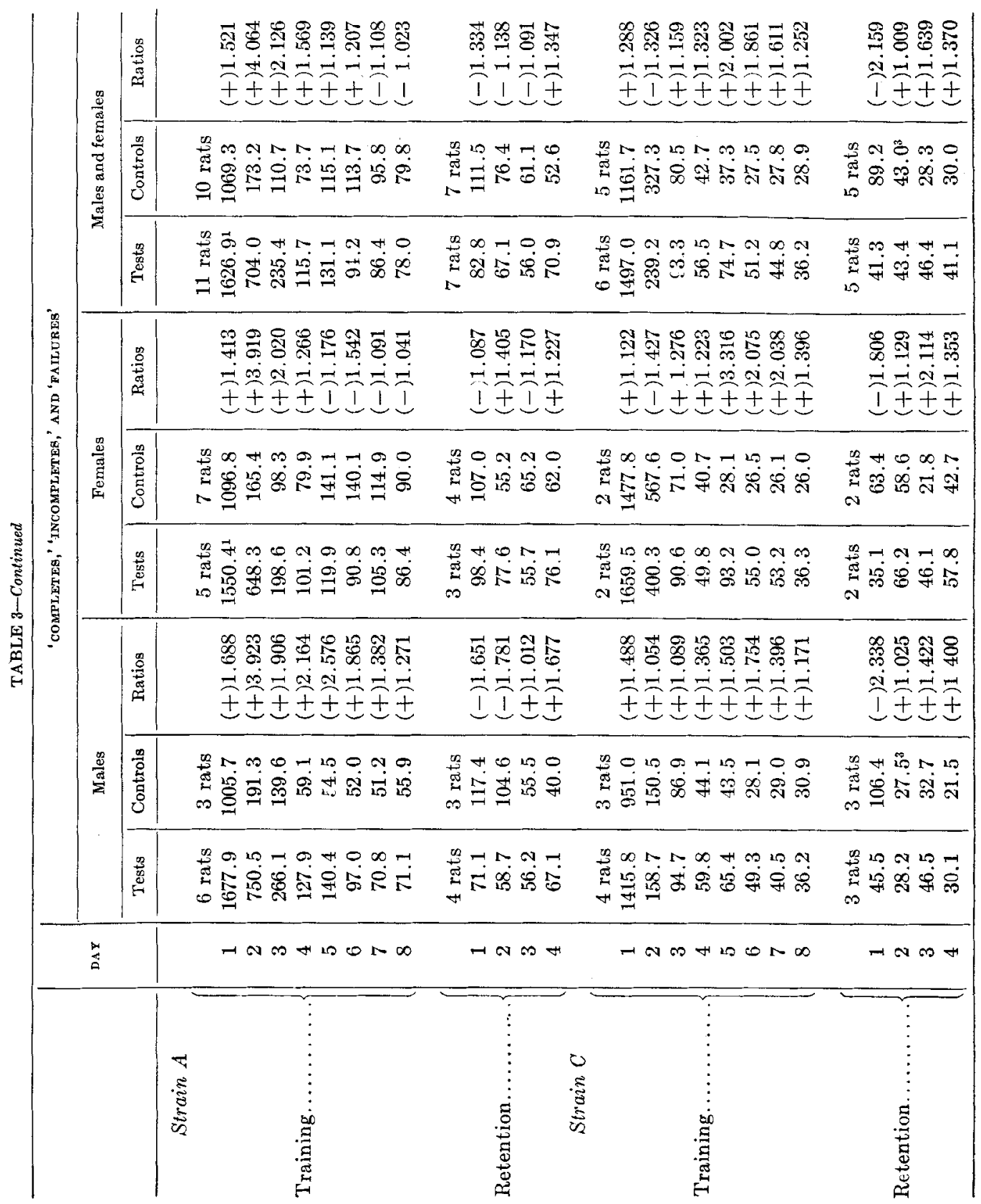




\begin{tabular}{|c|c|c|c|}
\hline 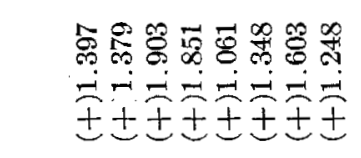 & 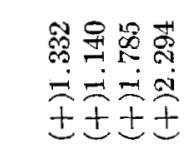 & 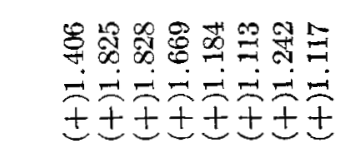 & 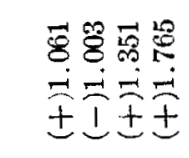 \\
\hline 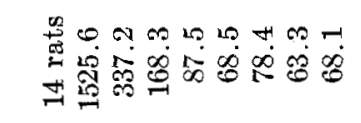 & 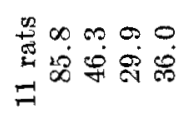 & 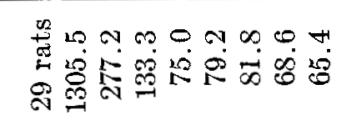 & 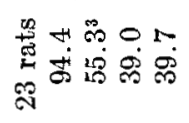 \\
\hline 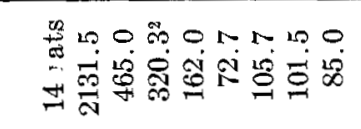 & 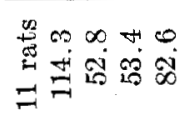 & 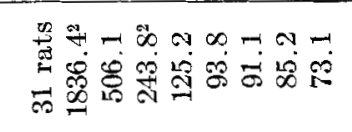 & 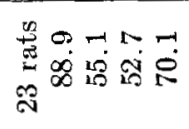 \\
\hline 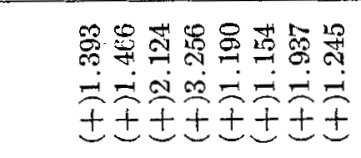 & 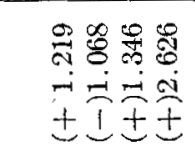 & 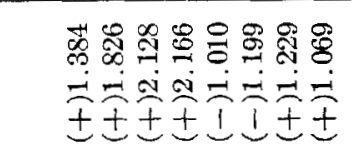 & 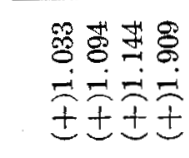 \\
\hline 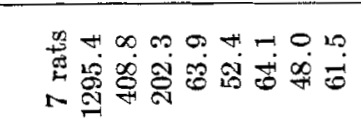 & 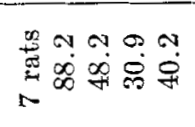 & 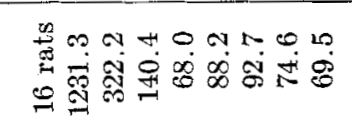 & 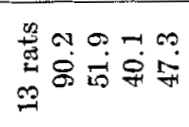 \\
\hline 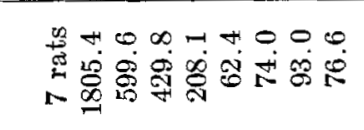 & 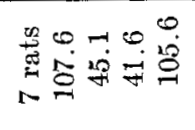 & 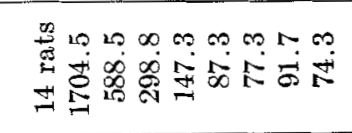 & 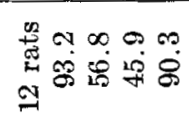 \\
\hline 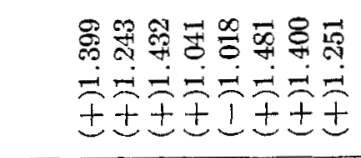 & 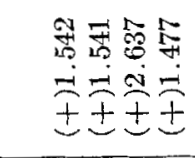 & 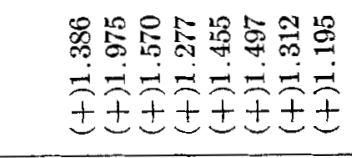 & 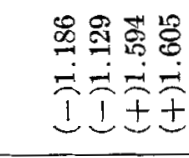 \\
\hline 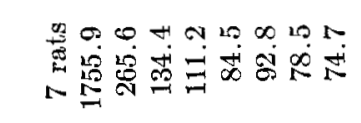 & 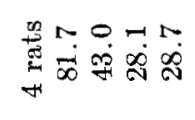 & 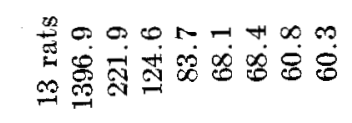 & 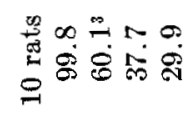 \\
\hline 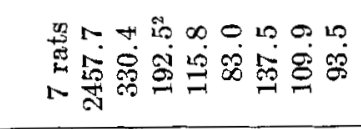 & 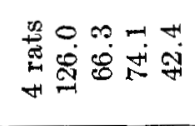 & 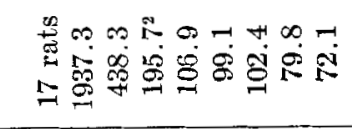 & 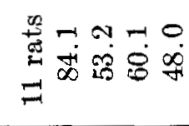 \\
\hline 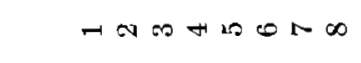 & $-N \infty$ & 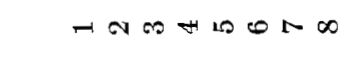 & 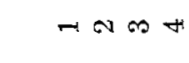 \\
\hline 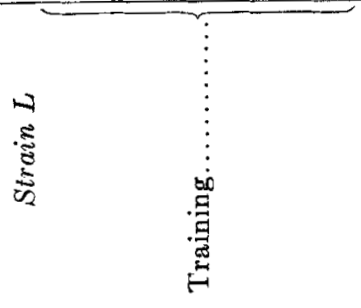 & 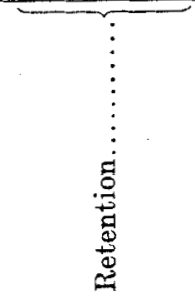 & 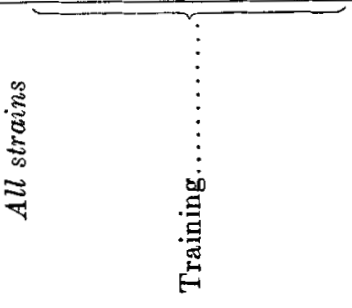 & 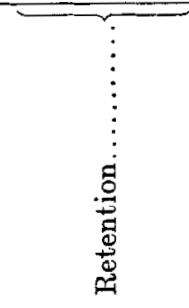 \\
\hline
\end{tabular}



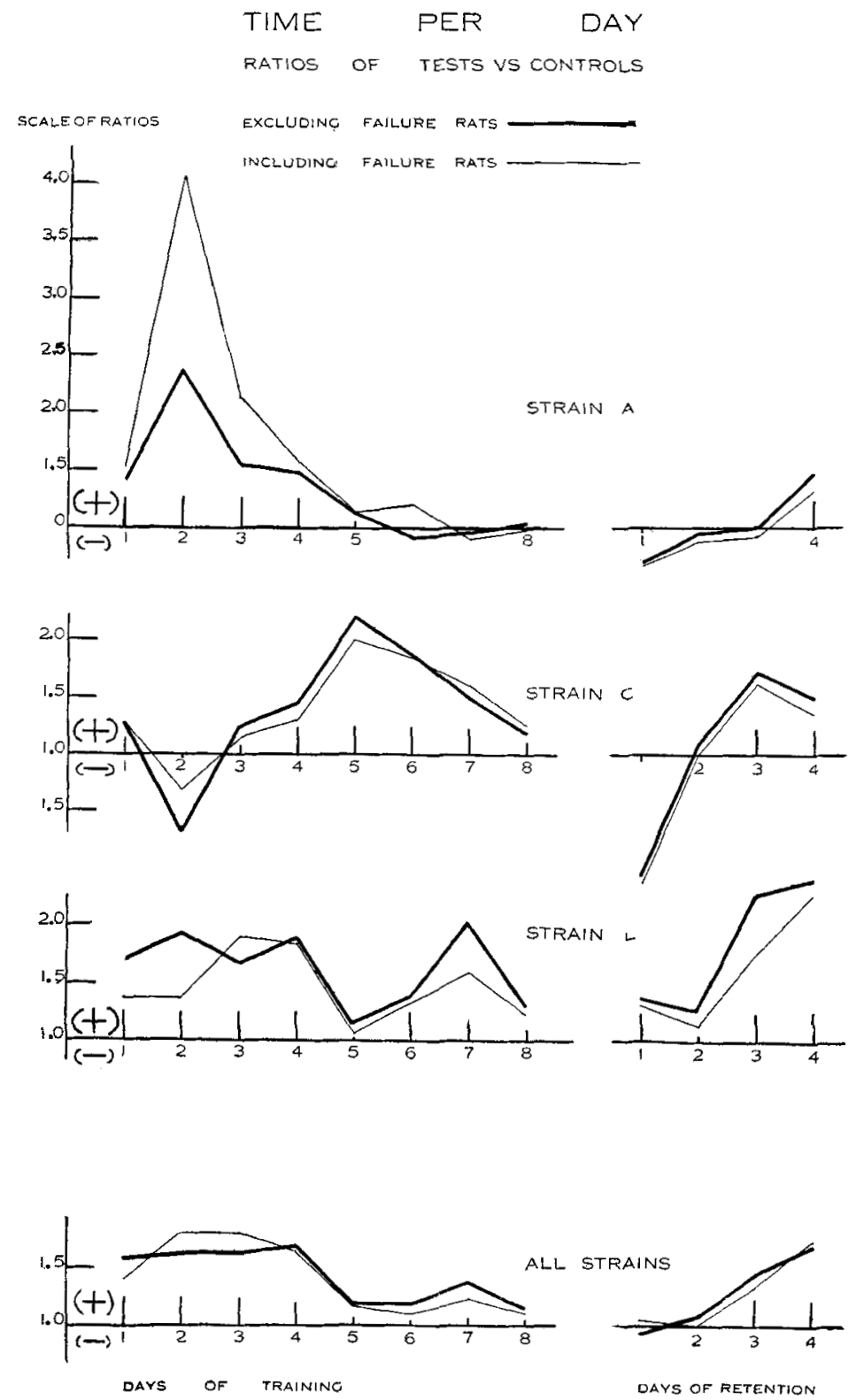

Fig. 4 Ratios of the time averages of the tests vs. controls on each day of training and retention. The base line represents equality, i.e., ratio of 1.000 ; points above the base line represent 'plus' ratios, those obtained when the test average was larger than, and so divided by, the control average; points below the base line represent 'minus' ratios, those obtained when the control average was larger than, and so divided by, the test average. Accordingly, points above the base line show that the tests took more time. The heavy lines are based on the 'completes' and 'incompletes'; light lines, upon the 'failures' as well. Units on the base lines are days: first series for training; the second series, retention; units on the vertical scale gives the size of the ratios. 
Above the line are plotted the 'plus ratios' (those that indicate that the test average was higher than the control average); below the line are plotted the 'minus ratios' (those indicating that the control averages were higher than the tests). The heavy line connects the plotted ratios for the group of rats excluding the 'failure' rats; the light line includes the 'failure' rats. Obviously, the strong tendency in each strain is for the line connecting the ratios to lie well above the base line of equality; in other words, the test averages tend to be higher (that is, take more time) than the control averages.

The following tabulations are given in consideration of the size of the ratios:

The number of ratios over 'plus' 1.500

\begin{tabular}{|c|c|c|c|}
\hline & MaLES & FEMALES & $\begin{array}{l}\text { MALES AND } \\
\text { FEMALES }\end{array}$ \\
\hline Excluding 'failure' rats . ............. & 20 & 18 & 17 \\
\hline Including 'failure' rats $\ldots \ldots \ldots \ldots \ldots \ldots$ & 16 & 14 & 17 \\
\hline
\end{tabular}

The number of ratios over 'minus' 1.500

\begin{tabular}{|c|c|c|c|}
\hline $\begin{array}{l}\text { Excluding 'failure' rats } \ldots \ldots \ldots \ldots \ldots \ldots \ldots \\
\text { Including 'failure' rats } \ldots \ldots \ldots \ldots \ldots \ldots\end{array}$ & $\begin{array}{l}3 \\
3\end{array}$ & $\begin{array}{l}2 \\
2\end{array}$ & $\begin{array}{l}2 \\
1\end{array}$ \\
\hline
\end{tabular}

Excluding 'failure' rats, 42.5 per cent of the 'plus' ratios are above $1.500 ; 25$ per cent of the 'minus' ratios are above 1.500 ; 17.5 per cent more of the 'plus' ratios are over 1.500. It is clear that besides being more frequent there is a larger proportion of high 'plus' ratios than high 'minus' ratios. This is brought out more plainly in the following graph (fig. 5), which gives the distributions of the ratios on each day for the sexes and strains separately (that is, not using ratios involving the repetition of data). The 'plus' ratios are shown in the solid line and the 'minus' ratios by the broken line. The mean of the 'plus' ratios is higher than the mean of the 'minus' ratios, but the difference has questionable statistical significance as tested by its probable error. (Average of 'plus' ratios $=1.685$; average of 'minus' ratios $=1.478$; difference $0.207 \pm 0.09=2.30$ times the probable error.) 
Unfortunately, probable errors can not be given for the groupings in which the strains or sexes are given separately, since the numbers are too small for the calculation of standard deviations; but such calculations have been made for the inclusive grouping of all strains and both sexes. In table 4 are given the differences between the test and control averages for each day of training and retention, both excluding and including the 'failure' rats. The probable errors of the differences and the differences in

TIME PER DAY

FREQUENCY DTSTRIBUTIONS OF RATIOS

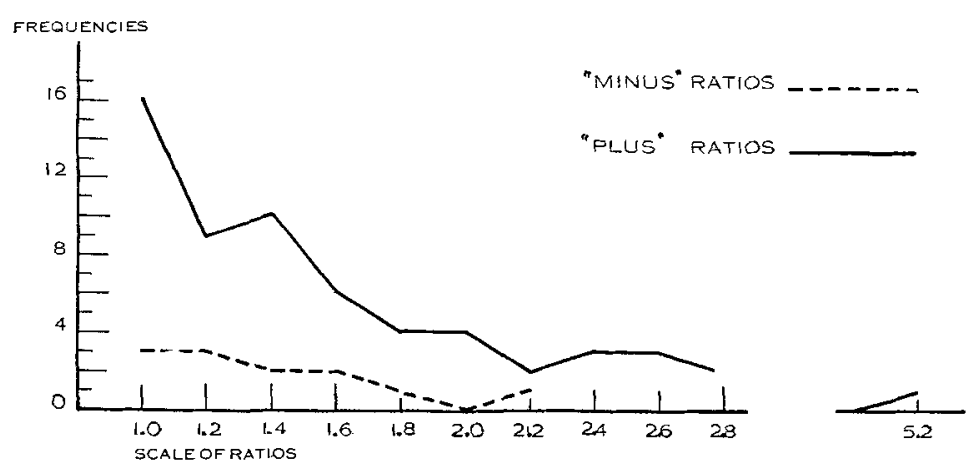

Fig. 5 Frequency distribution of the ratios of tests vs. controls, based on the averages of the time for each day with the sexes and strains treated separately (ratios given in table 3); the size of the ratios is shown on the base line; the vertical scale gives the numbers of ratios. The broken line gives 'minus' ratios (controls taking more time); the solid line gives 'plus' ratios (tests taking more time). 'Completes' and 'incompletes' are included, but not 'failures.'

terms of their probable errors (differences divided by their probable errors) indicate the statistical significance of the differences. The first four days of training and the last day of retention for the 'completes' and 'incompletes' show differences that are three or more times their probable errors. On the seventh day of training and the third day of retention the differences are only slightly below three times their probable errors (2.63 and 2.91 times). Adding the 'failures' gives the same results, with the exception that the difference on the third day of training falls a little below three times its probable error (2.51 times). 
The fact of there being a series of twelve comparisons, eleven of which go in the same direction, has, in itself, a significance independent of the probable errors obtained in each case from the standard deviations. There is presented a series of twelve terms; each term may be plus or minus. If the sign is due to chance, there should be as many plus as minus terms in the

TABIE 4

Showing the significance of the difference between the averages of the time of tests and controls on the different days of their training. These differences are taken from the averages of sexes and strains together in table 3 . The plus sign indicates that the average of the test is higher than the corresponding average of the control. Since the differences in the first part of training are greater than three times their probable errors, the tests appear to take a significantly longer time in the maze in this part of training

\begin{tabular}{|c|c|c|c|c|c|c|c|}
\hline \multirow{2}{*}{ PERIOD } & \multirow{2}{*}{ DAY } & \multicolumn{3}{|c|}{ 'COMPLETES' AND 'INCOMPLETES' } & \multicolumn{3}{|c|}{$\begin{array}{c}\text { 'COMPLETES' AND 'INCOMPLETES,' } \\
\text { AND 'FAILURES' }\end{array}$} \\
\hline & & Diff. & P. E. & Diff./P. E. & Diff. & P. E. & Diff./P. E. \\
\hline \multirow{7}{*}{ Training. } & 1 & \multicolumn{2}{|c|}{$+686.0 \pm 143.3$} & 4.79 & \multicolumn{2}{|c|}{$+530.9 \pm 130.2$} & 4.08 \\
\hline & 2 & $+130.8 \pm$ & 39.3 & 3.33 & \multicolumn{2}{|c|}{$+228.9 \pm 56.7$} & 4.03 \\
\hline & 3 & $+62.2 \pm$ & 15.8 & 3.94 & \multicolumn{2}{|c|}{$+110.5 \pm 44.0$} & 2.51 \\
\hline & 4 & $+44.7 \pm$ & 9.8 & 4.54 & & 3.50 \\
\hline & 5 & $+14.2 \pm$ & 11.3 & 1.24 & \multicolumn{2}{|c|}{$\begin{array}{r}+50.2 \pm 14.3 \\
+14.6 \pm 9.9\end{array}$} & 1.46 \\
\hline & 6 & $+14.3 \pm$ & 11.0 & 1.30 & \multicolumn{2}{|c|}{$+9.3 \pm 9.5$} & 0.98 \\
\hline & 7 & $+24.3 \pm$ & 9.2 & 2.63 & \multicolumn{2}{|c|}{$+16.6 \pm 8.3$} & 2.00 \\
\hline \multirow{5}{*}{ Retention. . } & 8 & $+9.9 \pm$ & 8.4 & 1.16 & \multicolumn{2}{|c|}{$+7.7 \pm 7.3$} & 1.06 \\
\hline & 1 & $-5.2 \pm$ & 8.5 & 0.61 & $5.5 \pm$ & 8.3 & 0.66 \\
\hline & 2 & $+3.8 \pm$ & 8.1 & 0.47 & $+0.2 \pm$ & 6.2 & 0.03 \\
\hline & 3 & $+18.3 \pm$ & 6.2 & 2.91 & $+13.7 \pm$ & 5.5 & 2.50 \\
\hline & 4 & $+27.5 \pm$ & 6.9 & 3.98 & $+30.4 \pm$ & 6.9 & 4.40 \\
\hline
\end{tabular}

long run. The chances that eleven out of twelve should be plus on a chance basis would be the same as the frequency of eleven heads when twelve coins are tossed simultaneously; departures from equality as great as this may be expected to occur once in 157 trials, which corresponds to a little over four times the probable error.

When each day of training is considered by itself, the averages in the great majority of cases show that the tests took more 
time than the controls in running the maze. In certain cases the tests took less time, but these differences tend to be smaller than the differences in the other direction. In the first half of the training period the differences are statistically significant.

Still further comparisons have been made, using the time for each successive trial instead of total time for each day. That is, averages of the first trials of all the rats in all the different combinations of sexes and strains have been calculated, and so for each of the thirty-six trials. This study gives results in full agreement with those obtained from the study of averages based on the total time for each day. The variability is naturally increased, but the number of points of comparison has been tripled; even without this evidence the conclusion is so unquestionable and the tables involved are so extensive that these summaries are not presented.

c. Variability of the tests vs. controls, judged by time. In table 5 are given the standard deviations of the averages for each rat for each of the six different groups of trials, when the males and females in all strains are put together. The tests have higher standard deviations in all groups of trials except in retention and, when the 'incompletes' and 'incompletes' and 'failures' are added, in the second half of training. The difference is more than three times the probable error of the difference in four of the six groups of trials when the 'completes' are alone; adding the 'incompletes' does not change this; but when the 'failure' rats are also added, none of the groups of trials give differences between the standard deviations that are significant; i.e., three times their probable error.

Table 6, which gives the standard deviations for each day, shows that the tests are significantly more variable on the first four days of training and on the fourth day of retention; with the 'failures' included, the tests are significantly more variable on the first, third, and fourth days of training and on the fourth day of retention. Although the differences in the standard deviations are not significant when the first twelve trials are taken together (first half of training) and the 'failures' included, 


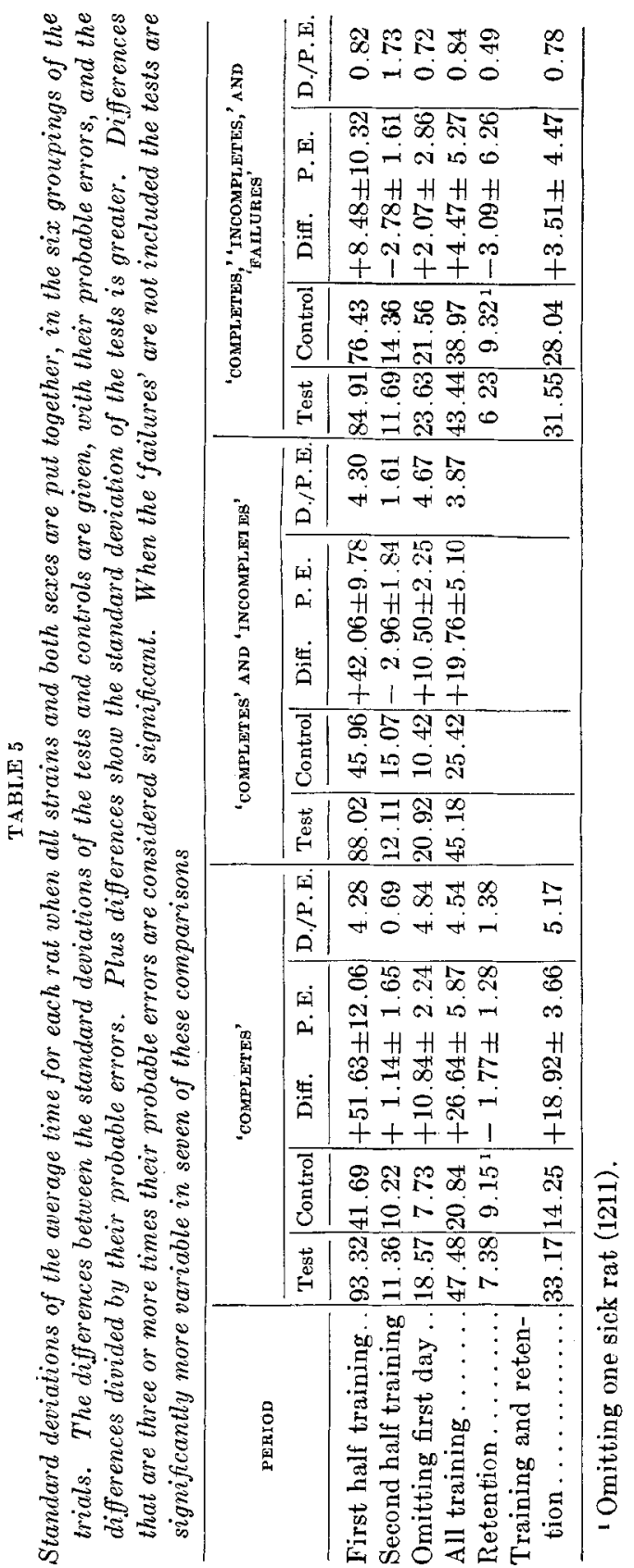

THE JOURNAL OF EXPERIMENTAL ZOÖLOGY, vOL. 33, NO. 1 


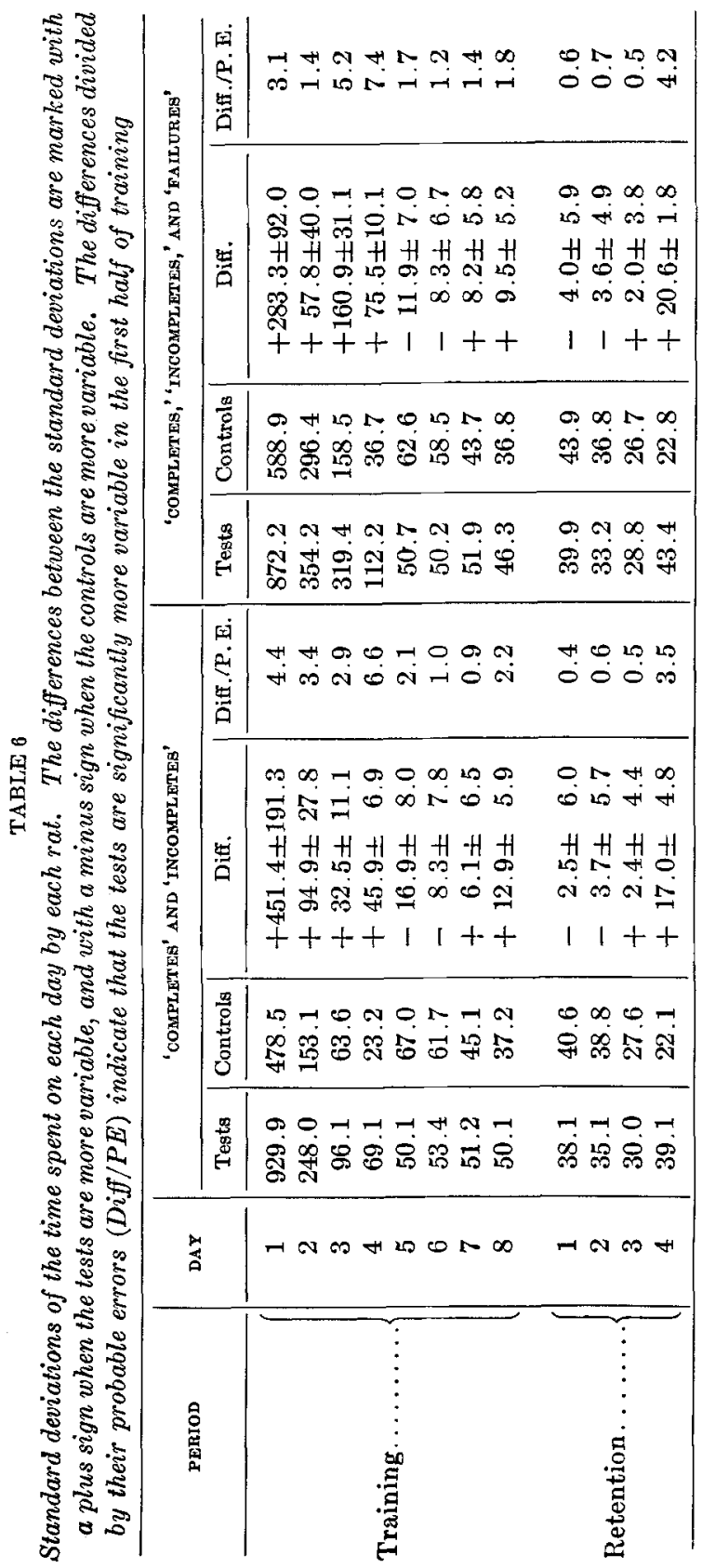


significant differences in the variability are found when the trials are separated into groups of three. It may be concluded, then, that there is a difference in the variability of the tests and controls in the first half of training, although when the 'failure' rats are included this is hidden if all the twelve trials are taken together.

d. What is the probability that the test data and control data for time are not random samples from the same population?2 It is believed that sufficient evidence has been presented to remove the slightest doubt from the conclusion that the tests as a group took more time in learning the maze than did the controls. So the presentation of the following method of comparing the time data of the tests and controls is of more interest from a methodological standpoint than from the standpoint of the findings, which, it may be stated in advance, fully substantiate the above conclusions.

Although the $\chi^{2}$ test is usually employed to measure the goodness of fit of a theoretical and an empirical curve, it also affords a method of measuring how poorly two curves agree; it measures the probability that two curves, differing as much as those in question, will occur as the result of random sampling from a single population. The following formula given by Pearson (Biometrica, '11, p. 250) has been used:

$$
\chi^{2}=\Sigma\left\{\frac{\mathrm{NN}^{\prime}\left(\frac{\mathrm{f}}{\mathrm{N}}-\frac{\mathrm{f}^{\prime}}{\mathrm{N}^{\prime}}\right)^{2}}{\mathrm{f}+\mathrm{f}^{\prime}}\right\}
$$

in which $\mathrm{N}=$ numbers in one sample; $\mathrm{N}^{\prime}=$ numbers in the other sample; $f=$ frequency of a class in one sample, $f^{\prime}=$ the frequency of a class in the other sample.

If the $x^{2}$ test indicates that such differences as are found may be expected to occur more often than once in twenty times (once in twenty times corresponds to three times the probable error), the curves could not be considered significantly different;

\footnotetext{
2 We are pleased to acknowledge the large part our colleague, Prof. H. D. Fish, has contributed in working out the methods used in this section.
} 
but if it shows that curves as different may be expected to occur less often than once in twenty times, they would be considered significantly different.

The number of rats is too small to permit the calculation of $x^{2}$ from curves based on the averages of each rat. But by using every trial of every rat, enough numbers are obtained. However, the actual time at the beginning and the end of training is so very different that it would not be possible to make satisfactory distribution curves by seriating these directly. For this reason ratios were substituted for the actual trials. A standard smooth curve was established by interpolation from the means of the control rats for each successive trial in training. For each trial of each rat (tests and controls) the ratio to the corresponding point on this assumed standard curve was calculated. In obtaining these ratios the smaller number was always divided into the larger; when the actual time was longer than the standard, the ratio was called 'plus,' when shorter, 'minus.' These ratios, tests and controls separately, were next seriated upon a scale with equality (ratio $=1.00$ ) as the central point and 'plus' ratios of increasing size extending to the right, 'minus' ratios of increasing size extending to the left. Figure 6 shows the distribution curves for these ratios grouped in classes of 1.725 in width, and also into classes 2.625 wide. The solid line represents the controls, the broken line the tests. In one pair of curves $\chi^{2}=58.5$; on the other hand, $\chi^{2}=44.5$. The value for $\mathrm{P}$ given in biometrica tables (p. 25, table XII) for both these values of $\chi^{2}$ and the number of classes in each curve is $0.000,000$. In other words, the odds against these pairs of curves being random samples from the same population are at least greater than $1,000,000$ to 1 .

e. Conclusions based on the time data. The data on time have been summarized in various ways with three groupings of the rats: 1) 'completes,' 2) 'completes' and 'incompletes,' 3) 'completes,' 'incompletes,' and 'failures;' averages per rat for the different periods of the training, averages per rat for each day by itself, males and females separately and together, the three strains grouped separately and together; in each method of 


TIME PER TRIAL

FREQUENCY DISTRIBUTIONS OF RATIOS

OF EACH TRIAL TO A STANDARD
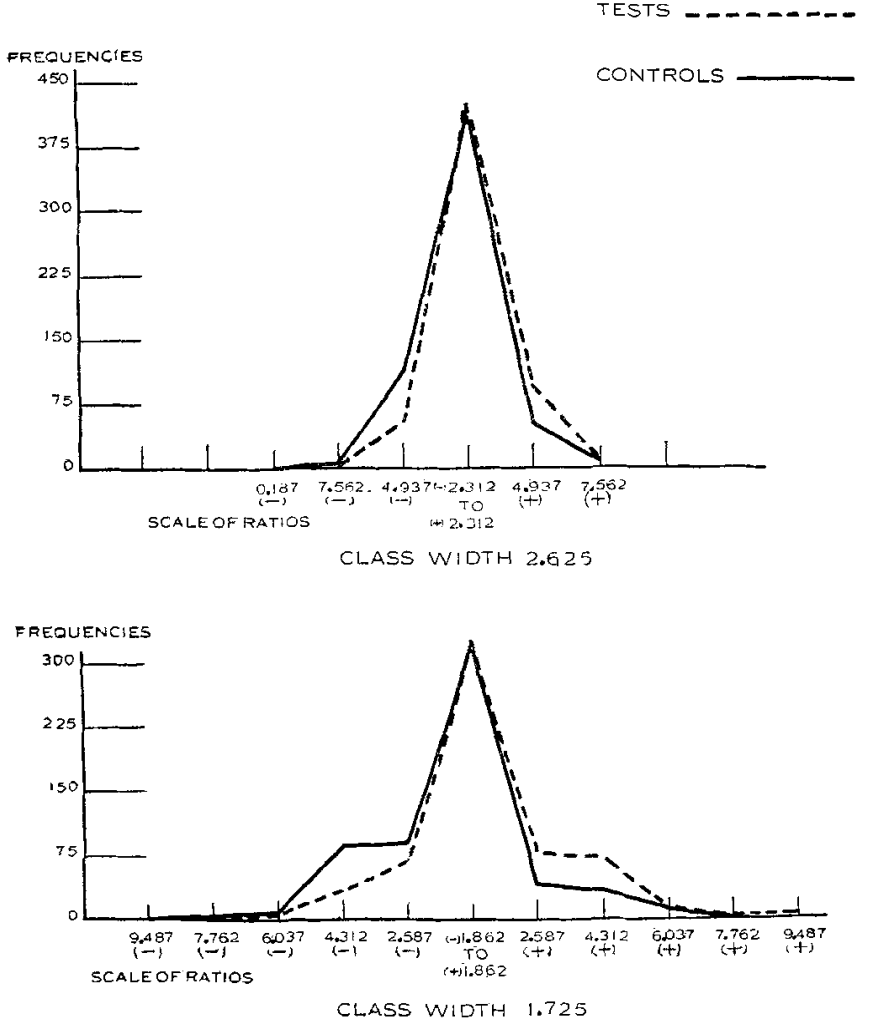

Fig. 6 Distributions of the ratios obtained by dividing each time record into, or by, the assumed standard for the corresponding trial in the training; 'plus' ratios, those at the right of the central point, were obtained when the record was larger than the standard, and so divided by the standard; 'minus' ratios, those at the left, were obtained when the record was smaller than the standard, and so divided into the standard. These ratios are grouped into classes of two widths, 2.625 and 1.725 wide, respectively. The numbers on the base lines are the outer limits of the ratios included in the classes; the vertical scale gives the numbers of ratios in each class. Broken lines show the tests; solid lines, the controls. These distributions have been used for the application of the $\chi^{2}$ test. 
summarizing the tests and controls have been compared. Standard deviations and probable errors have been calculated for all groupings that included large enough numbers; a special set of ratios to an assumed standard has been obtained for the purpose of applying the $\chi^{2}$ test to the frequency distributions of the test and control data. Every method of treating the time data leads to the same conclusion, namely, that the test rats as a group differ from the controls; this difference is more apparent in the first half of training while the learning was rapid, but even in the last half of training, after there was very little general improvement a similar though smaller difference is found. Tested by probable errors, significant differences are found between the averages involving the first half of training and the fourth day of retention; the distributions of all the data for tests and controls, compared by means of the $\chi^{2}$ test, are found to differ more widely than could be explained by random sampling.

\section{Comparison of the test and control rats on the basis of the distance covered in running each trial}

a. Distance: averages for different groups of trials. As explained in the first section, the data on distance were obtained from camera-lucida drawings of the course of each trial of each rat. As the rat went through the alleys of the maze, its image reflected upon the record sheet was followed with a pencil, thus making an accurate and lasting record of just where the rat went. These pencil lines were measured by means of a map measurer, or chartometer. Figure 7 reproduces a record sheet; it bears an inverted plan of the maze. These sheets are about $1 / 13$ th the size of the maze itself. In the early trials, when the rats were going long distances, several sheets were used to record one run. The data presented are in terms of the actual lengths in centimeters of the pencil lines that appear on the record sheets; accordingly, all the distances are $1 / 13$ th of the actual distances covered by the rats, but the relative difference between the tests and controls is the same as though the actual distances had been used. Leaving the data in the reduced form has saved the labor of transforming each record into the actual distance, as well as of handling much larger numbers in the summarizing. 
The distance data have been summarized for the 'completes' and 'incompletes' without giving 'completes' alone or including the 'failures,' for reasons given on page 217; otherwise, the same methods have been employed as for the time data. Table 7

\section{No. 1211}

Time :08.2 sec.

\section{Distance. 37 crn.}

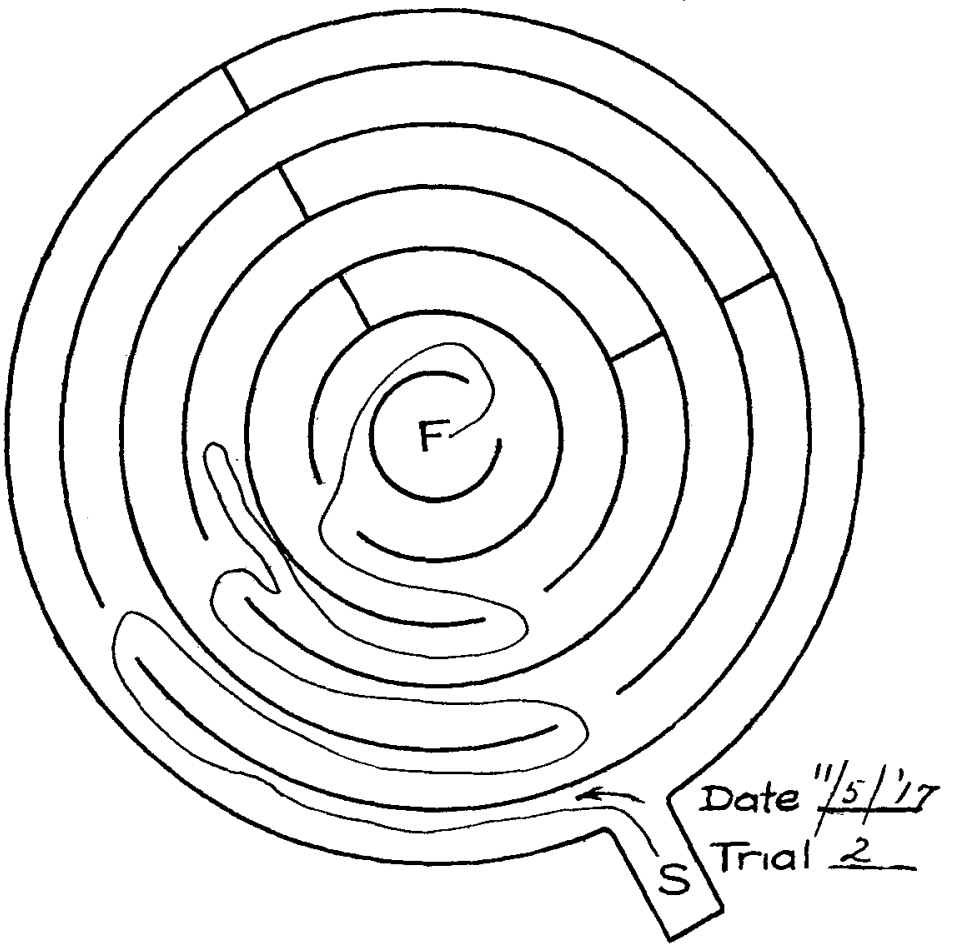

Fig. 7 Record sheet four-fifths actual size. This shows an inverted plan of the maze as reflected upon the sheet; the rats were started at $S$ and found food in $F$. The maze itself is 5 feet in diameter.

gives the averages for each of the six groupings of the trials (averages of the averages for each rat). The following groups of the rats have been used: sexes separate and strains separate; sexes together and strains separate; sexes separate and strains together; sexes together and strains together. The averages 


\begin{tabular}{|c|c|c|c|c|c|}
\hline & \multirow{2}{*}{ 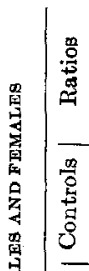 } & 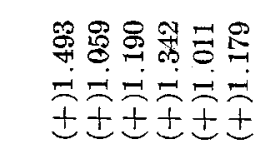 & 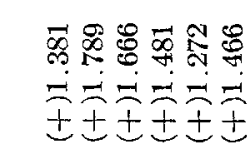 & 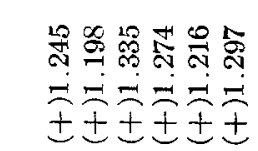 & 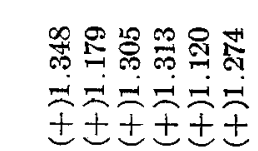 \\
\hline & & 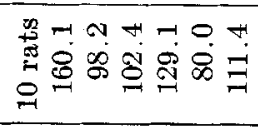 & 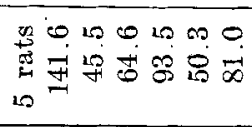 & 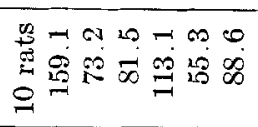 & 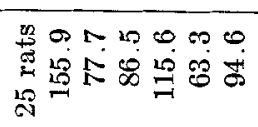 \\
\hline & 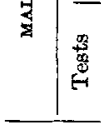 & 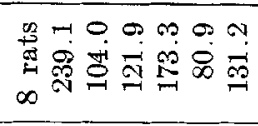 & 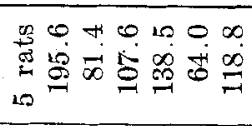 & 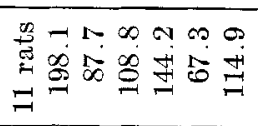 & 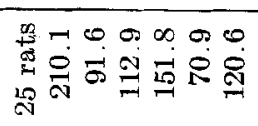 \\
\hline 苛 & 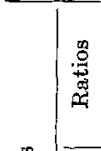 & 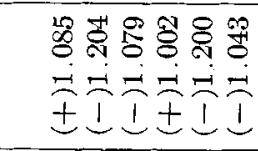 & 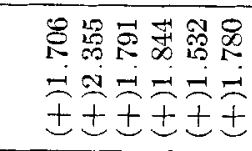 & 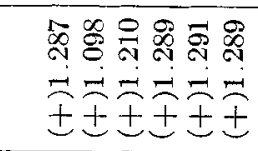 & 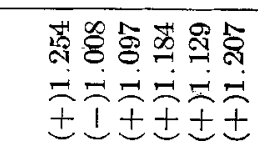 \\
\hline$\stackrel{\infty}{\stackrel{\infty}{*}}$ & 弯 & 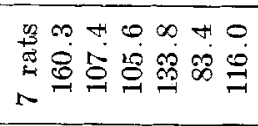 & 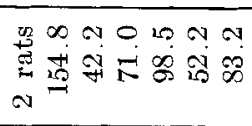 & 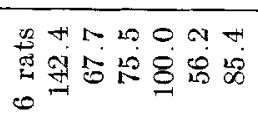 & 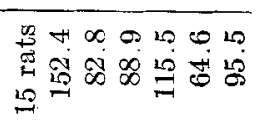 \\
\hline 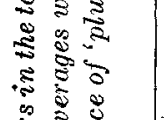 & 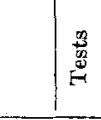 & 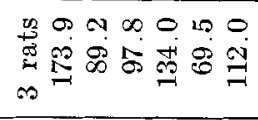 & 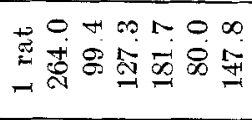 & 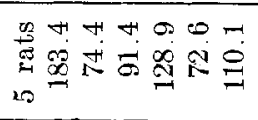 & 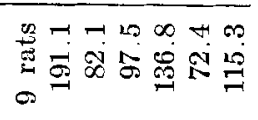 \\
\hline & : & 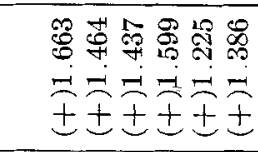 & 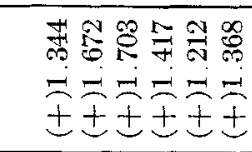 & 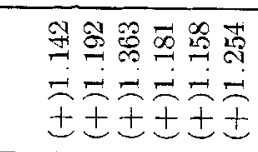 & 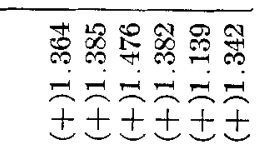 \\
\hline$=$ & $\frac{2}{8}$ & 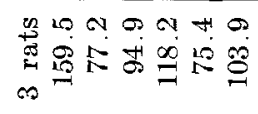 & 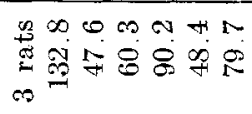 & 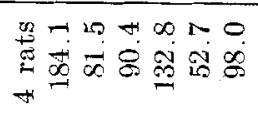 & 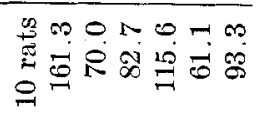 \\
\hline 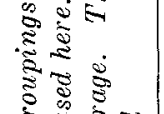 & 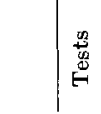 & 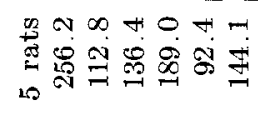 & 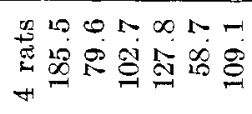 & 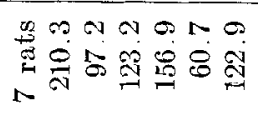 & 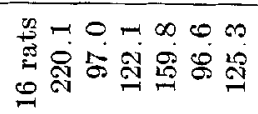 \\
\hline 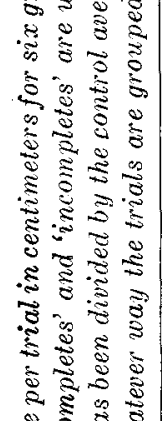 & 兽 & 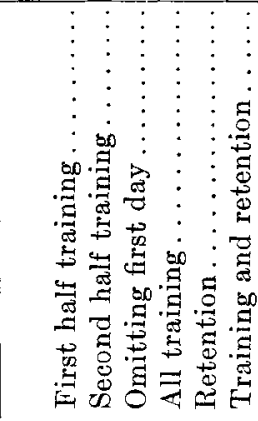 & 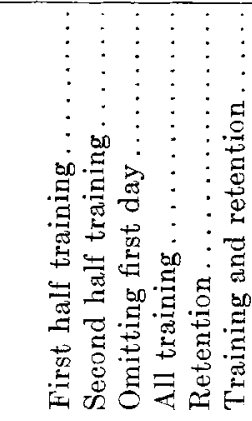 & 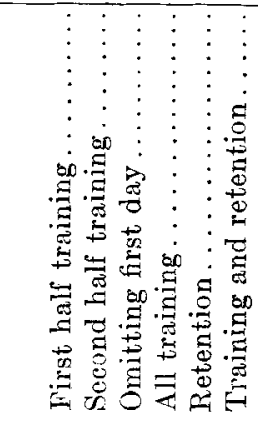 & 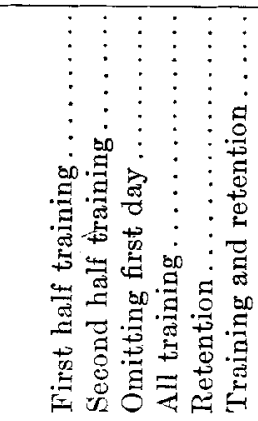 \\
\hline 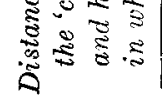 & 层 & 4 & 0 & A & $\bar{Z}$ \\
\hline
\end{tabular}


of the tests and controls are compared by the ratios of one to the other and not by their differences; a 'plus' ratio indicates that the test average is higher and has been divided by the control average; a 'minus' ratio indicates that the control average is higher and has been divided by the test average.

In the whole table there are sixty-seven 'plus' ratios against five 'minus' ratios. The highest 'minus' ratio is 1.204; fortynine of the 'plus' ratios are higher than this. The males give 'plus' ratios in all cases. The females give the five 'minus' ratios; strain A seems responsible for these. When the sexes

TABLE 8

Showing the significance of the differences between the distance averages, based on the averages of each rat for the different groupings of the trials. The differences are taken from the averages for sexes and strains together in table 7. Plus signs indicate that the averages of the tests are higher than the controls; in five of the six groupings the differences are probably significant, indicating that the distances covered by the tests are significantly greater

\begin{tabular}{|c|c|c|}
\hline PERIOD & DIFF. & DIFF./P. E. \\
\hline First half training $\ldots \ldots \ldots \ldots \ldots$ & $+54.2 \pm 9.2$ & $5: 9$ \\
\hline Second half training $\ldots \ldots \ldots \ldots$ & $+13.9 \pm 5.1$ & 2.7 \\
\hline Omitting first day ........ & $+26.4 \pm 5.3$ & 5.0 \\
\hline All training . . . . . . & $+36.2 \pm 6.2$ & 5.8 \\
\hline Retention . . . . . . . . . . . & $+7.6 \pm 4.2$ & 1.8 \\
\hline Training and retention ...... & $+26.0 \pm 5.2$ & 5.0 \\
\hline
\end{tabular}

are combined all the ratios become plus. In table 8 are given the differences between the test and control averages which include all the rats of both sexes and all strains, the probable errors of the differences, and the differences in terms of their probable errors.

In four of the six groups of trials the differences are well above three times their probable errors (5.9, 5.0, 5.8, and 5.0 times, respectively). For the second half of training the difference is only slightly below three times its probable error (2.7 times), but for retention the difference is only 1.8 times its probable error. For distance, as for time, the difference in favor of the controls is fully significant during the initial period of rapid 
learning, while in later trials the difference is reduced. Figure 8 gives the distributions of the averages of the individual rats for the six groups of trials. There appears a strong tendency for the test rats to lie further up the scale (to the right) than the controls. This is less marked in the second half of training; and in retention there is very little difference between the distributions of the tests and controls. The averages of the distance for each rat for each of the groups of trials from which the preceding summaries have been made are given in table $\mathrm{B}$ in the appendix.

b. Distance: averages for each day. The next step in the averages of the distance data is the comparison of the tests and controls on each of the eight days of training and on the four days of retention. In table 9 the averages are arranged in the same combination of sexes and strains as before, and then compared by their ratios; 'plus' ratios indicate that the tests covered more distance than the controls. The averages for each day, when the sexes and strains are put together, are shown by the curves in figure 9 ; in figure 10 are represented graphically the ratios of the tests vs. controls for the males and females together and the strains separately as well as together. Obviously, the tests covered more ground in the great majority of cases. The females in strain A show the reverse, but there can be no doubt that this is not a general sex difference nor a strain difference, since the females in the other two strains and the males in all three strains do show that the controls covered shorter distances on the average than did the tests. There is a tendency for the first day of retention to show the tests covering less distance, but it will be noticed that this is true of two of the strains, not of the third (L). The real interest lies in the table (10) where the significance of the differences may be found. This table is based on all the males and females in all strains together. It appears that on the first, third, and fourth days of training and on the fourth day of retention the differences between the averages of the tests and controls are more than three times their probable errors; on the second and sixth days of training the differences are only very slightly below three times their probable errors 

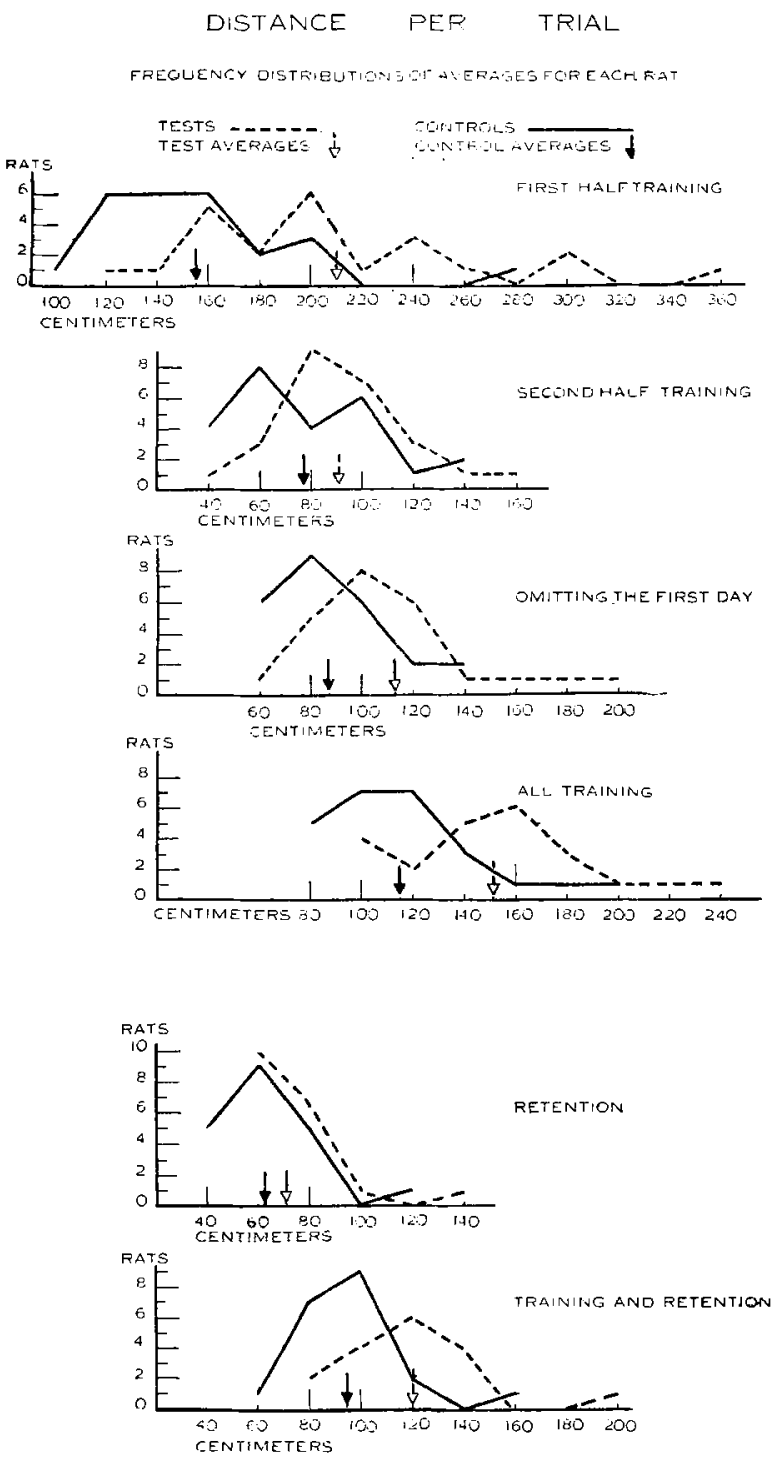

Fig. 8 Frequency distributions of the averages for each rat for distance per trial, based on six groupings of the trials. Broken lines give the tests; solid lines, the controls; units on the base line are centimeters; on the vertical scale, numbers of individuals; males and females in all strains are included, using the 'completes' and 'incompletes,' but not the 'fajlures.' 


\begin{tabular}{|c|c|c|c|c|c|}
\hline \multirow{3}{*}{\multicolumn{2}{|c|}{ 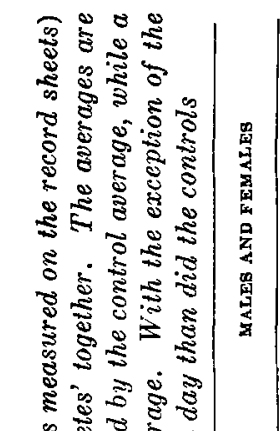 }} & \multirow{2}{*}{ 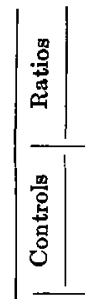 } & 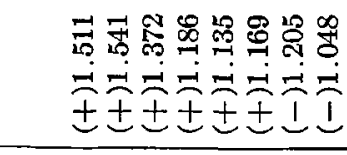 & \multirow{2}{*}{ 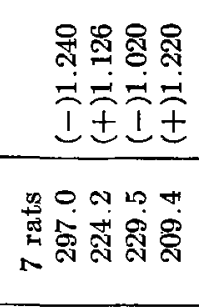 } & \multirow{2}{*}{ 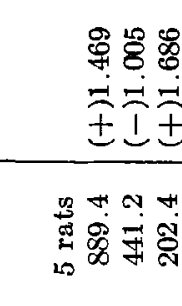 } \\
\hline & & & 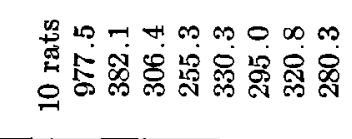 & & \\
\hline & & 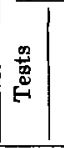 & 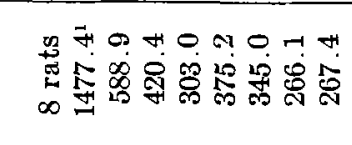 & 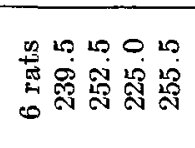 & 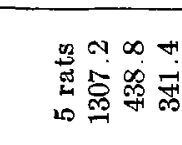 \\
\hline 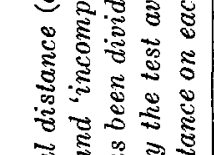 & & 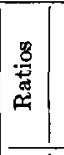 & 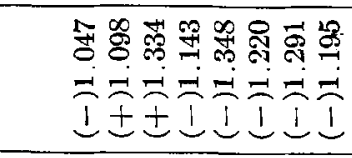 & 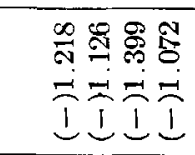 & 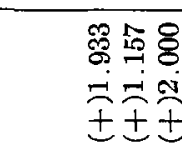 \\
\hline 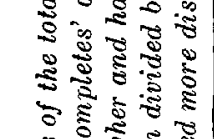 & 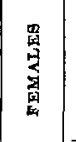 & 总 & 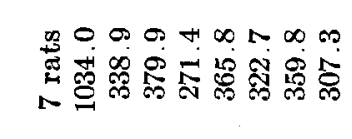 & 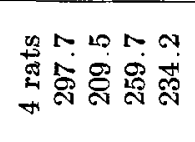 & 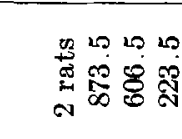 \\
\hline 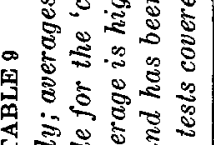 & & 总 & 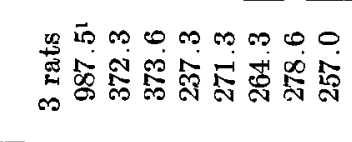 & 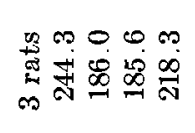 & 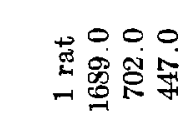 \\
\hline 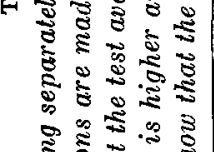 & & 承 & 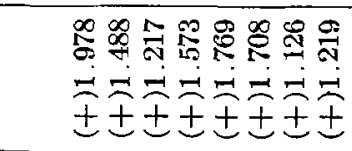 & 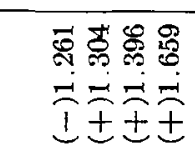 & 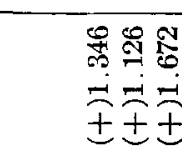 \\
\hline 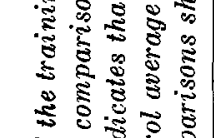 & 㽣 & $\begin{array}{c}m \\
0 \\
0 \\
0 \\
0 \\
0 \\
0\end{array}$ & 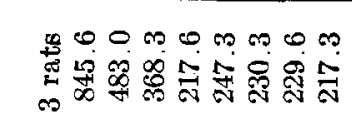 & 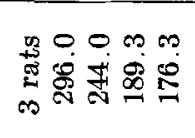 & 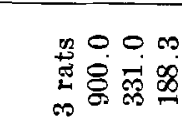 \\
\hline 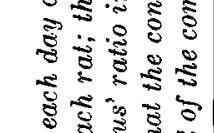 & & $\begin{array}{l}\text { 鼌 } \\
\stackrel{8}{6}\end{array}$ & 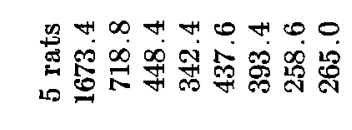 & 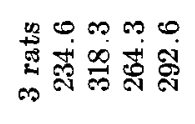 & 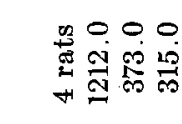 \\
\hline & $\stackrel{\Delta}{\Delta}$ & & $\pi N \infty \pi, 0 N$ & $\pi \infty \leftrightarrow$ & $\pi \infty$ \\
\hline 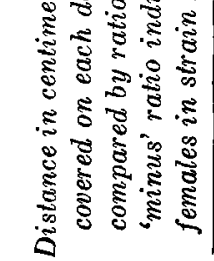 & & & - & 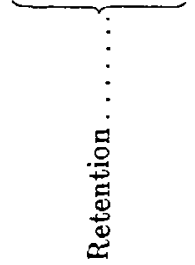 & 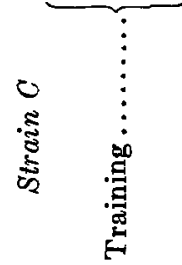 \\
\hline
\end{tabular}




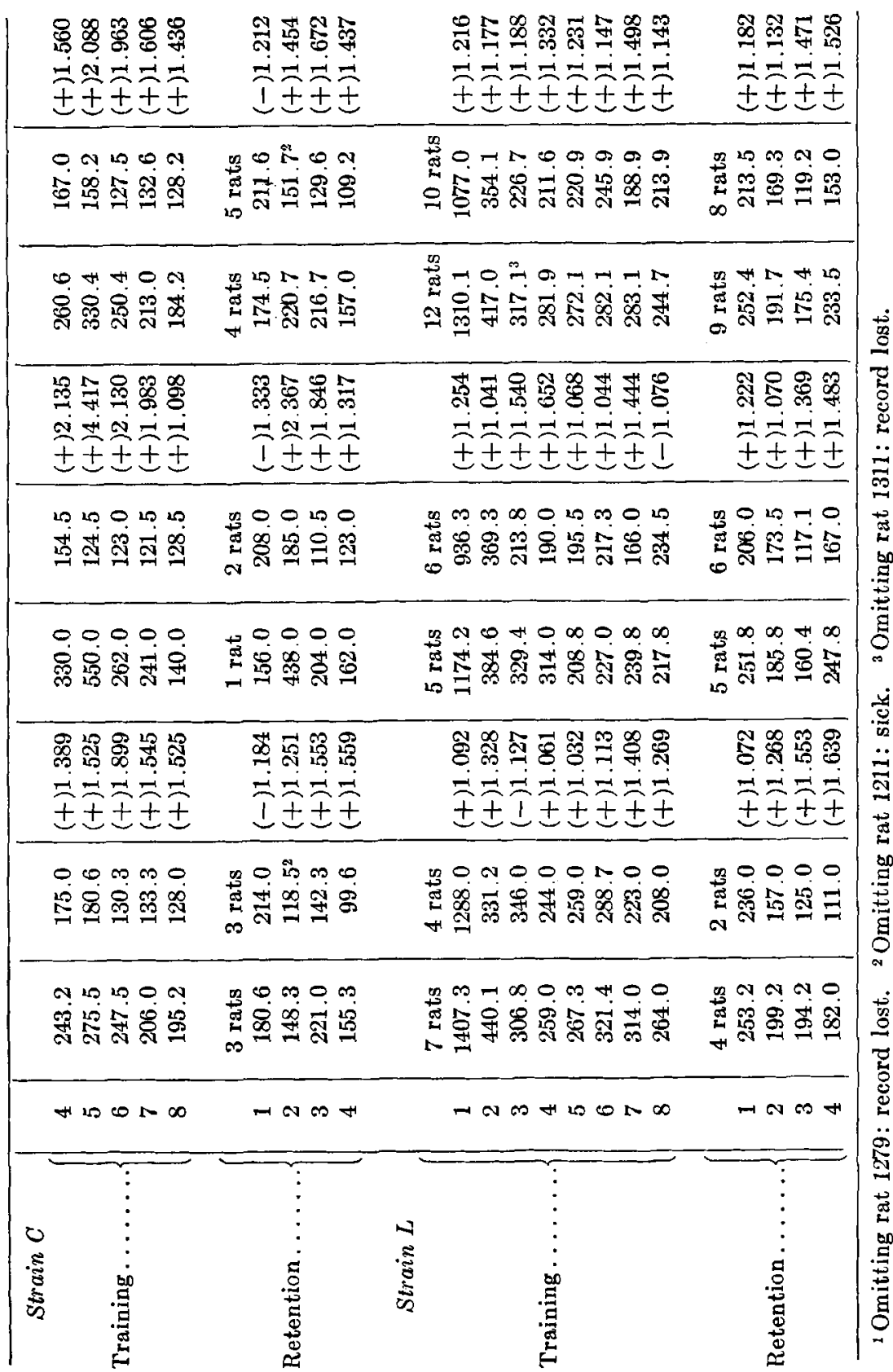




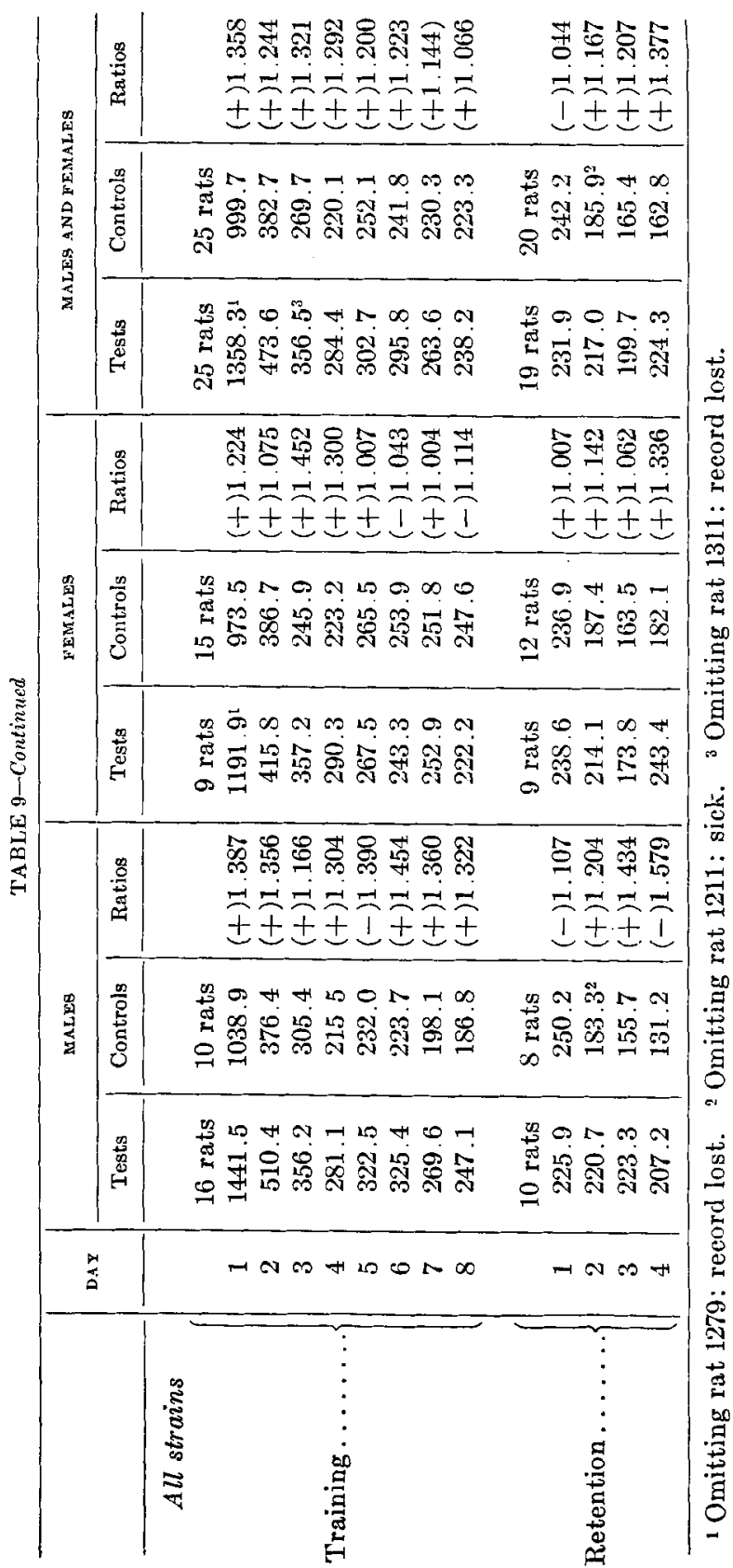




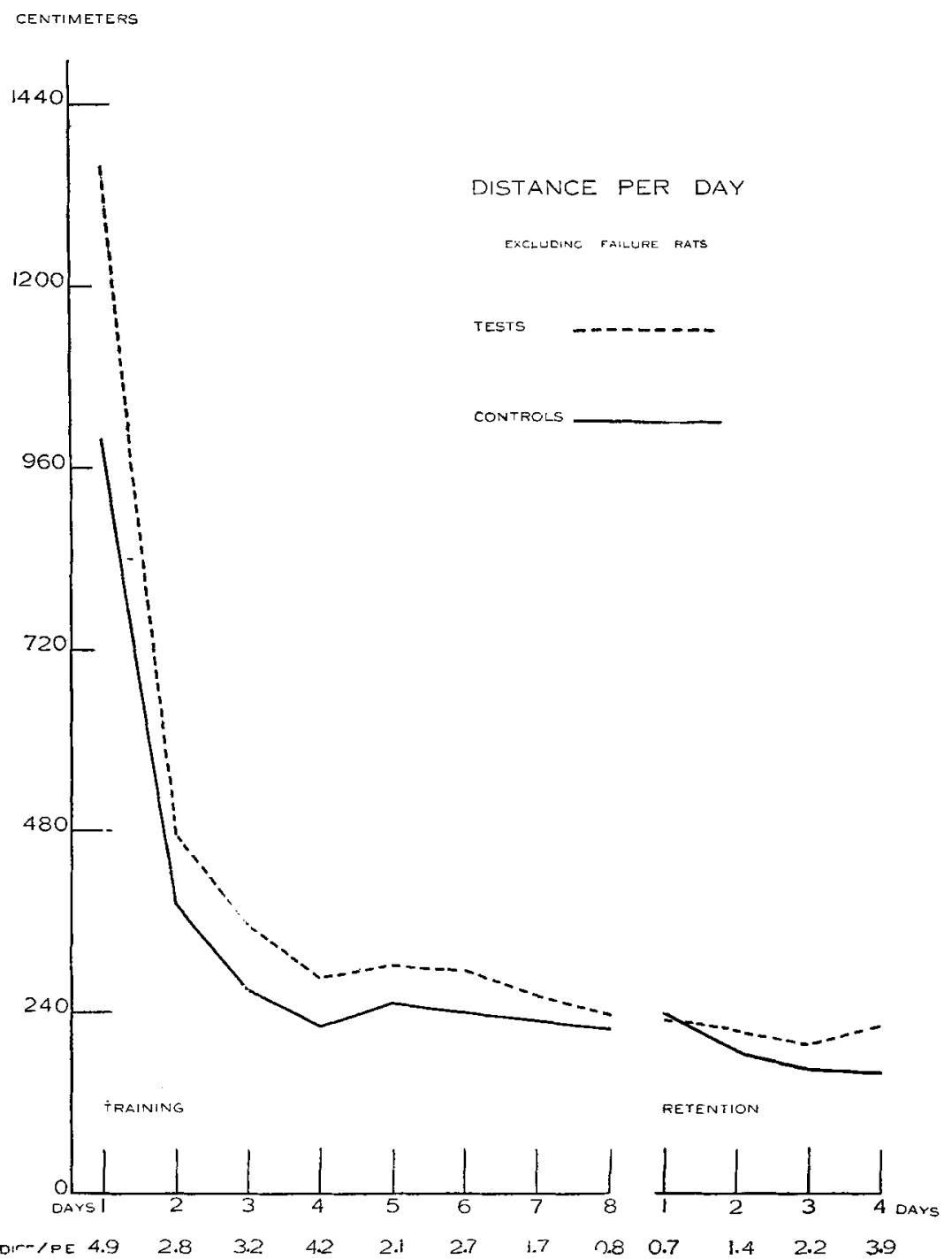

Fig. 9 Learning eurve based on distance; averages per trial on each day of training and retention. The broken lines are tests; the solid lines, controls. Units on the base line are days, units on the vertical scale are centimeters. The first series of days give training; the second series, retention. Males and females in all strains are put together in all averages. Based on the 'completes' and 'incompletes.' 


\section{DISTANCE PER DAY}

RATIOS OF TESTS VS CONTROLS

SCALE OF RATIOS
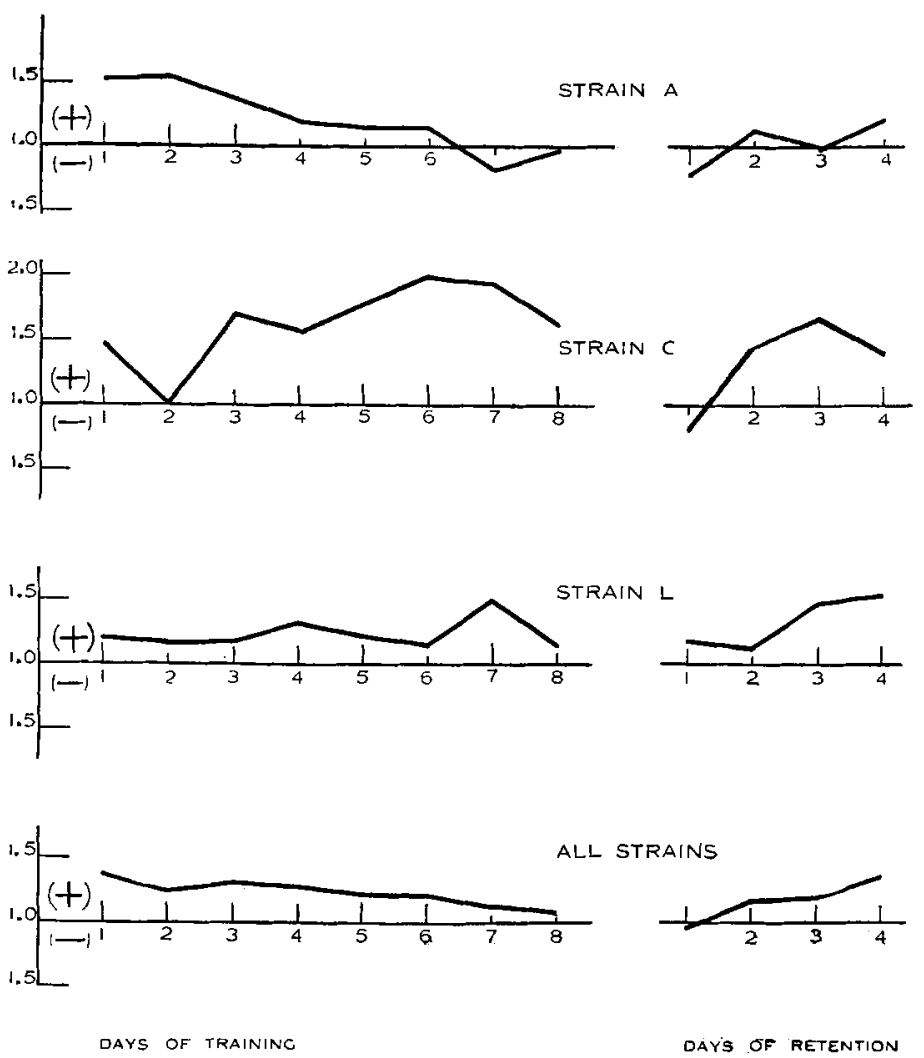

Fig. 10 Ratios of the distance averages of tests vs. controls on each day of training and retention. The base line represents equality of the test and control averages; that is, ratios of 1.000 ; points above the base line represent 'plus' ratios, obtained when the test average was larger and so divided by the control average; points below the base line represent 'minus' ratios, obtained when the control average was larger and so divided by the test average. Accordingly, points above the line show that the tests covered more distance than the controls. 'Completes' and 'incompletes' have been used, males and females together; vertical seale gives the size of the ratios; horizontal scale, days; the first series of days gives training; the second series, retention. 
(2.8 and 2.7 times). There are, then, six days on which the differences are probably significant, indicating that the tests went further than the controls, and there are no significant differences indicating the reverse.

Moreover that eleven out of twelve days should have the same sign has a significance quite apart from the probable errors on the individual days. Departures from equality as great as this may be expected in one out of 157 times if there is no real

\section{TABLE 10}

Showing the significance of the differences between the distance averages, based on the total distance covered by each rat on each day. These differences are taken from the averages for sexes and strains together in table 9. The plus sign indicates that the average of the test is higher than that of the control. In the first half of training the differences are either close to three times their probable errors or higher, so they may be considered significant

PERIOD
Training...........

difference between the tests and controls; but this is a smaller probability than when a difference is over four times its probable error.

A better idea of the differences between the 'plus' and 'minus' ratios in table 9 is given by the graphs in figure 11 . In these curves the frequency distribution of the 'plus' ratios is given in the solid line, of the 'minus' ratios in the broken line. These distributions include only those ratios that do not involve repetition of any primary data, namely, for males and females 
separately in the separate strains. The fifty-seven 'plus' ratios have an average of 1.503; the fifteen 'minus' ratios have an average of 1.203. The difference between these averages $(0.300 \pm$ 0.048 ) is 6.2 times its probable error. Besides a larger number of the ratios being 'plus,' it appears that the average size of the 'plus' ratios is significantly greater than the average size of the 'minus' ratios.
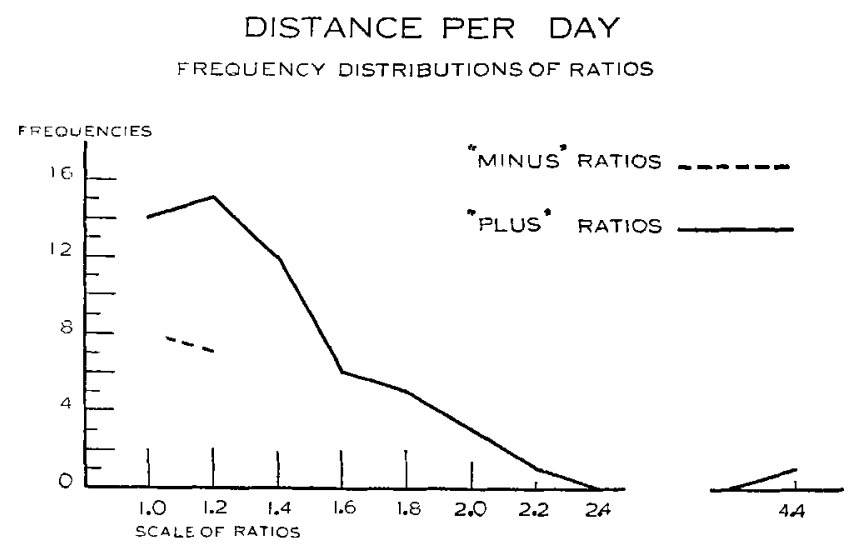

Fig. 11 Frequency distributions of the ratios of tests vs. controls, based on the averages of the distance for each day, with sexes and strains treated separately; the ratios are taken from table 9 . The size of the ratios is shown on the base line, the vertical scale gives the frequencies; the broken line shows the 'minus' ratios (controls taking more time); the solid line, the 'plus' ratios (tests taking more time); 'completes' and 'incompletes' included, but not 'failures.'

c. Variability of the tests vs. controls as judged by distance. Table 11 gives the standard deviations for the averages for each rat for each of the six groupings of the trials (see the distributions of the averages in figure 8). For the first half of training, omitting the first day, training, and training and retention, the standard deviations for the tests are higher; for the second half training and retention the standard deviations for the controls are slightly higher. This shows an agreement between the size of the means and the standard deviations, for it is in these last two groups of trials that the control averages are not significant. However, the differences between these standard deviations are in no group 
of trials surely significant; the nearest approach to three times the probable error is 2.77 times, for omitting the first day; then comes the first half of training, training and retention, and training with differences $2.49,2.09$, and 1.89 times their probable errors; for the other two groups of trials the differences are less than half as large as their probable errors. When the standard deviation of the averages for each day are calculated (table 12) the tests are proved the more variable on the first six days of training and on the second and fourth days of retention; but

TABLE 11

Standard deviations of the distance averages for each rat when all strains and both sexes are put together for the six groupings of the trials, calculated from the data given in table $B$ in the appendix. The differences, their probable errors, and the differences divided by their probable errors are given. Plus signs indicate that the standard deviations of the tests are greater than those of the controls; minus signs, that the standard deviations of the controls are larger. Although there are no fully significant differences, the differences that are over twice their probable errors are all in the direction of greater variability for the tests

\begin{tabular}{|c|c|c|c|c|}
\hline PERIOD & TESTS & CONTROLS & DIFF. & DIFF./P. E. \\
\hline First half training $\ldots \ldots \ldots$ & 54.24 & 38.08 & $+16.16 \pm 6.40$ & 2.49 \\
\hline Second half training . . . . . & 26.14 & 27.62 & $-1.48 \pm 3.62$ & 0.41 \\
\hline Omitting first day... & 32.50 & 22.01 & $+10.49 \pm 3.79$ & 2.77 \\
\hline All training . . . . . . & 35.66 & 27.37 & $+8.29 \pm 4.39$ & 1.89 \\
\hline Retention.......... & 19.35 & $19.78^{1}$ & $-0.43 \pm 3.02$ & 0.14 \\
\hline Training and retention.. & 26.46 & 18.81 & $+7.65 \pm 3.65$ & 2.09 \\
\hline
\end{tabular}

1 Omitting rat 1211.

when compared with their probable errors, the only significant difference is found on the second day of retention. On the seventh day of training the controls are significantly more variable. There does not seem to be any general difference in the variability of the averages of the tests and controls based on distance, although five of the comparisons show greater variability for the tests by differences twice their probable errors; there are only two significant differences, one showing the controls more variable, the other showing the tests more variable.

Averages for each of the thirty-six trials in training and retention have been obtained and the tests and controls compared on 
the basis of each trial by itself. The averages for all the various groupings of strains and sexes have been computed; the results are in full accord with those obtained when the averages for each day were compared. They are not presented because the additional evidence they would offer does not seem needed.

d. What is the probability that the test data and control data for distance are not random samples of the same population? From the control averages of each of the twenty-four successive trials

TABLE 12

Standard deviations of the averages for each rat when all strains and both sexes are put together for each day of the training. Conventions as in table 11

\begin{tabular}{|c|c|c|c|c|c|}
\hline PERIOD & DAY & TESTS & CONTROLS & DIFF, P. $\mathbf{E}$. & DIFF./P. E. \\
\hline \multirow{8}{*}{ Training. . } & 1 & 422.0 & 330.0 & $+92.0 \pm 51.8$ & 1.7 \\
\hline & 2 & 200.9 & 148.7 & $+52.2 \pm 23.8$ & 2.2 \\
\hline & 3 & 144.0 & 136.3 & $+7.7 \pm 19.0$ & 0.4 \\
\hline & 4 & 83.7 & 77.6 & $+6.1 \pm 1.9$ & 0.5 \\
\hline & 5 & 126.4 & 124.4 & $+2.0 \pm 16.8$ & 0.1 \\
\hline & 6 & 112.2 & 96.7 & $+15.5 \pm 14.1$ & 1.1 \\
\hline & 7 & 76.1 & 121.7 & $-45.6 \pm 13.6$ & 3.3 \\
\hline & 8 & 102.3 & 103.6 & $-1.3 \pm 13.8$ & 0.1 \\
\hline \multirow{4}{*}{ Retention. } & 1 & 59.2 & 77.9 & $-18.7 \pm 10.5$ & 1.8 \\
\hline & 2 & 127.0 & $64.4^{1}$ & $+62.6 \pm 15.6$ & 4.0 \\
\hline & 3 & 71.0 & 75.1 & $-4.1 \pm 11.1$ & 0.3 \\
\hline & 4 & 80.4 & 65.4 & $+15.0 \pm 11.2$ & 1.3 \\
\hline
\end{tabular}

1 Omitting rat 1211.

in training a curve was smoothed by interpolation; this was taken as the standard of comparison in computing a ratio for each trial of each rat. The distribution of these ratios above and below the central point of 1.000 , or unity, is shown in figure 12. Ratios at the left of the center are from trials less (shorter distance) than the assumed standard; ratios at the right of the center are from trials that were longer than the assumed standard. The ratios for the tests are shown by the broken line; the ratios for the controls by the solid line. In the first graph the ratios are classified in classes 1.699 in width; in the second graph the 
DISTANCE PER DAY

FREQUENCY DISTRIBUTIONS OF

RATIOS OF EACH TRIAL TO A STANDARD
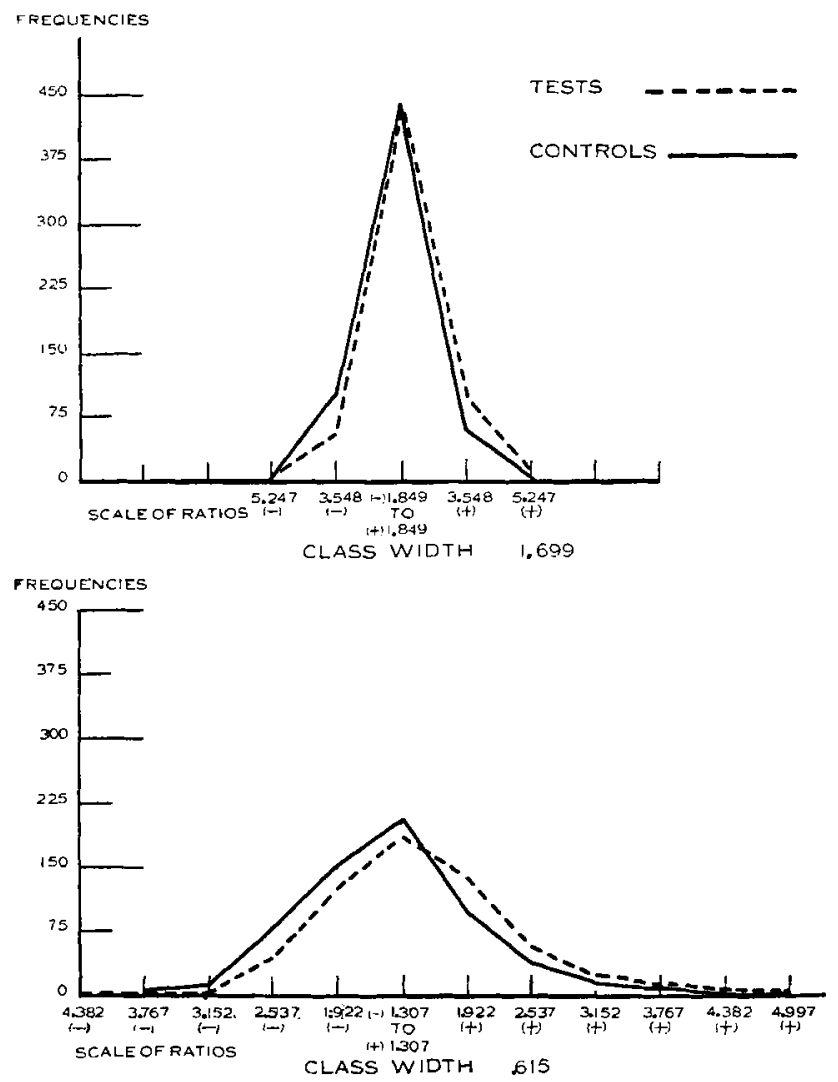

Fig. 12 Frequency distributions used for the application of the $x^{2}$ test. Distributions of the ratios obtained by dividing each distance record into, or by an assumed standard for the corresponding trial. 'Plus' ratios, those at the right of the central point, were obtained when the record was larger than the standard; 'minus' ratios, those at the left of the center, were obtained when the record was smaller than the standard. These ratios are grouped in two ways: into classes 1.699 and 0.615 wide. The numbers on the base line are the extreme ratios included in the respective classes; the vertical scale gives the number of ratios in each class. Broken lines are for the test ratios, solid lines for the control ratios. 
classes are 0.615 in width. The $\chi^{2}$ obtained from the two pairs of curves are 66.49 and 84.78 , both of which give values for $\mathrm{P}$ of $0.000,000$. In other words, the odds against curves as different as these occurring as random samples of the same population are at least over $1,000,000$ to 1 . As far as this statistical test is concerned, the distributions for tests and controls are proved to be different.

e. Summary of results from the distance data. When the test and control rats are compared on the basis of the distance covered in running their trials on the maze, the tests are found to go further. This has been shown in the summaries of the rats in various groupings according to the sex and strain, when the averages of each rat for six different groups of its trials are used as the basis, and when the averages of the total distances covered on each of the twelve days are used as the basis of comparison. Tested by their probable errors, significant differences are found for each period excepting the second half of training and the first three days of retention.

Apparently both sets of rats can completely master the maze, but the tests take more trials to cut down the excess distance than do the controls. It is a matter of the number of trials, then, before all the excess distance of both sets of rats is eliminated. However, when all the trials of the tests and of the controls in the form of ratios to the corresponding points in an assumed normal standard curve are classified in frequency distributions, the $\chi^{2}$ test indicates that there is a real difference in the distributions of the test and control ratios. All these results are in close agreement with those from the time data. The two sets of data are derived from the same movements of the same rats, but they differ in the mechanics of their origins; time from readings of the stop-watch operated synchronously with the rats' departures and arrivals, and distance from the readings of the chartometer after tracing the pencil lines on the record sheets.

f. Correlation between time and distance data. To test mathematically the similarity between the time and distance criteria, correlation coefficients have been calculated from the data of 
the group of 'completes.' For the test rats the correlation coefficient of $+0.9537 \pm 0.0028$ was found; for the controls, $+0.9607 \pm 0.0023$, a difference of $0.0070 \pm 0.0036$ which is 1.9 times its probable error. This indicates that the test and control rats agree in showing that the two criteria of time and distance are very closely related; if a rat makes a very poor time record, it generally has a poor distance record, and so if it makes a good time record the distance record is generally good. But, although the correlation coefficients take both these good and poor records into account, there is a difference in the relation in the two cases. It would be impossible for a very short time record to involve a long distance, but a very long time record may give a relatively short distance record; the rat may go very slowly along the correct path, or it may lie down. This means that in one half of the correlation table points may be located almost anywhere, but in the other half they are greatly restricted. In table 13 is given the part of the combined correlation tables for tests and controls that excludes trials taking more than five minutes. In the terms of the correlation coefficients the time and distance criteria are so nearly alike that they could be considered the same. This similarity is not great enough, however, to remove all the differences in the details of the summaries based on the two criteria separately, but as far as the comparison of the tests and controls is concerned in the present problem, the two criteria give the same general conclusions.

We have presented this mathematical proof as well as the empirical demonstration of the similarity of the results given by the two criteria not because there seemed any doubt as to the validity of either method, but to make it perfectly clear to all that the results are entirely independent of the method of treatment. For this same reason we have made the comparisons between the same groups of rats upon still another set of data derived equally from time and distance. 


\section{TABLE 13}

Correlation table of the time and distance data for all trials of the tests and controls together, that took five minutes or less. The numbers on the scales are the upper limits of the classes: at the top, distance in centimeters; at the left side, time in seconds. The correlation coefficients quoted in the text are based on all the trials, but with the tests and controls in separate tables

\begin{tabular}{|c|c|c|c|c|c|c|c|c|c|c|c|c|}
\hline \multirow{2}{*}{ TIME } & \multicolumn{12}{|c|}{ DIBTANCE IN CENTIMETERS } \\
\hline & 60 & 90 & 120 & 150 & 180 & 210 & 240 & 270 & 300 & $\mathbf{3 3 0}$ & 360 & 390 \\
\hline \multicolumn{13}{|l|}{ seconds } \\
\hline 10 & 121 & - & - & - & - & - & - & - & - & - & - & - \\
\hline 20 & 155 & 95 & 14 & - & - & - & - & - & - & - & - & - \\
\hline 30 & 20 & 51 & 37 & 9 & - & - & - & - & - & - & - & - \\
\hline 40 & 6 & 15 & 34 & 23 & 7 & - & - & - & - & - & - & - \\
\hline 50 & - & 11 & 24 & 14 & 11 & 1 & 1 & - & - & - & - & - \\
\hline 60 & - & 7 & 12 & 12 & 7 & 2 & 1 & - & - & - & - & 1 \\
\hline 70 & - & 3 & 13 & 9 & 9 & 4 & 1 & - & - & - & - & - \\
\hline 80 & - & 1 & 4 & 8 & 2 & 4 & - & 1 & - & - & - & - \\
\hline 90 & - & 3 & 7 & 5 & 2 & 4 & - & 1 & $\rightarrow$ & 1 & - & - \\
\hline 100 & - & - & - & 1 & 4 & 2 & $\overline{-}$ & 1 & - & - & - & - \\
\hline 110 & - & - & 1 & 3 & 3 & 0 & 1 & 3 & - & - & - & - \\
\hline 120 & - & 1 & - & 2 & 3 & 5 & - & - & - & - & - & - \\
\hline 130 & - & - & - & - & 1 & 1 & 1 & 1 & - & - & - & - \\
\hline 140 & - & - & - & - & 2 & - & - & - & 1 & - & - & - \\
\hline 150 & - & - & - & - & - & - & 1 & - & - & - & - & - \\
\hline 160 & - & - & - & 1 & 1 & 2 & 1 & 2 & 1 & 1 & - & - \\
\hline 170 & - & - & - & - & 1 & - & - & 2 & - & - & 1 & - \\
\hline 180 & - & - & - & - & 2 & 1 & 1 & - & - & - & - & - \\
\hline 190 & - & - & - & - & - & 1 & - & - & 3 & - & - & - \\
\hline 200 & - & - & - & - & - & - & - & - & - & - & - & - \\
\hline 210 & - & - & - & 2 & 2 & 1 & - & - & - & - & - & - \\
\hline 220 & - & - & - & - & 1 & - & - & 1 & - & - & - & - \\
\hline 230 & - & - & - & - & - & - & - & 1 & 1 & - & 1 & - \\
\hline 240 & - & - & - & - & - & 1 & - & - & - & - & 1 & 1 \\
\hline 250 & - & - & - & - & - & - & - & - & - & 1 & - & - \\
\hline 260 & - & - & - & - & 1 & - & - & - & - & - & - & - \\
\hline 270 & - & - & - & 1 & - & - & - & - & - & - & - & $\rightarrow$ \\
\hline 280 & - & - & - & 1 & - & - & - & - & - & - & - & - \\
\hline 290 & - & - & - & - & - & 1 & - & 2 & 1 & - & - & - \\
\hline 300 & - & - & - & - & - & - & - & - & - & - & 1 & - \\
\hline
\end{tabular}


4. Comparison of the test and control rats on the basis of the rate of running (speed)

The relationship between the time and distance records for each rat has been used as the basis of another comparison of the tests and controls, namely, the average speed of running, in terms of the number of centimeters covered per second (as measured on the record sheets). For each rat the distance covered on each day has been divided by the time spent on the same day.

TABIE 14

Average speed (centimeters per second) for training and retention. Plus signs indicate that the speed of the controls was greater than that of the tosts. The controls in two strains had higher speed; the tests in one strain had higher speed

\begin{tabular}{|c|c|c|c|c|c|c|c|}
\hline \multirow{2}{*}{ BTRAIN } & \multirow{2}{*}{ PERTOD } & \multicolumn{3}{|c|}{ MALEA } & \multicolumn{3}{|c|}{ FEMALES } \\
\hline & & Tests & Controls & Ratio & Tests & Controls & Ratio \\
\hline \multirow{2}{*}{ A } & Training & 3.187 & 3.549 & $(+) 1.113$ & 2.342 & 3.084 & $(+) 1.316$ \\
\hline & Retention & 4.010 & 3.806 & $(-) 1.053$ & 2.955 & 3.772 & $(+) 1.276$ \\
\hline \multirow{2}{*}{$\mathrm{C}$} & Training & 4.020 & 3.525 & $(-) 1.140$ & 3.883 & 3.593 & $(-) 1.080$ \\
\hline & Retention & 4.840 & 3.787 & $(-) 1.278$ & 4.250 & 3.951 & $(-) 1.075$ \\
\hline \multirow{2}{*}{ L } & Training & 2.549 & 2.848 & $(+) 1.117$ & 2.579 & 3.034 & $(+) 1.176$ \\
\hline & Retention & 3.166 & 4.170 & $(+) 1.317$ & 3.571 & 4.300 & $(+) 1.204$ \\
\hline \multirow{2}{*}{ All } & Training & 3.258 & 3.262 & $(+) 1.001$ & 2.645 & 3.144 & (十)1.188 \\
\hline & Retention & 3.921 & 3.890 & $(-) 1.007$ & 3.441 & 4.066 & $(+) 1.164$ \\
\hline
\end{tabular}

From these figures the averages for training and retention for the various combinations of sexes and strains have been obtained for the 'completes' (table 14). In training the speed of the tests is less than that of the controls both for the males and females in strains $\mathrm{A}$ and $\mathrm{L}$; but in strain $\mathrm{C}$ the males, as well as the females, give the averages for the tests higher than the controls. The same general relations hold for retention, the exception being the males in strain A, which give a higher average for the tests. Putting sexes and strains together gives higher averages for the controls in both training and retention (table 15), but in neither case is the difference significant. In training the difference is 
only half as large as its probable error (0.44 times); in retention the difference is about twice as large as its probable error $(2.07$ times).

No claim, on the basis of the statistical significance, can be made that the tests are really slower, but the greater number of comparisons do go in one direction, and so may appear to have some weight apart from the significance of the individual differences considered separately. This evidence is offset by the fact that the exceptions are strongly centered in one strain; they are not distributed at random as though due to irregular causes. 'The frequency distributions of each rat in the group of 'completes'

TABLE 15

Showing the significance of the difference in the speed (centimeters per second) of the tests and controls; sexes and strains together. The differences favor the controls, but are not significant

\begin{tabular}{|c|c|c|c|c|}
\hline \multirow{2}{*}{ PERIOD } & \multicolumn{2}{|c|}{$\begin{array}{c}\text { AV. SPEED (CMB, PER } \\
\text { BEC.) }\end{array}$} & \multirow{2}{*}{ DIFF. $\quad$ P. E. } & \multirow{2}{*}{ DEF./P. E. } \\
\hline & Tests & Controls & & \\
\hline All training . . . . & 2.982 & 3.203 & $+0.215 \pm 0.488$ & 0.44 \\
\hline Retention......... & 3.694 & 3.995 & $+0.301 \pm 0.145$ & 2.07 \\
\hline
\end{tabular}

upon which these comparisons are based are given in figure 13 for training and retention.

The averages of the speed for each day separately of training and retention have been studied. When the sexes are put together all but one day in strain $\mathrm{A}$, and two days in strain $\mathrm{L}$ show the controls with higher speeds; but every day in strain $\mathrm{C}$ shows the tests with higher speeds. This same general difference between the strains holds when each sex is averaged alone. So it appears that the averages for all training and retention represent differences that hold day by day for each strain, and they are not due to irregular circumstances effective only on some particular day or days. The findings are so unquestionably negative that it has not seemed necessary to present the tables.

This study of speed was undertaken to see if there was any difference in the general nature of the motor activity of the tests and controls apart from their success on the maze. In 
each strain the tests took more time and covered more distance in making their trials, yet in two strains the tests' rate of motion was slower than the controls, while in one it was faster. It must be concluded that, whatever difference there is between
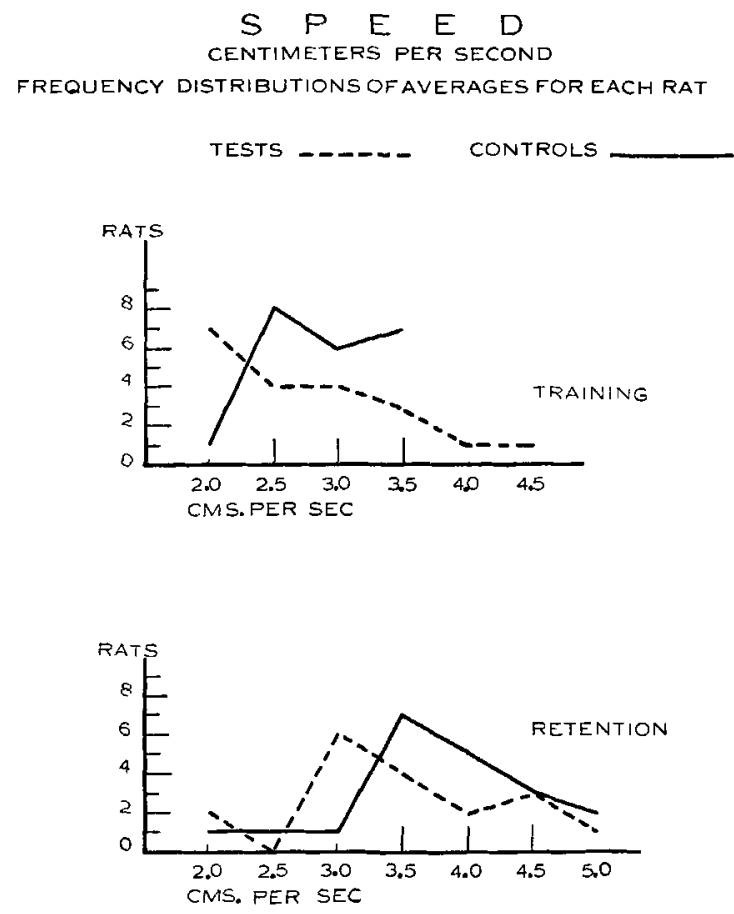

Fig. 13 Frequency distributions of the individual averages based on speed (centimeters per second). 'Completes' are used, males and females in all strains together. Units on the base lines are centimeters; the numbers given are the lower limits of the classes. Units on the vertical scale are the numbers of individuals. Broken lines show the tests; solid lines, controls. Based on distance as measured from the record sheets $=$ about $1 / 13$ th actual speed .

the rats with normal and those with alcoholized grandparents, it is not a matter of the general rate of their motor activity, or of their hypo- vs. hyperkinetic nature. 
5. Comparison of the tests and controls on the basis of the numbers of errors

a. All types of errors together. For the present purposes an error has been defined as a departure that extends more than half an inch from the true path as measured on the record sheets (approximately the length of a rat on the maze itself); it may involve passing a door it should enter, it may involve turning back in the true path. All types of errors, regardless of their length have been put together. Table 16 presents the error data summarized in the same way as the distance data in table 7 ; the numbers in the body of the table are averages of each rat's average per trial for the period and group indicated.

The table gives sixty-five 'plus' ratios and seven 'minus' ratios (six of which are due to the females in strain A); in sixtyfive pairs of averages the tests have more errors than the controls, while in seven the controls have more errors than the tests. Table 17 gives the differences between the averages and the probable errors of the differences when all strains and the sexes are put together. First half of training, omitting the first day, all training, and training and retention give differences that are over three times their probable errors. For the second half of training the difference is only a little below three times its probable error (2.52 times). Figure 14 shows the distributions of the individual averages in the different groups of trials.

These results are in accord with all that has gone before and they follow those for distance so closely, quantitatively as well as qualitatively, that the comparisons based on each day by itself may be assumed to give the same results. Although these averages have been calculated, they are not presented; we can state that the supposition that they would give the same results is borne out by the averages themselves. It has not seemed necessary to even make the calculations of the averages of all rats in each group for each of the thirty-six trials by itself.

The variability of the tests, judged by the standard deviations of the average number of errors for each rat, is significantly greater than that of the controls in the first half of training 


\begin{tabular}{|c|c|c|c|c|c|}
\hline \multirow{3}{*}{ 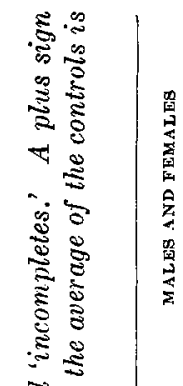 } & \multirow{3}{*}{ 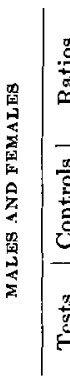 } & 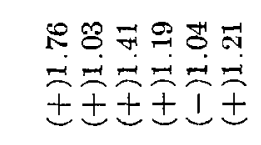 & 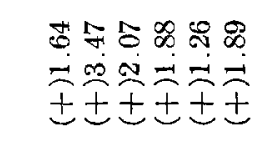 & 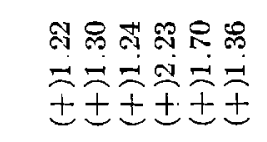 & 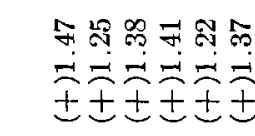 \\
\hline & & 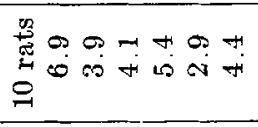 & 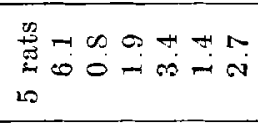 & 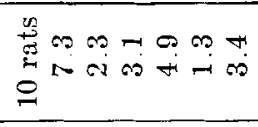 & 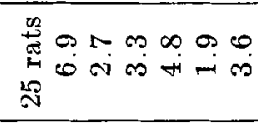 \\
\hline & & 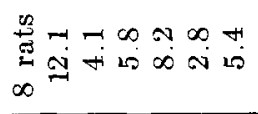 & 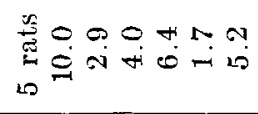 & 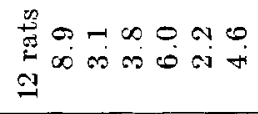 & 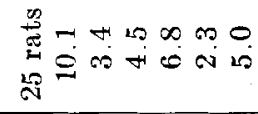 \\
\hline . & \multirow{3}{*}{ 兽 } & 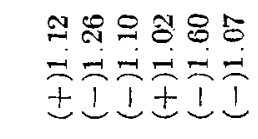 & 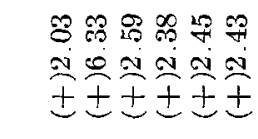 & 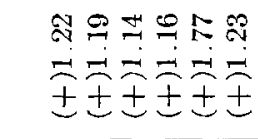 & 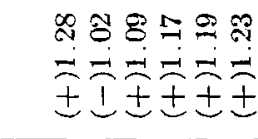 \\
\hline 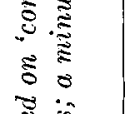 & & 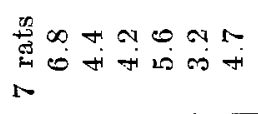 & 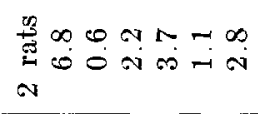 & 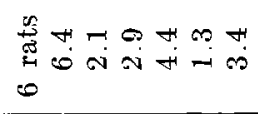 & 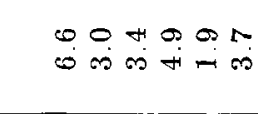 \\
\hline si & & 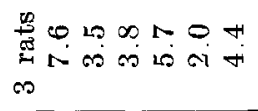 & 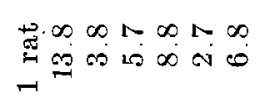 & 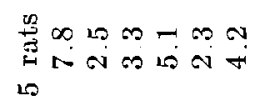 & 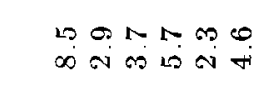 \\
\hline $\overrightarrow{0}$ & & 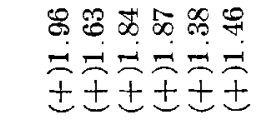 & 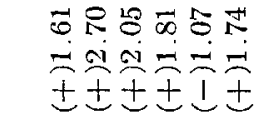 & 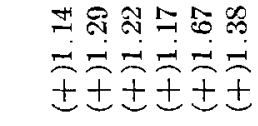 & 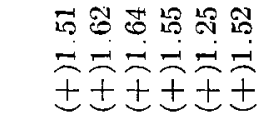 \\
\hline ह્心 & & 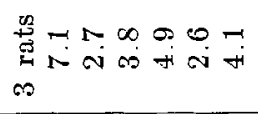 & 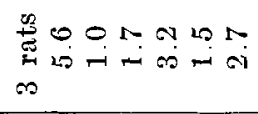 & 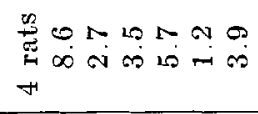 & $\begin{array}{l}\text { Q } \\
N\end{array}$ \\
\hline 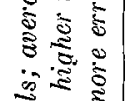 & & 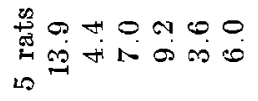 & 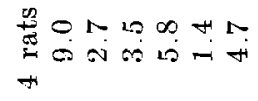 & 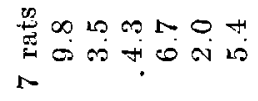 & 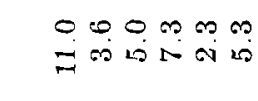 \\
\hline 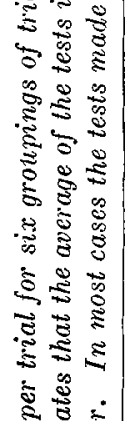 & 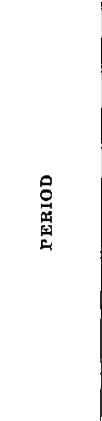 & 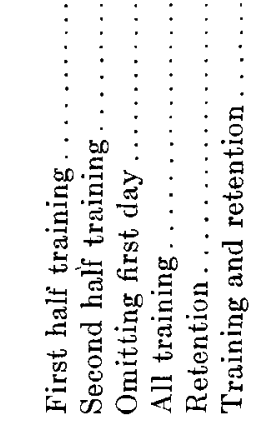 & 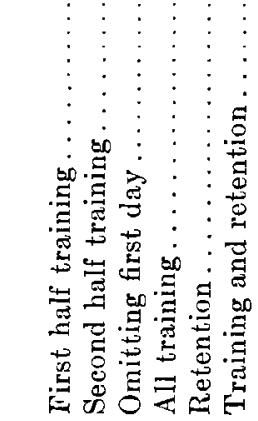 & 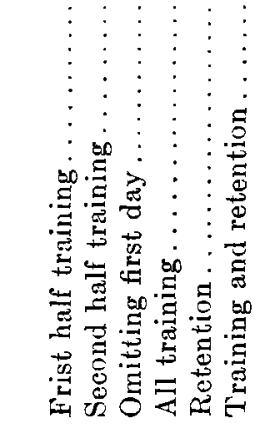 & 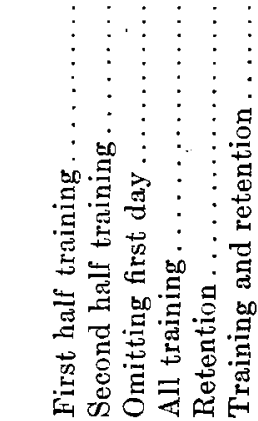 \\
\hline$\approx \cong$ & 晃 & $\varangle$ & 0 & - & $\varangle$ \\
\hline
\end{tabular}


(the difference is 4.13 times its probable error) and omitting the first day (2.95 times the probable error). In the other groups of trials there is no significant difference (table 18).

TABLE 17

Showing the significance of the differences between the averages of the number of errors made by the tests and controls in each of the six groupings of the trials. These differences are taken from the averages for all strains and both sexes in table 16. Plus signs indicate that the tests made more errors than the controls. There is a strong tendency for the tests to make more errors, and the differences in the averages are in most cases significant

\begin{tabular}{|c|c|c|}
\hline PERIOD & DIFF. & DIFF./P. E. \\
\hline First half training . . . . . . . . & $+3.25 \pm 0.62$ & 5.24 \\
\hline Second half training....... & $+0.68 \pm 0.27$ & 2.52 \\
\hline Omitting first day ......... & $+1.26 \pm 0.31$ & 4.06 \\
\hline All training $\ldots \ldots \ldots \ldots \ldots \ldots \ldots \ldots \ldots$ & $+1.97 \pm 0.43$ & 4.58 \\
\hline Retention $\ldots \ldots \ldots \ldots \ldots \ldots \ldots \ldots \ldots \ldots \ldots \ldots \ldots \ldots \ldots \ldots$ & $+0.41 \pm 0.27$ & 1.51 \\
\hline Training and retention $\ldots \ldots \ldots \ldots \ldots \ldots$ & $+1.35 \pm 0.27$ & 5.00 \\
\hline
\end{tabular}

\section{TABLE 18}

Standard deviations of the averages of tests and controls based on the number of errors per trial in each of the six groupings of trials; calculated from the averages for each rat given in table $C$ in the appendix. When the standard deviation of the tests is greater than that of the controls, the difference is called plus; when the controls have a greater standard deviation the difference is marked minus. The only significant differences are in the direction of greater variability in the average number of errors on the part of the tests

\begin{tabular}{|c|c|c|c|c|}
\hline PERIOD & TESTS & CONTROLS & DIFF. P. E. & DIFF./P. E. \\
\hline First half training . . . . . . . . . & 3.95 & 2.13 & $+1.82 \pm 0.44$ & 4.13 \\
\hline Second half training . . . . & 1.35 & 1.60 & $-0.25 \pm 0.20$ & 1.23 \\
\hline Omitting first day .... & 1.90 & 1.28 & $+0.62 \pm 0.21$ & 2.95 \\
\hline All training . . . . . . & 2.29 & 2.19 & $+0.10 \pm 0.26$ & 1.38 \\
\hline Retention .......... & 1.21 & 1.26 & $-0.05 \pm 0.18$ & 0.27 \\
\hline Training and retention... & 1.38 & 1.09 & $+0.29 \pm 0.19$ & 1.52 \\
\hline
\end{tabular}

b. Each type of error separately. The different types of errors seem to provide an excellent opportunity for a more analytical study of the behavior of the test and control rats; it seemed possible that the differences in the time and distance records might be accompanied by differences in the kind as well as the 
FREQUENCY DISTRIBUTIONS OF AVERAGES FOR EACH RAT
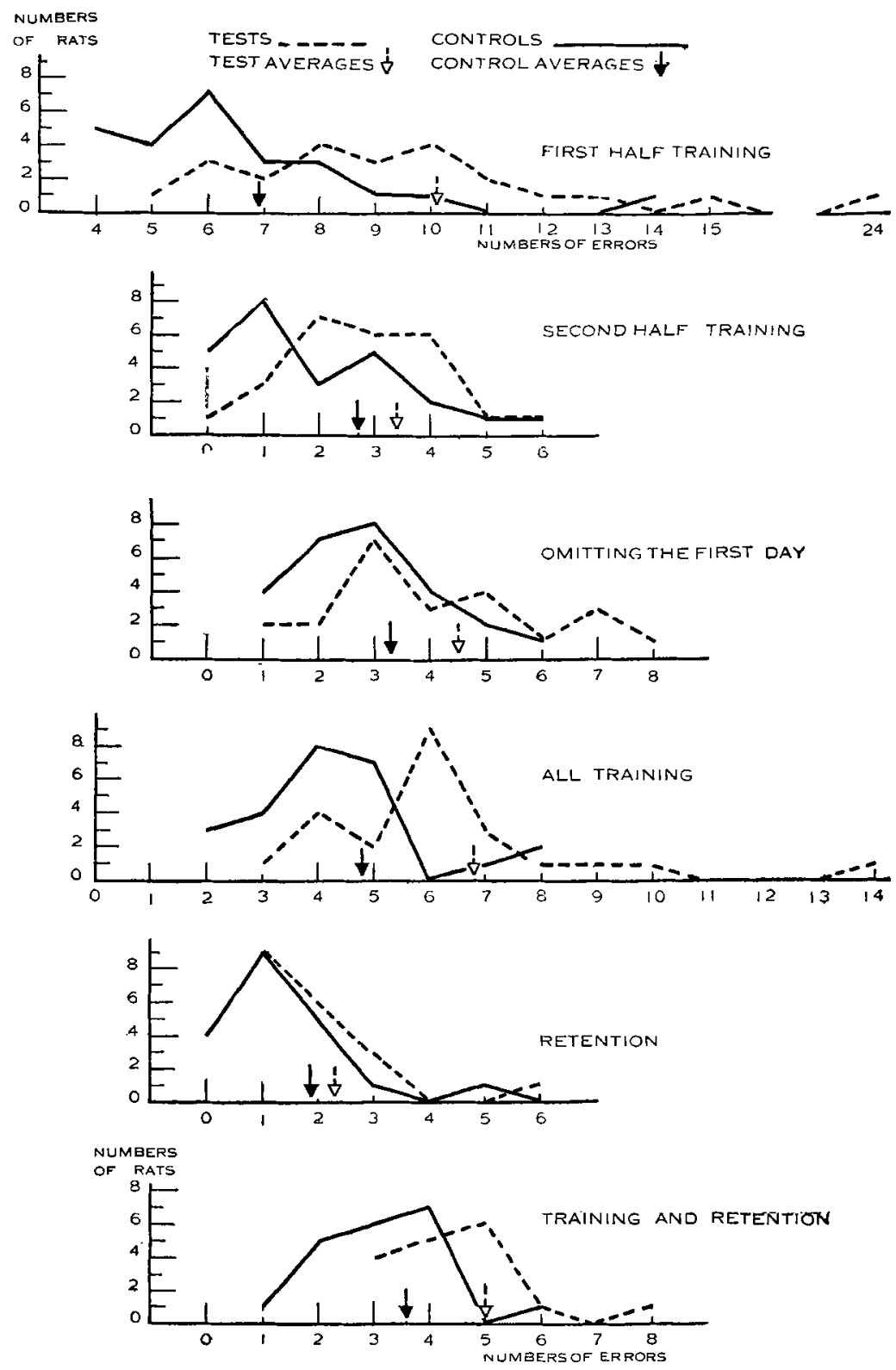

Fig. 14 Frequency distributions of the individual averages of the numbers of errors per trial, in the six groupings of the trials. Broken lines show the tests; solid lines, the controls. Units on the base line are numbers of errors; units on the vertical scale are numbers of rats. 'Completes' and 'incompletes' have been used, with the males and females in all strains together. 
numbers of errors made. Six types of errors have been recognized: type 1, passing a door that should be entered; type 2, turning the wrong way upon entering a door; type 3a, turning back on the correct path; type $3 \mathrm{~b}$, turning back on the wrong path; type $4 a$, retracing the correct path through a door; type $4 \mathrm{~b}$, retracing the wrong path through a door. About 70 per cent of the errors made are of types 1 and 2 . No clear difference between tests and controls was found on the basis of the percentage occurrence of each type of error in the total number of errors. When the strains and sexes are put together, for eighteen of the twenty-four trials in training, the averages of the tests for errors of type 1 are higher than the corresponding control averages; on twenty-one of the twenty-four trials the averages of the tests for errors of type 2 are higher than the corresponding averages of the controls. (These statements are made from curves based on the 'completes.') For errors of type 3a the tests have higher averages on ten trials; for errors of type $3 \mathrm{~b}$, the tests have higher averages on eleven trials; for errors of type $4 \mathrm{a}$, the tests have higher averages on ten trials; for errors of type $4 \mathrm{~b}$, the tests have higher averages on seven trials (controls higher on one trial). The last three types of errors occur so infrequently that in most cases after the first seven trials there is no difference between the averages of the tests and controls. In the initial trial for each type the tests have more errors. If the comparisons in figure 14 had been based upon errors of types 1 and 2 alone, the differences would have been accentuated. The conclusion may be drawn that, although there does not seem to be much difference between tests and controls in the number of the more unusual errors, the tests are clearly less successful in eliminating the more persistent errors (types 1 and 2). This conclusion is strengthened by the following analysis.

c. The number of trials before each type of error was eliminated. For the purposes of this comparison, an error was said to be eliminated when it occurred only once in four successive trials; these four trials are included in the number of trials before the error was eliminated. 


\begin{tabular}{|c|c|c|c|c|c|c|}
\hline & \multicolumn{6}{|c|}{ TYPE OF ERROR } \\
\hline & 1 & 2 & $3 a$ & $3 \mathrm{~b}$ & $4 \mathrm{a}$ & $4 b$ \\
\hline Tests . . . . . . . . . . . . . & 12.8 & 15.5 & 10.3 & 5.3 & 5.1 & 4.7 \\
\hline Controls . . . . . . . . . & 9.6 & 14.4 & 9.4 & 4.9 & 5.5 & 4.7 \\
\hline Difference........... & +3.2 & +1.1 & +0.9 & +0.4 & -0.4 & 0.0 \\
\hline
\end{tabular}

The controls eliminated errors of type 1, three trials sooner; they eliminated errors of types 2 and $3 a$ about one trial sooner than the tests. The elimination of the other types of errors is very slightly different for the tests and controls. Comparing the numbers of test and control rats that did not eliminate each type of error in the twenty-four trials in training, the following numbers are found:

\begin{tabular}{|c|c|c|c|c|c|c|}
\hline & \multicolumn{6}{|c|}{ TYPE OF ERROR } \\
\hline & 1 & 2 & $3 a$ & $3 \mathrm{~b}$ & $4 a$ & $4 b$ \\
\hline $\begin{array}{l}\text { Number of rats failing to eliminate: } \\
\text { Tests } \ldots \ldots \ldots \ldots \ldots \ldots \ldots \ldots \ldots \ldots\end{array}$ & 3 & 14 & 0 & 0 & 0 & 0 \\
\hline Controls. & 0 & 10 & 1 & 0 & 0 & 0 \\
\hline
\end{tabular}

In types 1 and 2, three and four more tests than controls failed to eliminate the respective types of errors. Although the controls eliminated errors of type $3 \mathrm{a}$ on the average sooner than the tests, one of the control rats did not eliminate this type of error at all. Otherwise, the numbers of rats that did eliminate the respective types of errors and the rapidity in doing so fully agree in favoring the controls.

The comparisons based on the error data may be summarized as follows: the tests made more errors; this difference was due mainly to errors of types 1 and 2 , as approximately equal numbers of errors of the other two types were made by the tests and controls; the tests were slower in eliminating errors of types 1 and 2, but very little difference was found in the number of trials required for the elimination of errors of the other types. The variability in the number of errors is significantly greater for the tests for two groups of trials (first half of training and omitting first day). 


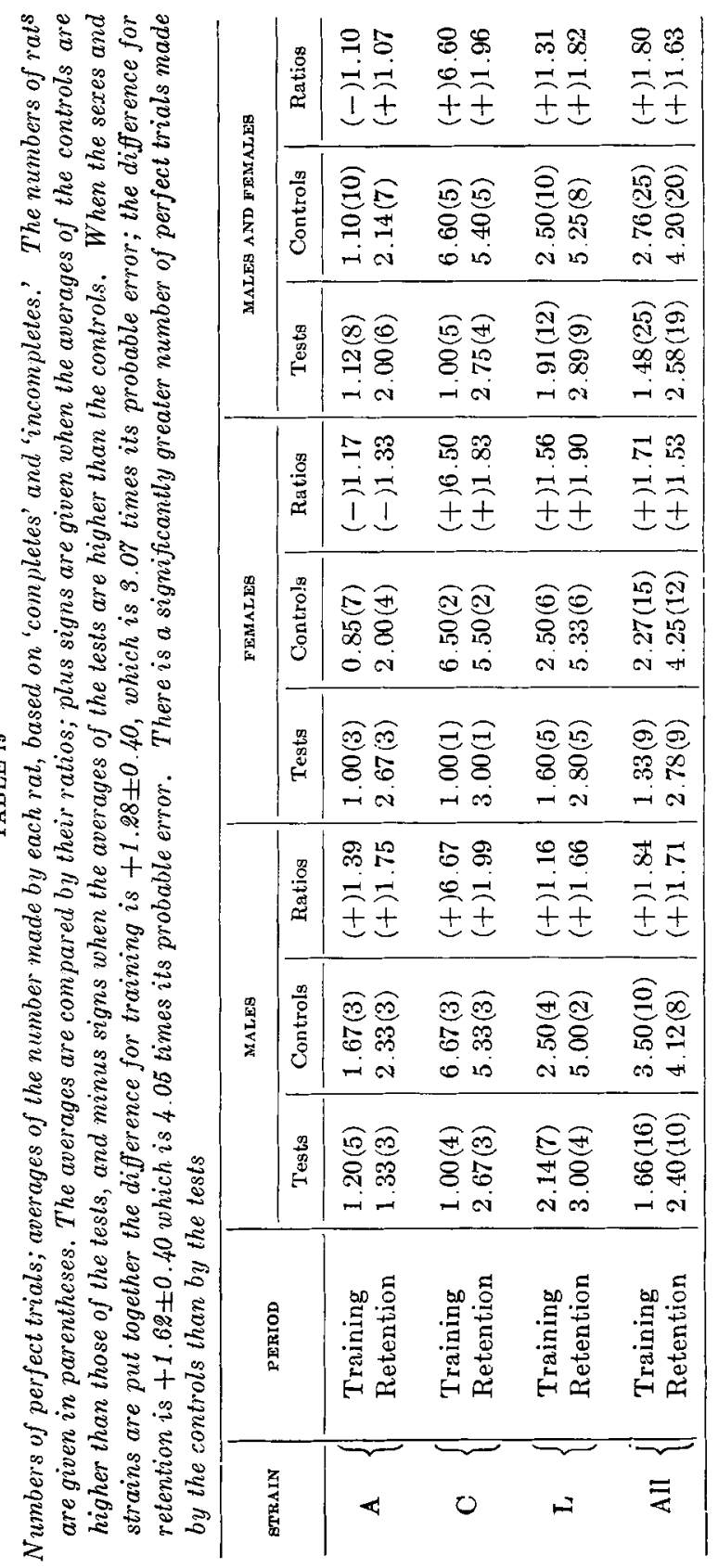


6. Comparison of the tests and controls on the basis of perfect trials

a. Number of perfect trials. The error data provide another set of comparisons, namely, the trials on the 0 point of the scale of errors, those with no errors, or perfect trials. Table 19 presents the averages of the number of perfect trials for each rat for training and retention, with the strains separately and together. In this table the plus sign is given to the ratios when the tests' averages are lower than the controls'.

\section{TABLE 20}

Standard deviations of the numbers of perfect trials when all strains and both sexes are put together; based on 'completes' and 'incompletes.' The differences and their significance in terms of their probable errors are given. The plus signs indicale that the tests are less variable than the controls. The tests are significantly less variable than the controls in the number of perfect trials they made in training; in retention the difference lies in the same direction and is very nearly great enough to be considered significant

\begin{tabular}{|c|c|c|c|c|}
\hline PERIOD & TESTS & CONTROLS & DIFF. & DIFF./P.E. \\
\hline Training. & 1.60 & 2.50 & $+0.90 \pm 0.30$ & 3.00 \\
\hline Retention $\ldots \ldots \ldots \ldots \ldots \ldots \ldots$ & 1.49 & 2.20 & $+0.71 \pm 0.28$ & 2.53 \\
\hline
\end{tabular}

The ratios indicate that the tests had fewer perfect trials than the controls; the females in strain A make the only exception. Combining the strains removes all minus signs; that is, the tests in all cases have fewer perfect trials. The differences between the averages, when the sexes and strains are combined, favor the controls; for training, the difference is $+1.28 \pm 0.40$, which is 3.07 times its probable error; for retention, $+1.62 \pm 0.40$, which is 4.05 times its probable error. These differences are fully significant. In figure 15 the distribution of the numbers of perfect trials of each rat are shown for training and retention.

Compared by the standard deviations of the numbers of perfect trials, the controls are more variable than the tests (table 20). The difference is 3 times the probable error for training and 2.53 times for retention.

This is the only criterion that gives a significantly greater variability for the controls. But obviously this has a different 
meaning from the varjability in the other data. In both time and perfect trials the variability is controlled by the high variates, since the low variates are limited by the physical possibilities of speed in time, and in perfect trials, by the absence of a

FREQUENCY DISTRIBUTIONS OF
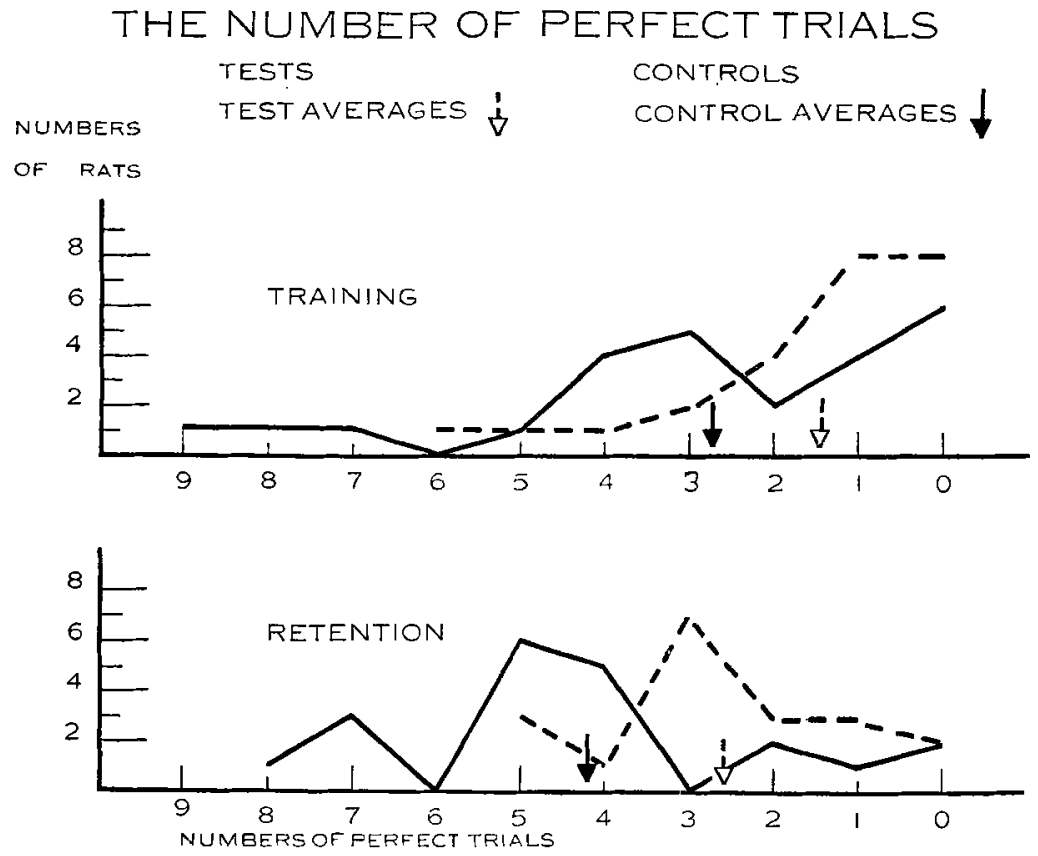

Fig. 15 Frequency distributions of the numbers of perfect trials made by each rat. Units on the vertical scale are numbers of rats, units on the base line are numbers of perfect trials. In order to keep inferiority at the right as in preceding charts, the scale reads from right to left. Broken line shows the tests; solid line, the controls. 'Completes' and 'incompletes' are used, with males and females in all strains together.

single perfect trial. A larger number of high variates, i.e., greater variability, is associated with inferiority in time; in perfect trials, with superiority.

$b$. The number of trials before the first perfect trial. The number of trials before the first perfect trial is a further basis for comparison of the tests and controls. Table 21 gives the average 
number of trials before the first perfect trial for strains separately and together. The 'plus' before each ratio sign indicates that perfect trials appeared later in the training of the tests than in the training of the controls. In every case the averages of the tests are higher; that is, they took more trials before making their first perfect trial. When all the rats in each group are put together, the difference between the tests and controls is significant as tested by the probable errors $(+5.66 \pm 1.66$; that is, 3.41 times the probable error). Two test rats and one control had no perfect trial during all the thirty-six trials. In calculating the mean number of trials before the first perfect trial these three rats were given the total number (thirty-six). Many more trials may have been required, however, before attaining a perfect trial. If these rats are excluded from the averages, the difference is still about the same $(+5.09 \pm 1.44$, which is 3.53 times the probable error). The frequency distribution of the numbers of trials, from which these averages have been calculated are given in figure 16. Besides having made fewer perfect trials, the tests required more trials before they made a perfect one.

c. Time spent in running perfect trials. A third criterion involving perfect trials is the time spent on running them. In figure 17 are shown the perfect trials classified according to the time spent; the frequencies are in terms of per cents of the total numbers of perfect trials. Thus the differences in the numbers of perfect trials for tests and controls is removed and the difference observed between the curves is due alone to the fact that the tests spent more time in running their perfect trials than did the controls. The curves are based upon 102 perfect trials for the tests and 163 for the controls; the average number of perfect trials per rat in training and retention together is, for the tests 4.08 , for the controls 6.50 . The average time spent on a perfect trial is, for the tests 8.48 seconds, for the controls 7.52 seconds; making a difference of $0.96 \pm 0.25$, which is 3.84 times its probable error and accordingly a significant difference.

The tests made fewer perfect trials, required more training before making the first one and took more time in running them than did the controls. 


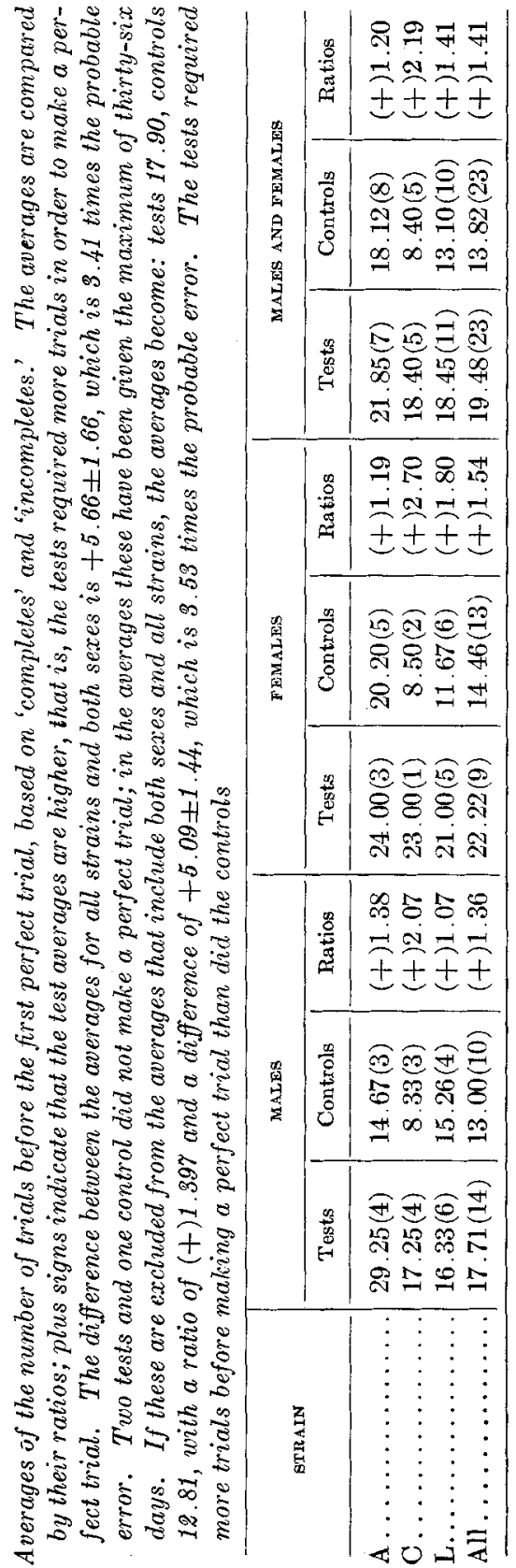


FREQUENCY DISTRIBUTIONS OF

THE NUMBER OF TRIALS

BEFORE THE FIRST PERFECT TRIAL
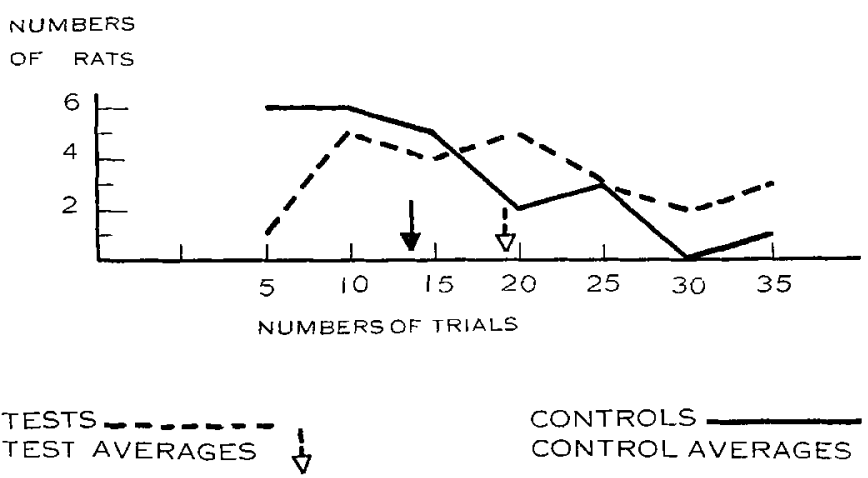

CONTROLS

CONTROL AVERAGES

Fig. 16 Frequency distributions of the number of trials required before the first perfect trial. Units on the base line are trials; units on the vertical scale are individuals.

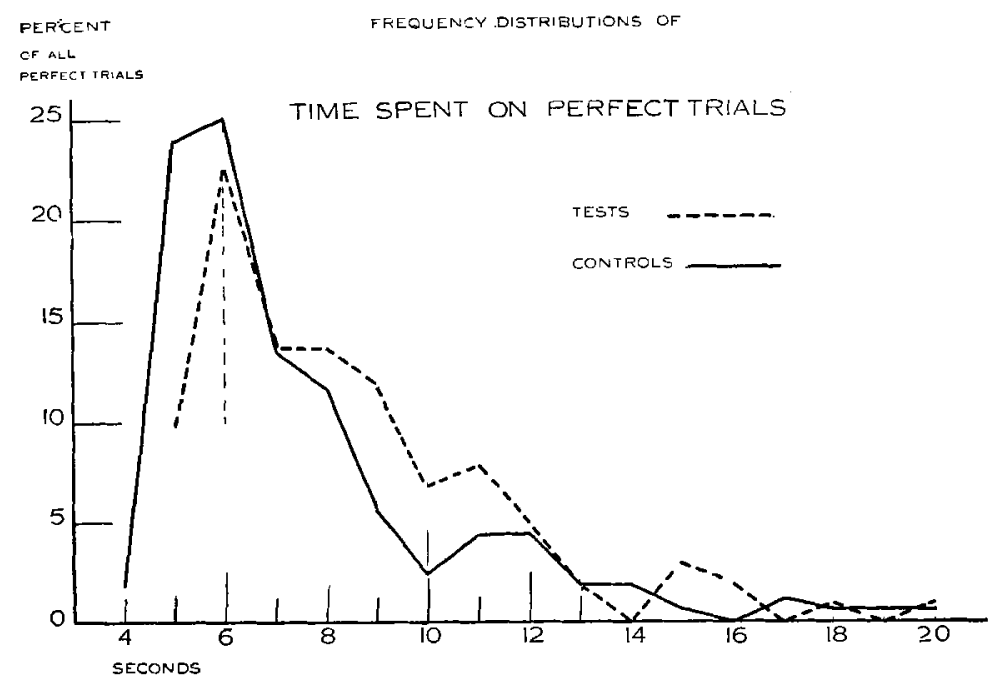

Fig. 17 Percentage distribution of the time spent in running perfect trials. Units on the base line are seconds, units on the vertical scale are per cent. The broken line shows the tests; the solid line, the controls. 


\section{DISCUSSION}

Although no general discussion of the literature upon experimental alcoholism is presented in this paper, reference must be made to one paper on account of the very close similarity of the present subject with some of the work therein described. Arlitt, '19 (pp. 41-44), has presented the results of training in a maze, the grandchildren of alcoholized white rats. The alcohol was administered with the food; doses of different sizes were given for different periods to various sets of animals obtained from a dealer. In order to eliminate strain differences, these sets were chosen at random; animals from the same source were used as controls. Three sets of rats are given in the third generation (the grandchildren of alcoholics by alcoholics) that are parallel to the ones we have described in this paper. Four of the nine grandchildren of rats that received 0.5 ce. of 90 per cent alcohol per day for five months did not succeed in making a single trip through the maze, so they are not included in the averages; the other five in this group were inferior to normals by each of the three criteria: total time spent, total number of errors made, and number of trials required to attain a certain degree of perfection in running the maze. The eleven grandchildren of rats that were given $0.25 \mathrm{cc}$. per day for thirty-nine days were inferior to normals in the time spent, and practically equal to normals in the number of errors and the number of trials required to master the maze. The eleven grandchildren of rats that were given $0.25 \mathrm{cc}$. per day for four months spent more time than the normal, but made fewer errors and learned the maze in fewer trials than the normals. These results are based on comparisons with five normal rats by means of group averages unchecked by probable errors of the averages or of the differences.

The irregularity in the results leads us to suspect two things: 1) that the differences between the averages do not have significance directly in proportion to their size, and that some of the differences observed would not be significant at all if compared with their probable errors; 2) that, although random selection of the rats to be treated and to be used as controls may have eliminated strain differences in the generation treated with 
alcohol, the subsequent inbreeding has isolated strain differences which mask the effects of the alcohol in the third generation. The great mass of experiments upon artificial selection give strong support to the belief that strain differences are revealed at once when inbreeding is started from a general population; the great variety of characters that have yielded strain differences upon inbreeding leads to the opinion that they may be found even in the ability of white rats to learn a maze. Arlitt admits this point and used random selections of rats in the beginning, "In order to eliminate group or strain differences" (p. 6). The comparison of the second and third generations of her rats affords evidence that such genetic differences between the sets do exist: "The behavior of the third generation closely resembles that of their parents" (p. 41, second sentence). The sets in the third generation that were superior and inferior to normals came from parents that were respectively superior and inferior. If this doubt as to the elimination of strain differences is correct, even accepting all the differences in the averages as though statistically significant, the results cannot be considered significant. The normals are no longer truly controls, since there is involved in the third generation, a second source of difference whose effect cannot be separated from that of the alcohol. Although the final conclusion reached on this subject by Arlitt is in agreement with our own, namely, that alcoholization effects the learning ability of the grandchildren, we do not feel that this agreement really strengthens our evidence. It seems entirely possible that a repetition of Arlitt's experiments with the same procedure and methods throughout, and accordingly with the alcohol exerting the same effect, might give a different conclusion, due to the chance selection of a slow strain to be used as normals.

\section{GENERAL SUMMARY}

This paper deals with the maze-behavior of the second nonalcoholized generation after alcoholic treatment of both grandparents. The normal controls were the grandchildren of the non-alcoholized brothers and sisters of the rats that were given 
the alcohol treatment. Brother-by-sister matings were made throughout. The rats were given three trials a day for eight days on a circular maze (training), and after thirty-one days (during which time they were trained in our multiple-choice apparatus) they were given four days more, twelve trials (retention). Sixty rats in this generation were trained, thirty-one tests and twenty-nine controls. The records of ten of these rats include one or more trials that were not successful; these rats have been called 'failure' rats. No satisfactory method of treating the successful records of these rats has been found; accordingly, they have been omitted from most of the summaries. In order to show that the results so obtained do not depend upon the omission of these rats, they have been included as well as excluded in the summaries based on the criterion of time.

1. During the period of rapid learning the test rats spent more time than the controls in running their trials. In reaching this conclusion, the averages of the tests have been compared with the averages of the controls in each of the following groupings of the data: males and females separately and together in each strain by itself and in all strains combined for each of the following groups of trials: first half of training, second half of training, omitting the first day, training, retention, training and retention, and each day of training and retention by itself. In the group of rats including all strains and both sexes the averages of the tests are higher in each of the eighteen groups of the trials. The probable errors of the differences between the averages of the tests and controls for the first half of training, omitting the first day, training, training and retention, first, second, third, fourth days of training and the fourth day of retention, show that these differences are significant. The frequency distribution of the ratios of all the test trials to corresponding points in an assumed standard learning curve differs from the frequency distribution of the ratios of all the control trials to the same standard learning curve. When these two distributions are compared by means of the $\chi^{2}$ test, it is found that the probability 
that they are not random samples of the same population is, at least, greater than $1,000,000$ to 1 .

2. In the first half of training the variability of the time averages is greater for the tests.

3. The test rats covered more distance than the controls, especially in the period during rapid learning. This is based on the same groupings of the sexes, strains, and trials as were used for the time data. When the strains and sexes are put together, the averages of the tests are higher than the controls for each of the eighteen groups of trials. The probable errors indicate that the differences are statistically significant for the following groups of trials: first half of training, omitting the first day, training, training and retention. The test of the similarity of the frequency distributions of the ratios of each trial of the tests and controls to the corresponding points in an' assumed standard normal curve indicates that the chances against these two frequency distributions being random samples from the same population are, at least, more than $1,000,000$ to 1 .

4. There is no significant difference between the variability of the distance averages of the tests and controls for any of the different groupings of the trials.

5. The speed of running (number of centimeters per second) does not show any clear difference between the tests and controls. Although the tests ran slower than the controls in two strains, in the third the controls ran slower than the tests. This difference in the strains appeared consistently in all the different groupings of the trials, so the alcohol treatment of the grandparents does not seem to have any consistent influence upon the general rate of motor activity.

6. The time and distance data are closely correlated; this is equally true for the data from the tests and the controls; tests, $\mathrm{r}=0.95$; controls, $\mathrm{r}=0.96$.

7. The test rats made more errors than the controls. This is shown by the averages based on the averages for the following periods which give full significant differences: first half of training, omitting the first day, training, training and retention. The variability of the tests is significantly greater than the controls 
in the two groupings of the trials, the first half of training and omitting the first day. The averages for each day have not been calculated.

8. The difference between the tests and controls in the number of errors depends upon two of six types of errors. The tests make more errors of types 1 and 2 , but there is no real difference in the numbers of errors of the other four types made by the tests and controls.

9. The tests required three more trials on the average to eliminate errors of type 1 ; the tests required one more trial to eliminate errors of type 2 . The other types of errors were eliminated in about the same number of trials by each group. This is based on the averages of the number of trials before each rat eliminated each type of error; an error was said to be eliminated when it occurred only once in four successive trials.

10. Seven more tests than controls failed to eliminate errors of types 1 and 2 ; the only rat failing to eliminate the other types of errors was a control.

11. The tests made fewer perfect trials than the controls. This statement is based on the average numbers of perfect (errorless) trials in training and retention separately.

12. The tests required more trials before making the first perfect trial than did the controls.

13. The tests spent more time in running their perfect trials than did the controls; this is based on the average time spent on perfect trial by the two sets of rats.

We believe that the above points show that the test and control rats differ, as groups, in their behavior in the maze. From the standpoint of learning their way to the center and going there for food, the tests are less successful than the controls. The alcoholic treatment of the grandparents is the only basis upon which the rats have been divided into the two groups of tests and controls; therefore the alcoholic treatment appears to be responsible for the inferiority of the tests in running the maze. If this is true, a modification of the genetic basis of inheritance is demonstrated. 


\section{LITERATURE CITED}

ARLitT, A. H. 1919 The effect of alcohol on the intelligent behavior of the white rat and its progeny. Psychological Monog., vol. 26, no. 4.

Stockard, C. R., and Papanicolaod, G. N. 1916 A further analysis of the hereditary transmission of degeneracy and deformities by the descendants of alcoholized mammals. Amer. Nat., vol. 50, pp. 65-88, 144-177.

1918 Further studies on the modification of the germ cells in mammals: The effect of alcohol on treated guinea-pigs and their descendants. Jour. Exp. Zoöl., vol. 26, pp. 119-226.

Watson, J. B. 1914 A circular maze with camera-lucida attachment. J. Animal Behav., vol. 4, pp. 56-59. 
TABLE A

Averages of the time taken by each individual rat in each of the six groupings of the trials. The sign $(F)$ indicales that this rat had one or more unsuccessful trials

\begin{tabular}{|c|c|c|c|c|c|c|c|c|c|}
\hline ETRAIN & & $\begin{array}{c}\text { RAT } \\
\text { NUM- } \\
\text { BER }\end{array}$ & $\operatorname{sex}$ & $\begin{array}{c}\text { FIRST } \\
\text { FALF OF } \\
\text { TRAINING }\end{array}$ & $\begin{array}{c}\text { SECOND } \\
\text { H.ALF OF } \\
\text { TRAIN- } \\
\text { ING }\end{array}$ & $\begin{array}{l}\text { OMIT- } \\
\text { TING } \\
\text { FIRST } \\
\text { DAY }\end{array}$ & $\begin{array}{c}\text { ALt } \\
\text { TRAINING }\end{array}$ & $\begin{array}{c}\text { RE- } \\
\text { TENTION }\end{array}$ & $\begin{array}{l}\text { TRAIN- } \\
\text { ING AND } \\
\text { RE- } \\
\text { TENTION }\end{array}$ \\
\hline \multirow{21}{*}{$A$} & Test (F) & 1169 & $0^{x}$ & & 28.61 & & & 12.23 & \\
\hline & Test & 1170 & $\sigma^{7}$ & 127.71 & 30.83 & 33.58 & 79.27 & 19.07 & 59.20 \\
\hline & Test & 1192 & $0^{7}$ & 165.40 & 19.05 & 29.40 & 92.22 & 16.15 & 66.86 \\
\hline & Test & 1193 & $\sigma^{7}$ & 261.40 & 51.43 & 80.76 & 156.41 & 36.93 & 116.58 \\
\hline & Test & 1351 & $\sigma^{x}$ & 234.48 & 25.70 & 43.63 & 130.09 & & \\
\hline & Test & 1354 & $\sigma^{7}$ & 300.18 & 34.01 & 100.10 & 167.10 & & \\
\hline & Test & 1168 & ㅇ & 146.16 & 41.36 & 59.83 & 93.76 & 20.88 & 69.46 \\
\hline & Test & 1277 & 운 & 88.63 & 36.28 & 36.11 & 62.45 & 24.50 & 49.80 \\
\hline & Test & 1279 & 우 & & 31.10 & 33.68 & & 31.61 & \\
\hline & Test (F) & 1352 & 우 & 244.47 & 19.41 & 90.48 & 127.05 & & \\
\hline & Test (F) & 1353 & 우 & 328.36 & 39.53 & 101.44 & 177.67 & & \\
\hline & Gontrol & 1171 & $\sigma^{7}$ & 128.26 & 12.27 & 28.06 & 70.26 & 22.60 & 54.39 \\
\hline & Control & 1172 & $0^{\pi}$ & 105.65 & 23.66 & 36.34 & 64.65 & 10.80 & 46.70 \\
\hline & Control & 1265 & $\sigma^{7}$ & 114.88 & 19.05 & 22.94 & 69.05 & 45.95 & 61.35 \\
\hline & Control & 1173 & q & 136.53 & 36.63 & 45.95 & 86.58 & 37.05 & 70.07 \\
\hline & Contro] & 1174 & 우 & 110.71 & 18.35 & 31.80 & 64.53 & 23.70 & 50.92 \\
\hline & Control & 1175 & 우 & 100.93 & 24.93 & 28.08 & 62.93 & 17.55 & 47.80 \\
\hline & Control & 1266 & 우 & 87.51 & 45.33 & 37.41 & 66.42 & 18.21 & 50.35 \\
\hline & Control & 1331 & 우 & 203.28 & 72.65 & 56.45 & 137.96 & & \\
\hline & Control & 1332 & 우 & 130.25 & 48.53 & 44.59 & 89.39 & & \\
\hline & Control & 1334 & 우 & 71.08 & 37.21 & 32.36 & 54.15 & & \\
\hline \multirow{11}{*}{$\mathrm{C}$} & Test & 1177 & 0 & 141.10 & 14.45 & 21.08 & 77.77 & 13.15 & 56.23 \\
\hline & Test & 1178 & $\sigma^{7}$ & 136.83 & 20.23 & 24.53 & 78.53 & 13.76 & 56.94 \\
\hline & Test & 1179 & $\sigma^{7}$ & 106.02 & 20.13 & 34.56 & 63.07 & 10.64 & 45.59 \\
\hline & Test & 1182 & $\sigma^{x}$ & 192.45 & 9.03 & 15.99 & 100.74 & & \\
\hline & Test & 1183 & q & 193.06 & 22.93 & 37.09 & 108.00 & 19.53 & 78.51 \\
\hline & Test (F) & 1184 & q & 173.63 & 16.68 & 37.03 & 95.15 & 13.66 & 67.98 \\
\hline & Control & 1209 & $\sigma^{x}$ & 75.68 & 10.73 & 12.95 & 43.20 & 21.58 & 35.99 \\
\hline & Control & 1211 & $\sigma^{x}$ & 109.18 & 10.00 & 14.58 & 59.59 & $65.70^{*}$ & 61.29 \\
\hline & Control & 1213 & $0^{x}$ & 123.25 & 12.15 & 31.46 & 67.70 & 8.25 & 47.88 \\
\hline & Control & 1208 & 우 & 236.90 & 8.40 & 50.79 & 122.65 & 9.65 & 84.98 \\
\hline & Control & 1210 & q & 122.61 & 9.38 & 24.06 & 66.00 & 21.43 & 51.14 \\
\hline \multirow{7}{*}{$L$} & Tests & 1311 & $\sigma^{3}$ & & 19.15 & & & 19.03 & \\
\hline & Tests & 1313 & $0^{7}$ & 374.06 & 31.68 & 44.00 & 202.78 & 19.85 & 141.86 \\
\hline & Tests & 1318 & $0^{7}$ & 333.08 & 23.60 & 35.25 & 178.34 & 35.43 & 130.70 \\
\hline & Tests & 1255 & $8^{7}$ & 139.86 & 41.80 & 58.81 & 90.83 & .28 .63 & 70.09 \\
\hline & Tests & 1224 & $\sigma^{x}$ & 251.68 & 39.73 & 56.95 & 145.71 & & \\
\hline & Tests & 1225 & $\sigma^{7}$ & 191.71 & 55.43 & 71.75 & 123.57 & & \\
\hline & Tests & 1227 & $0^{7}$ & 329.08 & 35.95 & 52.59 & 182.52 & & \\
\hline
\end{tabular}


TABLE A-Continued

\begin{tabular}{|c|c|c|c|c|c|c|c|c|c|}
\hline STRAIN & & $\begin{array}{l}\text { RAT T } \\
\text { NUM- } \\
\text { BER }\end{array}$ & $\operatorname{sex}$ & $\begin{array}{c}\text { FIRST } \\
\text { HALF OF } \\
\text { TRAINING }\end{array}$ & $\begin{array}{c}\text { SECOND } \\
\text { HALF OF } \\
\text { TRAIN- } \\
\text { ING }\end{array}$ & $\begin{array}{l}\text { OMIT- } \\
\text { TINA } \\
\text { FIRST } \\
\text { DAY }\end{array}$ & $\begin{array}{c}\text { ALL } \\
\text { TRAINING }\end{array}$ & $\begin{array}{c}\text { RE- } \\
\text { TENTION }\end{array}$ & \begin{tabular}{|} 
TRAIN- \\
ING AND \\
RE- \\
TENTION
\end{tabular} \\
\hline \multirow{21}{*}{$\mathrm{L}$} & Tests & 1256 & $q$ & 143.36 & 36.63 & 48.86 & 90.00 & 15.18 & 65.06 \\
\hline & Tests & 1257 & q & 212.58 & 48.10 & 55.36 & 130.34 & 24.41 & 95.03 \\
\hline & Tests & 1315 & q & 413.43 & 22.93 & 85.68 & 218.18 & 31.18 & 155.84 \\
\hline & Tests & 1316 & 운 & 123.78 & 15.70 & 28.46 & 69.74 & 25.15 & 54.87 \\
\hline & Tests & 1317 & 암 & 173.71 & 11.45 & 24.38 & 92.58 & 20.00 & 68.38 \\
\hline & Tests (F) & 1312 & iq & & 17.91 & & & 24.68 & \\
\hline & Tests (F) & 1314 & q & 205.41 & 25.76 & 60.34 & 115.59 & 34.35 & 88.51 \\
\hline & Control & 1306 & $0^{3}$ & 187.93 & 24.76 & 29.78 & 106.35 & 17.00 & 76.56 \\
\hline & Control & 1310 & $\sigma^{7}$ & 152.25 & 30.70 & 29.13 & 91.50 & 14.40 & 65.80 \\
\hline & Control & 1194 & $\sigma^{3}$ & 221.75 & 32.70 & 43.90 & 127.22 & & \\
\hline & Control & 1195 & $\sigma^{x}$ & 122.31 & 15.50 & 20.18 & 68.91 & & \\
\hline & Control (F) & 1305 & $0^{\pi}$ & 175.18 & 36.38 & 65.36 & 102.76 & 16.55 & 73.20 \\
\hline & Control (F) & 1247 & $0^{\pi}$ & 184.74 & 20.36 & 40.65 & 98.98 & 12.56 & 69.35 \\
\hline & Control (F) & 1196 & $0^{3}$ & 207.76 & 32.52 & 51.59 & 120.14 & & \\
\hline & Control & 1244 & q & 154.26 & 16.36 & 28.35 & 85.31 & 14.65 & 61.76 \\
\hline & Control & 1703 & O & 66.90 & 13.12 & 19.47 & 40.00 & 9.47 & 29.82 \\
\hline & Control & 1304 & \% & 113.91 & 37.07 & 32.42 & 75.49 & 19.10 & 56.69 \\
\hline & Control & 1307 & o & 182.56 & 15.28 & 29.22 & 99.42 & 11.95 & 70.26 \\
\hline & Control & 1308 & 9 & 63.41 & 21.76 & 33.92 & 42.59 & 17.47 & 34.21 \\
\hline & Control & 1309 & o & 101.06 & 11.78 & 25.10 & 56.42 & 13.07 & 41.97 \\
\hline & Control (F) & 1246 & ㅇ & 467.28 & 15.40 & 131.81 & 241.34 & 35.41 & 172.69 \\
\hline
\end{tabular}

* Sick. 
TABLE B

Averages of the distance covered by each rat in each of the six groupings of the trials, and the speed in terms of centimeters per second. The sign $(F)$ indicates that this rat belongs to the 'failure' group

\begin{tabular}{|c|c|c|c|c|c|c|c|c|c|c|c|}
\hline \multirow[b]{2}{*}{ 孞 } & & \multirow[b]{2}{*}{ 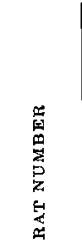 } & \multirow[b]{2}{*}{$\begin{array}{l}\underset{⿴ 囗 十}{*} \\
\sigma\end{array}$} & \multicolumn{6}{|c|}{ DISTANCE PER TRIAL } & \multicolumn{2}{|c|}{$\begin{array}{l}\text { SPEED (CENTI- } \\
\text { METERS PER } \\
\text { SECOND) }\end{array}$} \\
\hline & & & & 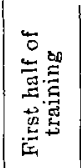 & 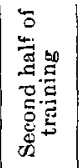 & 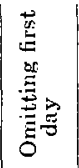 & 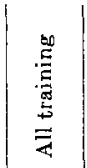 & 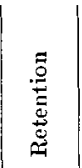 & 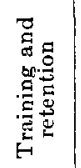 & 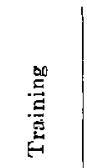 & 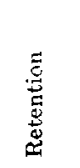 \\
\hline \multirow{32}{*}{$\mathrm{C}$} & Test & 1170 & $\sigma^{7}$ & 169.8 & 99.0 & 99.3 & 134.4 & 63.4 & 110.7 & 3.298 & 3.486 \\
\hline & Test & 1192 & $0^{7}$ & 207.5 & 87.2 & 109.1 & 147.4 & 78.9 & 124.5 & 3.738 & 4.973 \\
\hline & Test & 1193 & $0^{7}$ & 291.2 & 165.2 & 189.7 & 228.2 & 135.1 & 197.1 & 2.528 & 3.572 \\
\hline & Test & 1351 & $0^{7}$ & 302.0 & 103.0 & 124.3 & 202.5 & & & & \\
\hline & Test & 1354 & $\sigma^{7}$ & 355.5 & 109.8 & 159.4 & 232.6 & & & & \\
\hline & Test (F) & 1169 & $\sigma^{\pi}$ & & & & & & & & \\
\hline & Test & 1168 & 우 & 226.1 & 116.5 & 136.9 & 171.3 & 77.0 & 139.8 & 2.410 & 3.751 \\
\hline & Test & 1277 & 9 & 121.7 & 71.9 & 75.6 & 96.8 & 59.0 & 84.2 & 2.099 & 2.714 \\
\hline & Test & 1279 & 웅 & & 79.3 & 81.0 & & 72.5 & & 2.517 & 2.398 \\
\hline & Test (F) & 1352 & \% & & & & & & & & \\
\hline & Test (F) & 1353 & 우 & & & & & & & & \\
\hline & Control & 1171 & $\sigma^{x}$ & 189.7 & 63.8 & 95.5 & 126.7 & 86.0 & 113.1 & 3.978 & 4.005 \\
\hline & Control & 1172 & $\sigma^{7}$ & 152.9 & 96.8 & 112.3 & 124.9 & 51.8 & 100.5 & 3.159 & 5.017 \\
\hline & Control & 1265 & $0^{x}$ & 136.0 & 70.5 & 76.9 & 103.2 & 88.5 & 98.3 & 3.511 & 2.398 \\
\hline & Control & 1173 & 우 & 204.3 & 131.3 & 132.6 & 167.8 & 121.9 & 152.5 & 2.928 & 3.260 \\
\hline & Control & 1174 & 우 & 146.7 & 84.0 & 101.3 & 115.4 & 78.3 & 103.0 & 3.401 & 3.656 \\
\hline & Control & 1175 & 우 & 163.0 & 101.5 & 100.4 & 132.2 & \begin{tabular}{|l|}
75.3 \\
$\mid$
\end{tabular} & 113.2 & 3.510 & 4.452 \\
\hline & Control & 1266 & 우 & 150.5 & 89.0 & 80.2 & 119.7 & 58.1 & 99.1 & 2.498 & 3.722 \\
\hline & Control & 1331 & 웅 & 205.5 & 138.8 & 122.0 & 171.9 & & & & \\
\hline & Control & 1332 & $q$ & 124.7 & 100.5 & 104.5 & 112.6 & & & & \\
\hline & Control & 1334 & $q$ & 127.5 & 106.6 & 98.4 & 117.1 & & & & \\
\hline & Test & 1177 & $0^{\pi}$ & 187.2 & 73.1 & 85.1 & 130.2 & 64.5 & 108.3 & 4.149 & 5.041 \\
\hline & Test & 1178 & $\sigma^{7}$ & 199.0 & 101.5 & 99.4 & 150.3 & 61.3 & 120.4 & 3.928 & 4.687 \\
\hline & Test & 1179 & $\sigma^{7}$ & 167.3 & 78.0 & 103.2 & 122.6 & 50.4 & 98.5 & 3.202 & 4.792 \\
\hline & Test & 1182 & $\sigma^{7}$ & 160.6 & 55.2 & 123.3 & 107.9 & & & & \\
\hline & Test & 1183 & ㅇ & 264.0 & 99.4 & 127.2 & 2181.7 & 80.0 & 147.8 & 3.883 & 4.250 \\
\hline & Test (F) & 1184 & 우 & & & & & & & & \\
\hline & Control & 1209 & $0^{7}$ & 127.8 & 47.9 & 52.1 & 87.8 & 57.3 & 77.6 & 3.850 & 3.677 \\
\hline & Control & 1211 & $\sigma^{\pi}$ & 128.3 & 43.9 & 53.3 & 86.0 & 79.4 & 83.8 & 3.512 & 2.547 \\
\hline & Control & 1213 & $\sigma^{7}$ & 142.5 & 51.2 & 75.6 & \begin{tabular}{|l|l|}
3 & 96.8
\end{tabular} & 39.6 & 77.7 & 3.215 & 5.137 \\
\hline & Control & 1208 & $q$ & 144.0 & 42.9 & 75.9 & \begin{tabular}{|l|l|}
9 & 93.4
\end{tabular} & 40.1 & 75.6 & 3.664 & 4.390 \\
\hline & Control & 1210 & q & 165.6 & 41.6 & 66.1 & 103.6 & 64.3 & 90.5 & 3.522 & 3.513 \\
\hline
\end{tabular}


TABLE B-Continued

\begin{tabular}{|c|c|c|c|c|c|c|c|c|c|c|c|}
\hline \multirow[b]{2}{*}{ 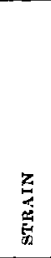 } & & \multirow[b]{2}{*}{ 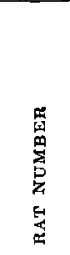 } & \multirow[b]{2}{*}{ 昏 } & \multicolumn{6}{|c|}{ DISTANCE PER TRIAL } & \multicolumn{2}{|c|}{$\begin{array}{l}\text { SPEED (CENTT- } \\
\text { METERS PER } \\
\text { BECOND) }\end{array}$} \\
\hline & & & & 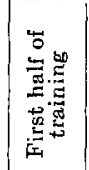 & 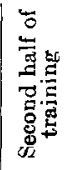 & 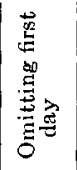 & & 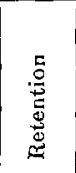 & 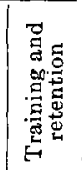 & 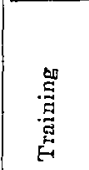 & 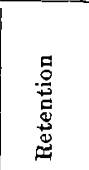 \\
\hline \multirow{28}{*}{ L } & Test & 1311 & $0^{x}$ & & 58.8 & & & 54.1 & & 2.784 & 3.082 \\
\hline & Test & 1313 & $\sigma^{7}$ & 205.0 & 81.5 & 92.9 & 143.2 & 61.0 & 115.8 & 2.600 & 3.451 \\
\hline & Test & 1318 & $0^{7}$ & 246.6 & 72.6 & 84.7 & 159.6 & 77.4 & 132.2 & 2.454 & 2.451 \\
\hline & Test & 1255 & $\sigma^{7}$ & 197.0 & 115.2 & 127.4 & 156.1 & 50.3 & 120.8 & 2.360 & 3.682 \\
\hline & Test & 1224 & $0^{\pi}$ & $|202.8| r \mid$ & 111.5 & 109.8 & 157.1 & & & & \\
\hline & Test & 1225 & $0^{7}$ & 170.2 & 139.6 & 129.3 & 154.9 & & & & \\
\hline & Test & 1227 & $\sigma^{\pi}$ & $240.5 \mid$ & 101.1 & 195.2 & 170.8 & & & & \\
\hline & Test & 1256 & 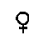 & 167.3 & 84.7 & 94.7 & 126.0 & 54.0 & 102.0 & 2.099 & 4.167 \\
\hline & Test & 1257 & \& & 201.2 & 98.5 & 111.4 & 149.8 & 83.0 & 127.5 & 2.038 & 3.845 \\
\hline & Test & 1315 & q & $246.2 \mid$ & 80.6 & 108.8 & 163.4 & 91.3 & 139.3 & 2.222 & 3.314 \\
\hline & Test & 1316 & \& & $|143.2|$ & 59.5 & 82.0 & 101.4 & 77.0 & 93.2 & 3.113 & 3.478 \\
\hline & Test & 1317 & $q$ & 159.5 & 48.7 & 60.3 & $|104.1|$ & 58.0 & 88.7 & 3.426 & 3.050 \\
\hline & Test (F) & 1312 & 9 & & & & & & & & \\
\hline & Test (F) & 1314 & 9 & & & & & & & & \\
\hline & Control & 1306 & $0^{7}$ & 181.0 & 80.2 & 81.2 & 130.6 & 57.2 & 106.1 & 2.659 & 4.399 \\
\hline & Control & 1310 & $0^{7}$ & $\mid 132.3$ & 90.4 & 79.2 & 111.3 & 47.6 & 90.0 & 2.576 & 3.942 \\
\hline & Control & 1194 & $\sigma^{7}$ & 278.8 & 101.4 & 132.5 & 190.1 & & & & \\
\hline & Control & 1195 & $0^{x}$ & $\mid 144.2$ & 54.1 & 68.9 & 99.2 & & & & \\
\hline & Control (F) & 1305 & $\sigma^{\pi}$ & & & & & & & & \\
\hline & Control (F) & 1247 & $0^{7}$ & & & & & & & & \\
\hline & Control (F) & 1196 & $0^{x}$ & & & & & & & & \\
\hline & Control & 1244 & $q$ & $|157.5|$ & 62.3 & 70.4 & 109.9 & 47.6 & 89.1 & 2.817 & 3.687 \\
\hline & Control & 1303 & $q$ & 103.5 & 53.1 & $|59.4|$ & 78.3 & 47.6 & 68.0 & 3.290 & 4.445 \\
\hline & Control & 1304 & $\%$ & 160.9 & 113.0 & 97.4 & 105.7 & 67.1 & 92.8 & 2.844 & 3.870 \\
\hline & Control & 1307 & 웅 & 205.5 & 58.4 & 79.1 & 131.5 & 54.3 & 105.7 & 2.912 & 4.695 \\
\hline & Control & 1308 & 8 & $|111.2|$ & 67.5 & 81.2 & 89.4 & 66.0 & 81.6 & 2.984 & 4.591 \\
\hline & Control & 1309 & 9 & 116.0 & 52.0 & 65.5 & 85.3 & 55.1 & 75.2 & 3.358 & 4.511 \\
\hline & Control (F) & 1246 & \& & & & & & & & & \\
\hline
\end{tabular}


TABLE $\mathrm{C}$

Averagcs of the number of errors made by each rat in each of the six groupings of the trials

\begin{tabular}{|c|c|c|c|c|c|c|c|c|c|}
\hline STRAIN & & $\begin{array}{c}\text { RAT } \\
\text { NUM- } \\
\text { BER }\end{array}$ & $\operatorname{sex}$ & $\begin{array}{c}\text { FIRST } \\
\text { HALF OF } \\
\text { TRAIN- } \\
\text { ING }\end{array}$ & $\begin{array}{c}\text { SECOND } \\
\text { HALF OF } \\
\text { TRAIN- } \\
\text { ING }\end{array}$ & $\begin{array}{l}\text { OMIT- } \\
\text { TING } \\
\text { FIRST } \\
\text { D.AY }\end{array}$ & $\begin{array}{c}\text { ALL } \\
\text { TRAIN- } \\
\text { ING }\end{array}$ & $\begin{array}{c}\text { RETEN- } \\
\text { TION }\end{array}$ & $\begin{array}{l}\text { TRAIN- } \\
\text { XNGAND } \\
\text { RETEN- } \\
\text { TION }\end{array}$ \\
\hline \multirow{21}{*}{$\mathrm{A}$} & Test & 1170 & $\sigma^{7}$ & 6.7 & 3.4 & 8.1 & 5.1 & 1.7 & 4.0 \\
\hline & Test & 1192 & $\sigma^{2}$ & 10.1 & 3.3 & 4.8 & 6.7 & 2.7 & 5.4 \\
\hline & Test & 1193 & $\sigma^{7}$ & 12.7 & 6.9 & 7.9 & 9.8 & 6.4 & 8.7 \\
\hline & Test & 1351 & $0^{7}$ & 24.8 & 4.0 & 7.6 & 14.4 & & \\
\hline & Test & 1354 & $0^{7}$ & 15.6 & 4.6 & 6.6 & 10.1 & & \\
\hline & Test (F) & 1169 & $\sigma^{7}$ & & & & & & \\
\hline & Test & 1168 & 9 & 10.0 & 4.6 & 5.2 & 7.3 & 2.7 & 5.7 \\
\hline & Test & 1277 & 9 & 5.2 & 2.9 & 3.2 & 4.1 & 1.4 & 3.2 \\
\hline & Test & 1179 & 9 & & 2.9 & 3.0 & & 2.0 & \\
\hline & Test (F) & 1352 & 웅 & & & & & & \\
\hline & Test (F) & 1353 & 9 & & & & & & \\
\hline & Control & 1171 & o & 8.5 & 1.6 & 3.6 & 5.0 & 2.9 & 4.3 \\
\hline & Control & 1172 & $\sigma^{7}$ & 6.9 & 3.6 & 4.6 & 5.2 & 1.6 & 3.9 \\
\hline & Control & 1265 & $\sigma^{7}$ & 6.0 & 3.0 & 3.1 & 4.5 & 3.4 & 4.1 \\
\hline & Control & 1173 & & 8.9 & 5.9 & 5.7 & 7.4 & 5.8 & 6.9 \\
\hline & Control & 1174 & 웅 & 6.7 & 2.7 & 3.5 & 4.7 & 2.7 & 4.0 \\
\hline & Control & 1175 & 우 & 6.5 & 3.7 & 3.6 & 5.1 & 2.8 & 4.4 \\
\hline & Control & 1266 & 웅 & 5.4 & 4.0 & 3.1 & 4.7 & 1.4 & 3.6 \\
\hline & Control & 1331 & 우 & 9.2 & 6.9 & 5.7 & 8.0 & & \\
\hline & Control & 1332 & ㅇ & 4.7 & 3.7 & 4.2 & 4.2 & & \\
\hline & Control & 1334 & 우 & 6.2 & 4.2 & 4.0 & 5.2 & & \\
\hline \multirow{11}{*}{$\mathrm{C}$} & Test & 1177 & $\sigma$ & 10.3 & 2.5 & 3.6 & 6.4 & 1.6 & 4.8 \\
\hline & Test & 1178 & $\sigma^{\pi}$ & 9.7 & 3.5 & 3.8 & 6.6 & 1.7 & 4.9 \\
\hline & Test & 1179 & $\sigma^{x}$ & 8.6 & 3.2 & 4.7 & 5.9 & 1.0 & 4.3 \\
\hline & Test & 1182 & $0^{7}$ & 7.4 & 1.6 & 2.1 & 4.5 & & \\
\hline & Test & 1183 & 웅 & 13.8 & 3.8 & 5.7 & 8.8 & 2.7 & 6.8 \\
\hline & Test (F) & 1184 & $q$ & & & & & & \\
\hline & Control & 1209 & $0^{7}$ & 4.8 & 0.9 & 1.3 & 2.9 & 1.4 & 2.4 \\
\hline & Control & 1211 & $\sigma^{2}$ & 4.8 & 0.7 & 1.2 & 2.7 & 2.8 & 2.8 \\
\hline & Control & 1213 & $\sigma^{7}$ & 7.1 & 1.4 & 2.7 & 4.1 & 0.4 & 2.9 \\
\hline & Control & 1208 & q & 6.1 & 0.7 & 2.3 & 3.4 & 0.6 & 2.4 \\
\hline & Control & 1210 & q & 7.5 & 0.5 & 2.1 & 4.0 & 1.7 & 3.2 \\
\hline \multirow{7}{*}{$\mathbf{L}$} & Test & 1311 & $0^{7}$ & & 1.2 & & & 1.2 & \\
\hline & Test & 1313 & $\sigma^{7}$ & 9.5 & 2.6 & 3.6 & 6.0 & 1.6 & 4.5 \\
\hline & Test & 1318 & $0^{\pi}$ & 11.4 & 2.4 & 3.0 & 6.9 & 2.2 & 5.7 \\
\hline & Test & 1255 & $\sigma^{x}$ & 9.6 & 4.8 & 5.5 & 7.2 & 3.2 & 5.9 \\
\hline & Test & 1224 & $\sigma^{7}$ & 8.6 & 4.6 & 1.8 & 6.6 & & \\
\hline & Test & 1225 & $\sigma^{7}$ & 8.1 & 5.6 & 7.8 & 6.3 & & \\
\hline & Test & 1227 & $0^{7}$ & 11.8 & 3.3 & 4.2 & 7.6 & & \\
\hline
\end{tabular}


ALCOHOLISM AND BEHAVIOR OF WHITE RATS

TABLE C-Continued

\begin{tabular}{|c|c|c|c|c|c|c|c|c|c|}
\hline STRAIN & & $\begin{array}{c}\text { BAT } \\
\text { NUUY- } \\
B E R\end{array}$ & $\operatorname{sex}$ & $\begin{array}{c}\text { FIRST } \\
\text { HALF OF } \\
\text { TRAIN- } \\
\text { ING }\end{array}$ & $\begin{array}{l}\text { SECOOND } \\
\text { HALF OF } \\
\text { TRAIN- } \\
\text { ING }\end{array}$ & $\begin{array}{l}\text { OurT- } \\
\text { TINa } \\
\text { FIRST } \\
\text { DAY }\end{array}$ & $\begin{array}{c}\text { ARAL } \\
\text { IRAIN- } \\
\text { ING }\end{array}$ & $\begin{array}{c}\text { RETEN- } \\
\text { TION }\end{array}$ & \begin{tabular}{|} 
TRAIN- \\
ING AND \\
RETEN- \\
TION
\end{tabular} \\
\hline \multirow{20}{*}{$\mathrm{L}$} & Test & 1256 & ○ & 7.0 & 2.8 & 3.2 & 4.9 & 1.2 & 3.7 \\
\hline & Test & 1257 & 웅 & 8.7 & 4.2 & 5.0 & 6.4 & 3.4 & 5.4 \\
\hline & Test & 1315 & $q$ & 10.2 & 2.7 & 3.8 & 6.4 & 3.0 & 5.3 \\
\hline & Test & 1316 & 우 & 6.3 & 1.8 & 2.9 & 4.1 & 2.7 & 3.6 \\
\hline & Test & 1317 & q & 6.9 & 0.8 & 1.6 & 3.9 & 1.4 & 3.0 \\
\hline & Test (F) & 1312 & $q$ & & & & & & \\
\hline & Test (F) & 1314 & 우 & & & & & & \\
\hline & Control & 1306 & $\sigma^{7}$ & 8.7 & 2.7 & 3.2 & 5.9 & 1.2 & 4.4 \\
\hline & Control & 1310 & $\sigma^{7}$ & 5.9 & 1.3 & 2.7 & 4.5 & 1.2 & 3.4 \\
\hline & Control & 1194 & $0^{x}$ & 14.0 & 3.6 & 6.1 & 8.8 & & \\
\hline & Control & 1195 & $0^{7}$ & 5.7 & 1.5 & 1.9 & 3.6 & & \\
\hline & Control (F) & 1305 & $\sigma^{7}$ & & & & & & \\
\hline & Control (F) & 1247 & $0^{\pi}$ & & & & & & \\
\hline & Control (F) & 1196 & $0^{\pi}$ & & & & & & \\
\hline & Control & 1244 & $q$ & 7.6 & 1.8 & 2.5 & 4.7 & 0.8 & 3.4 \\
\hline & Control & 1303 & $q$ & 4.1 & 1.2 & 1.7 & 2.7 & 0.4 & 1.9 \\
\hline & Control & 1304 & $q$ & 6.3 & 4.0 & 4.2 & 5.9 & 2.7 & 4.8 \\
\hline & Control & 1307 & $q$ & 10.1 & 1.4 & 2.8 & 5.7 & 1.3 & 4.3 \\
\hline & Control & 1308 & $q$ & 4.9 & 2.8 & 3.5 & 3.9 & 1.6 & 3.1 \\
\hline & Control & 1309 & & 5.6 & 1.4 & 2.5 & 3.5 & 1.2 & 2.7 \\
\hline
\end{tabular}

